Lara Rosana Vieira Silva

DETERMINAÇÃO DE VARIAÇÕES MORFOMÉTRICAS EM IMPRESSÕES DIGITAIS DE IDOSOS: ESTUDO LONGITUDINAL RETROSPECTIVO

$$
\text { Brasília - DF }
$$

Agosto de 2015 


\title{
DETERMINAÇÃO DE VARIAÇÕES MORFOMÉTRICAS EM IMPRESSÕES DIGITAIS DE IDOSOS: ESTUDO LONGITUDINAL RETROSPECTIVO
}

\author{
em Ciências Médicas. \\ Universidade de Brasília - UNB \\ Faculdade de Medicina \\ Programa de Pós-Graduação em Ciências Médicas
}

Dissertação de Mestrado apresentada ao Programa de Pós-graduação em Ciências Médicas da Universidade de Brasília, como requisito para a obtenção do título de Mestre

Orientadora: Profa. Dra. Selma Aparecida Souza Küchelhaus

Brasília - DF

Agosto de 2015 
FICHA CATALOGRÁFICA

Ficha catalográfica elaborada automaticamente, com os dados fornecidos pelo(a) autor(a) Silva, Lara Rosana Vieira
S586d DETERMINAÇÃO DE VARIAÇÕES MORFOMÉTRICAS EM
IMPRESSÕES DIGITAIS DE IDOSOS: ESTUDO LONGITUDINAL RETROSPECTIVO / Lara Rosana Vieira Silva; orientador Selma Aparecida Souza Küchelhaus. -- Brasília, 2015. $112 \mathrm{p}$.

Dissertação (Mestrado - Mestrado em Ciências Médicas) - - Universidade de Brasilia, 2015.

1. Papiloscopia. 2. Impressões digitais de idosos. 3. Alterações morfométricas. I. Küchelhaus, Selma Aparecida Souza, orient. II. Título. 


\title{
TERMO DE APROVAÇÃO
}

Lara Rosana Vieira Silva

\section{DETERMINAÇÃO DE VARIAÇÕES MORFOMÉTRICAS EM IMPRESSÕES DIGITAIS DE IDOSOS: ESTUDO LONGITUDINAL RETROSPECTIVO}

\begin{abstract}
Dissertação aprovada como requisito parcial para o grau de mestre no curso de PósGraduação em Ciências Médicas da Universidade de Brasília, como requisito para a obtenção do título de Mestre em Ciências Médicas.
\end{abstract}

Banca Examinadora. Brasília - DF, 28 de agosto de 2015.

Profa Dra Selma Aparecida Souza Küchelhaus

Presidente/Orientadora

Prof. Dr. Manoel Eugenio dos Santos Modelli

Membro Titular Externo

Prof. Dr. Rafael Perseghini Del Sarto

Membro Titular Externo

Prof. Dr. José Roberto Pimenta de Godoy

Membro Suplente 
Dedico este trabalho a todos os peritos em papiloscopia que exercem suas atividades com altruísmo e empenho a serviço da sociedade. 
"Ó profundidade das riquezas, tanto da sabedoria, como da ciência de Deus! Quão insondáveis são os seus juízos, e quão inescrutáveis os seus caminhos! Por que quem compreendeu a mente do Senhor? Ou quem foi seu conselheiro? Ou quem the deu primeiro a Ele, para que Ihe seja recompensado? Porque dEle e por Ele, e para Ele, são todas as coisas; glória, pois, a Ele eternamente." Bíblia Sagrada. Romanos 11:33-36 



\section{AGRADECIMENTOS}

À minha orientadora, Professora Dra. Selma Aparecida Souza Küchelhaus por sua disposição em contribuir com seus conhecimentos e experiência acadêmica, orientação e acompanhamento na pesquisa e sua constante motivação.

Ao programa de Pós Graduação em Ciências Médicas da Universidade de Brasília, aos professores que contribuíram na construção do conhecimento e aos servidores por seu apoio e solicitude, e aos colegas discentes de curso que partilharam as etapas dos estudos e contribuíram com a minha formação.

À Polícia Civil do Distrito Federal, ao Departamento de Polícia Técnica, ao Instituto de Identificação, na pessoa do Diretor Claudionor Batista dos Santos, pelo incentivo à pesquisa acadêmica para aprimoramento dos serviços prestados para a segurança pública.

Aos amigos Papiloscopistas Policiais Mestre Leila Lopes Mizokami, Bruna Ester Ferreira de Faria, Mestre Paola Rabello Vieira, Mestre Rodrigo Meneses de Barros, Dr. Rafael Perseghini Del Sarto, pela imensurável contribuição nas diferentes etapas da pesquisa, sugestões, revisões, incentivo e companheirismo.

Aos colegas Papiloscopistas Policiais, Daniel Flávio Vidal Bebiano, Márcio Barbosa Ribeiro, Petterson Vitorino de Morais, Alan Blanco Cinantti, e, Perito Criminal, Vitor Leone Rossi, pela assistência técnica e sugestões. Aos colegas do Laboratório de Necropapiloscopia e companheiros de trabalho pelo apoio, incentivo e compreensão das demandas decorrentes da pesquisa.

Aos servidores e colegas Papiloscopistas Policiais lotados no posto de identificação "Na Hora" da Rodoviária de Brasília, Quitéria Tavares de Mesquita, Carlos Eduardo Lima da Silva e Adilson Alves de Oliveira que colaboraram no atendimento aos idosos. Aos colegas Papiloscopistas Policiais da seção de arquivo que, com disponibilidade, puderam contribuir com sua experiência profissional, em especial ao Carlos Roberto Figueiredo dos Santos na localização de prontuários antigos.

Aos voluntários participantes da pesquisa por sua compreensão e disposição em contribuir com o aprimoramento científico da Perícia Papiloscópica. 
À minha família, meus pais, irmãos, cunhados e sobrinhos pelo constante apoio, compreensão e "grande torcida," em especial, ao meu pai, Francisco Vieira Silva, e minha mãe, Nadir Vieira Silva, pelos ensinamentos ao longo da vida, constante orientação, incentivo aos estudos e pelo amor demonstrado nas diversas formas.

Aos amigos que expressaram palavras motivacionais e a todos que de alguma forma contribuíram com este trabalho.

A Deus por tornar todas as coisas possíveis; a quem pertencem todas as coisas e para quem são todas as coisas. 


\section{PREFÁCIO}

Muitas são as limitações vivenciadas na prática das perícias forenses de identificação papiloscópica que tem por escopo individualizar uma pessoa por meio dos seus caracteres distintivos e buscar informações que possam indicar, além da autoria, a dinâmica de um crime. Essa atividade engloba campos interdisciplinares que abrangem às diversas ciências desde a Biologia, Medicina, Química, Física até Engenharia e Tecnologia Computacional.

Desde 2009, o Departamento de Polícia Técnica - DPT/PCDF estabeleceu a identificação papiloscópica obrigatória a todos os cadáveres removidos ao Instituto Médico Legal Leonidio Ribeiro - PCDF com o objetivo de ampliar a segurança na emissão das declarações de óbito que é uma causa legal de extinção da punibilidade da pessoa falecida. Desde então, a experiência na prática necropapiloscópica demonstrou a dificuldade inerente a alguns indivíduos para obtenção do registro dos datilogramas devido aos processos transformativos cadavéricos e, em especial, na população idosa com suas peculiaridades. De forma empírica, foram notadas discrepâncias existentes entre as impressões de indivíduos idosos e seus padrões arquivados que foram obtidos em idade anterior, com decurso significativo de lapso temporal. Essas discrepâncias e a baixa qualidade das impressões, em alguns casos, prejudicou a autenticação da identidade de alguns indivíduos gerando desdobramentos jurídicos para seus familiares, como a necessidade de autorização judicial para registro do óbito.

Outro aspecto comumente observado é o transtorno que muitos idosos passam quando utilizam sistemas automáticos de identificação, por exemplo, para acesso de locais controlados, caixas de banco, máquinas equipadas com leitores biométricos de impressão digital. Sendo assim, as dificuldades surgidas da prática pericial, o crescimento da população idosa e a percepção do cotidiano motivaram a iniciação da pesquisa tendo como foco as alterações morfométricas advindas do envelhecimento da pele e refletidas na qualidade das impressões digitais.

Com o intuito de agregar conhecimento científico e aperfeiçoamento das práticas periciais, em 2010 iniciou-se um diálogo do Instituto de Identificação do Distrito Federal - II/PCDF com a Universidade de Brasília - UnB. As pesquisas científicas no II/PCDF foram incrementadas com a parceria acadêmica da UnB. De 
forma pioneira, a professora Dra. Selma Aparecida Sousa Kückelhaus criou a linha de pesquisa em Morfologia aplicada às Ciências Forenses, no Programa de Pós Gradução da Faculdade de Medicina - UnB.

Dentre os projetos de pesquisa dirigidos pela Profa. Dra. Selma Kückelhaus, um dos segmentos estabelecido foi a análise morfométrica da pele quando submetida a fenômenos transformativos, na qual tem sido estudada a influência do envelhecimento da pele sobre os dermatóglifos. Essa integração da academia com a prática pericial papiloscópica ainda é incipiente no Brasil, tendo encontrado neste Programa um caminho frutífero e ainda bastante promissor para o País, considerando a amplitude do banco de dados de identificação civil existente nos arquivos dos órgãos públicos de segurança e a constante necessidade de aperfeiçoamento profissional. 


\section{RESUMO}

A biometria tem sido cada vez mais empregada como forma de dispositivo de segurança, sendo a autenticação ou a identificação por meio das impressões digitais um dos métodos mais comumente empregados. Nas perícias forenses de identificação papiloscópicas, os sistemas automatizados são associados à análise criteriosa do especialista. A expectativa de vida vem aumentando gradativamente e isso implica em acréscimo da população idosa. Sendo assim, faz-se necessário o aprimoramento de técnicas para identificação papiloscópicas de indivíduos idosos considerando as alterações teciduais que ocorrem com o envelhecimento. $O$ objetivo deste estudo foi determinar variações qualitativas e quantitativas em impressões digitais coletadas de indivíduos idosos em comparação aos seus padrões obtidos quando adultos. O trabalho desenvolvido foi um estudo longitudinal retrospectivo descritivo em 40 indivíduos (20 homens e 20 mulheres). Para obtenção das impressões dos idosos, foi empregado o método de entintamento das polpas digitais e registro em uma ficha de papel (individual datiloscópica); para comparação, foram localizados os prontuários arquivados no II/PCDF registrados em idade adulta; os indivíduos foram classificados conforme 0 interstício temporal dos registros, de 14 a 30 anos, de 31 a 40 anos e de 41 a 50 anos. Para avaliação qualitativa, as impressões foram examinadas por um especialista quanto à nitidez, visibilidade das cristas e minúcias; para obtenção de dados quantitativos, foi delimitada uma área de $1 \mathrm{~cm}^{2}$ do dedo indicador direito na impressão do indivíduo idoso e a mesma área correspondente da impressão obtida em idade adulta nas quais foram contabilizadas as cristas de friç̧ão, assinaladas as minúcias, as linhas subsidiárias e as linhas albodactilares visíveis; em seguida, os dados obtidos foram analisados de forma pareada. Os resultados obtidos demonstraram que: 1) qualitativamente, houve perda da nitidez na impressão dos idosos com redução na visibilidade das cristas de fricção, alterações pontuais na conformidade das cristas, minúcias e linhas subsidiárias e maior frequência de linhas albodactilares; 2) foi significativa a redução da mediana de cristas visíveis 18,0 na fase adulta para 15,0 dos idosos no grupo masculino, e de 17,5 para 15,0 no grupo feminino; 3) não houve diferença significativa no total de minúcias de adultos e idosos com mediana (Adulto $=25$; Idoso $=22$ ) para os homens e média $\pm \mathrm{DP}$ (Adulto $=27,0 \pm 8,7$; Idoso $=27,3 \pm 8,3$ ) para as mulheres, entretanto, considerando o interstício temporal, houve redução da média $\pm D P$ no total de minúcias para a classe de 41 a 50 anos do grupo masculino, com $(24,4 \pm 7,0)$ na fase adulta e $(17,6 \pm 4,9)$ fase idosa $(\mathrm{p}=0,005)$; 4) não houve diferença na quantidade de linhas subsidiárias para homens, enquanto para mulheres foram mais encontradas na fase adulta, com mediana $(1,15)$, do que na fase idosa $(0,08)$ $(p=0,0033) ; 5)$ a mediana de linhas albodactilares aumentou para homens e mulheres na fase idosa, de 0,0 para 2,0 para os homens $(p=0,0008)$ e de 0,5 para 3,5 para as mulheres $(p=0,0004) ; 6)$ foi possível identificar $57,5 \%$ dos indivíduos com uso exclusivo do sistema AFIS, na associação do sistema AFIS com análise do especialista foi possível determinar a identidade de $70 \%$ deles, enquanto pelo confronto direto foram identificados $90 \%$ do grupo; 7 ) para o grupo estudado, não houve correlação da identificação/inconclusão com as patologias, (hipertensão arterial sistêmica e diabetes), com atividade laboral danosa ou com o uso de cosméticos. Assim, o estudo mostrou que os datilogramas dos idosos sofreram alterações morfométricas no tempo transcorrido entre a obtenção dos padrões, adulto e idoso, de um mesmo indivíduo, indicando a necessidade de outros estudos para aprimoramento dos critérios analisados pelos peritos em papiloscopia e aperfeiçoamento dos sistemas automatizados de identificação.

Palavras-chave: Dermatóglifos; Biometria; Morfometria; Impressão digital; Idoso; Envelhecimento. 


\begin{abstract}
The biometrics has been increasingly employed as security device, in this way the authentication or identification through fingerprints has been one of the methods most commonly employed. In law enforcement agencies the automated systems are associated to a careful analysis of forensic specialist. The life expectance is increasing and this implies in elderly population growth. Therefore, it is necessary the improvement on techniques for fingerprints identification of elderly individuals considering the tissue changes that occur with aging. The objective of this study was to determine qualitative and quantitative variations in fingerprints collected from elderly subjects compared to their registers obtained in earlier age. This was a retrospective longitudinal study in 40 subjects $(20$ men and 20 women). In order to obtain the fingerprints of the elderly, we used the method of inking fingertips and record on a paper card; for comparison, the records stored in II / PCDF recorded in adulthood were located; the individuals were classified as temporal interstitial records from 14 to 30 years, 31-40 years and 41-50 years. Qualitative evaluation was performed by a fingerprint specialist which examined the sharpness, visibility of ridges and minutiae; to obtain quantitative data, it was bounded an $1 \mathrm{~cm}^{2}$ area of right index fingerprint from the elderly and the same corresponding area from the fingerprint obtained in adulthood, then the friction ridges were counted and minutiae, interpapillarie lines and white lines (wrinckled) were marked and counted; the data were paired analyzed. The results showed that: 1) qualitatively, the fingerprint from elderly had a loss of sharpness with reduced visibility of friction ridges, specific changes in the shape of the ridges, minutiae and subsidiary lines and were more frequent white lines; 2 ) there was significant reduction in count ridges with median from 18,0 in adulthood to 15,0 of the elderly in the male group, and from 17,5 to 15,0 in the female group; 3 ) there was no significant difference in the total adult minutiae and the elderly with a median (Adult=25; Aged=22) for men and mean \pm SD (Adult=27,0 $\pm 8,7$; Elderly $=27,3 \pm 8,0$ ) for women, however, considering the temporal interstices, there was a reduction of mean \pm SD of total minutiae for class 41-50 years male group, with (24.4 \pm 7.0$)$ in adulthood and $(17,6 \pm 4,9)$ aging stage $(p=0,005)$. 4) there was no difference in the amount of subsidiary lines for men, while for women they were most frequent in adulthood with median $(1,15)$ than in the older age $(0,08)$ $(p=0,0033) ; 5)$ the median of white lines increased for men and women in the older age, from 0,0 to $2,0$ for men ( $p=0,0008)$ and 0,5 to 3,5 for women $(p=0,0004) ; 6) 57,5 \%$ of individuals were identified with exclusive use of the AFIS; the fingerprint specialist analysis in association to the AFIS processing achieved $70 \%$ of their identity, while the direct comparison obtained $90 \%$ identification of the group; 7 ) for the studied group, there was no correlation between identification/inconclusion with pathologies (hypertension and diabetes), neither with harmful labor activity or with the use of cosmetics. Thus, the study showed that fingerprints suffered morphometric changes throughout life indicating the need for further studies to improve the criteria analyzed by fingerprint experts and the enhancement of automated fingerprint identification systems.
\end{abstract}

Keywords: Dermatoglyphics; Biometrics; Morphometry; Fingerprint; Elderly; Aging. 


\section{SUMÁRIO}

1. INTRODUÇÃO

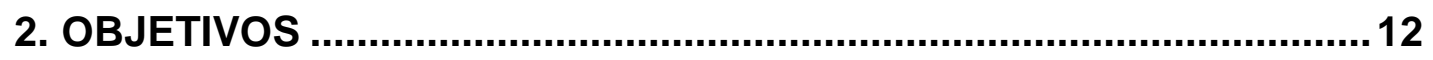

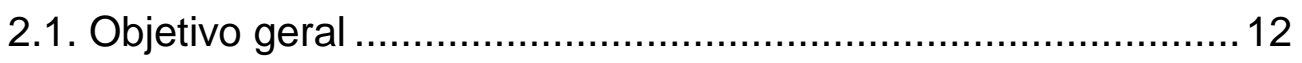

2.2. Objetivos específicos ............................................................ 11

3. MATERIAIS E MÉTODO

3.1. Delineamento do estudo ............................................................. 14

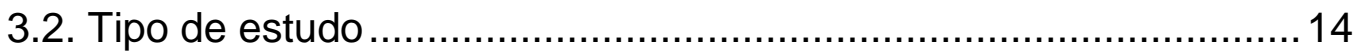

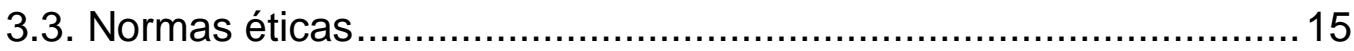

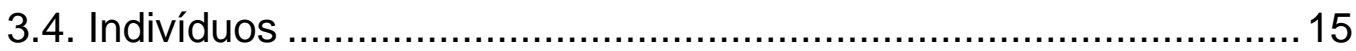

3.5. Obtenção das impressões digitais de idosos.................................16

3.6. Pesquisa dos prontuários civis para a obtenção das impressões digitais para o estudo comparativo ................................................... 16

3.7. Determinação dos tipos fundamentais e padronização

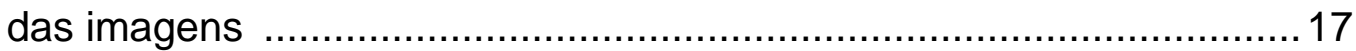

3.8. Marcação das minúcias e linhas subsidiárias .................................19

3.9. Quantificação das cristas de friç̧ão .............................................20

3.10. Comparação entre os padrões datiloscópicos ..............................21

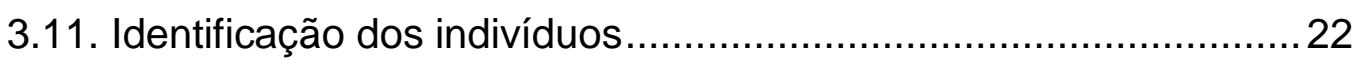

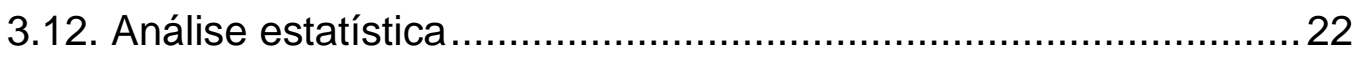

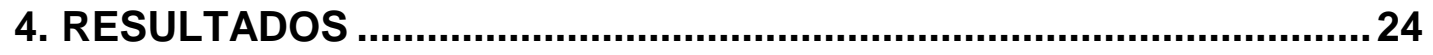

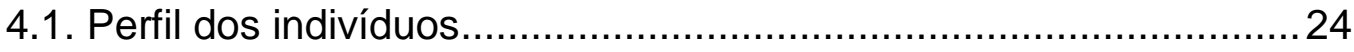

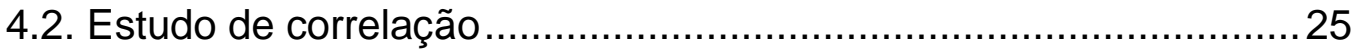

4.3. Descrição dos datilogramas .....................................................26

A. Qualidade das impressões....................................................26

B. Classificação dos tipos fundamentais ......................................2

C. Perfil individual dos datilogramas quanto ao total de cristas e minúcias

4.4. Determinação do total de cristas de fricção, minúcias e linhas subsidiárias 
B. Determinação do total de minúcias .............................................34

C. Determinação do total de linhas subsidiárias ...............................35

D. Determinação do total de linhas albodactilares ..........................36

4.5. Avaliação dos datilogramas em diferentes interstícios temporais ..37

A. Avaliação das cristas de fricção no interstício temporal................37

B. Avaliação das minúcias no interstício temporal ...........................39

4.6. Avaliação dos percentuais de coincidências entre os padrões

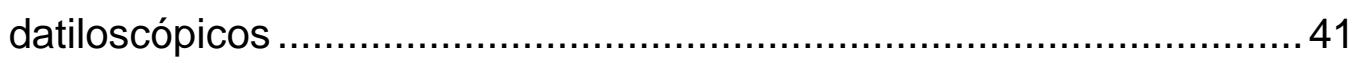

A. Percentual de cristas de friç̧ão visíveis ..................................... 41

B. Percentual de minúcias coincidentes ........................................42

C. Percentual de linhas subsidiárias coincidentes........................... 43

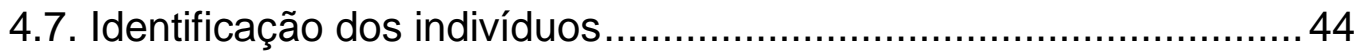

5. DISCUSSÃO

5.1. Considerações sobre a obtenção dos datilogramas ....................... 48

5.2. O perfil dos indivíduos e a qualidade dos datilogramas.................. 49

5.2.1. A influência do envelhecimento .............................................. 49

5.2.2. A influência dos fatores extrínsecos ......................................51

5.2.3. A influência das patologias ...................................................53

5.3. Considerações sobre a frequência dos tipos fundamentais.............53

5.4. Considerações acerca dos parâmetros qualitativos no confronto ...54

5.5. Considerações sobre os parâmetros quantitativos dos dermatóglifos no

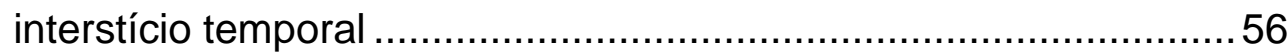

5.5.1. Total de cristas de fricção...................................................56

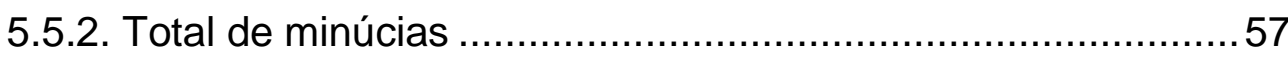

5.5.3. Total de linhas subsidiárias .................................................58

5.6. Considerações sobre os parâmetros quantitativos dos dermatóglifos por

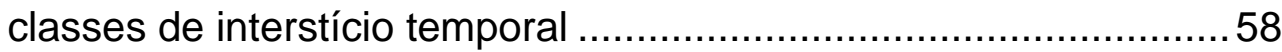

5.6.1. Percentual de cristas de fricção visíveis ...............................59 
5.6.2. Percentual de minúcias coincidentes 60

5.6.3. Percentual de linhas subsidiárias coincidentes .....................61

5.7. Considerações sobre a identificação dos indivíduos .......................62

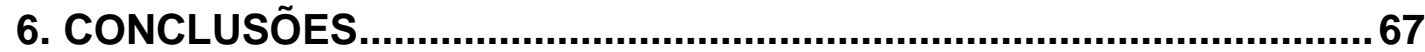

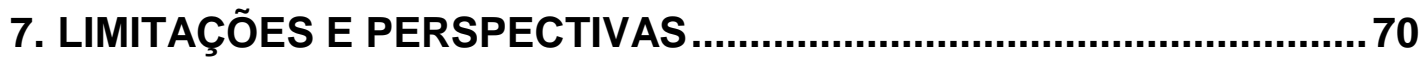

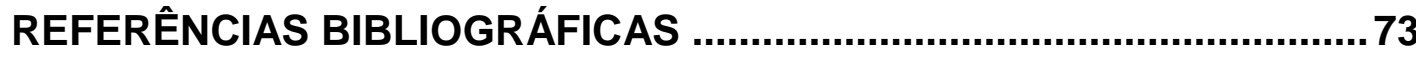

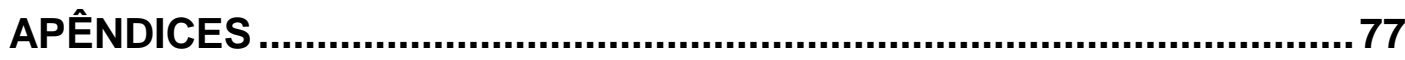

APÊNDICE A. Termo de Consentimento Livre e Esclarecido ..........77

APÊNDICE B. Questionário ........................................................... 79

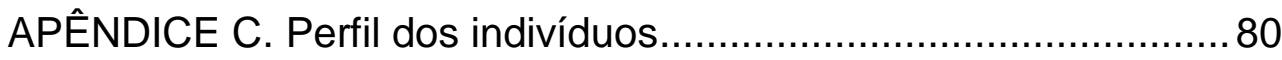

APÊNDICE D. Quantidade de cristas, minúcias, linhas subsidiárias e linhas albodactilares observadas nos indivíduos em idade adulta e idosa

APÊNDICE E. Frequência dos tipos fundamentais por quirodáctilo observada na individual decadactilar dos indivíduos idosos 82 APÊNDICE F .Número de cristas na área de $1 \mathrm{~cm}^{2}$ do dedo indicador direito distribuído por tipo fundamental. 83 APÊNDICE G. Quantificação das minúcias e linhas subsidiárias marcadas e coincidentes 84

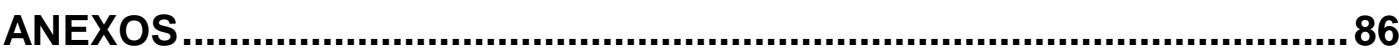

ANEXO 1. Autorização do Comitê de Ética FM/UNB ......................86

ANEXO 2. Termo de Concordância da Polícia Civil do Distrito Federal 


\section{LISTA DE ILUSTRAÇÕES}

Figura 1. Fotografia da superfície digital de um indivíduo mostrando os desenhos formados por cristas de fricção (seta) e sulcos (asterisco) que caracterizam a pele espessa de mãos e pés (ampliado 20 vezes)

Figura 2. Esquema da pele mostrando a relação entre as cristas de fricção presentes na superfície epitelial e as papilas dérmicas que se projetam para a epiderme. Ilustração de Rodrigo Meneses de Barros (Mizokami, 2014) 3

Figura 3. Impressão digital ilustrativa dos três conjuntos de cristas de fricção utilizados no sistema de classificação de Vucetich. A seta indica um delta (Vanrell, 2012) 3

Figura 4. Tipos Fundamentais de datilogramas, segundo a classificação de Vucetich, sendo o arco (1), presilha interna (2), presilha externa (3), ou verticilo (4) (II/PCDF) 4

Figura 5. Fluxograma exibindo o delineamento do estudo experimental da comparação qualitativa e quantitativa de impressões de adultos e idosos ......14

Figura 6. Sistema de fotodocumentação utilizado para a digitalização das impressões digitais pertencente ao Instituto de Identificação do Distrito Federal 16

Figura 7. Fotografia dos datilogramas coletados do mesmo indivíduo do sexo masculino ( $\mathrm{n}^{\circ}$ 19) em idades distintas, fase adulta (A) e idosa (B). Ambas as fotografias foram rotacionadas e alinhadas nos eixos vertical e horizontal para manter a equivalência das distâncias entre dois pontos característicos e correspondentes. 18

Figura 8. Fotografias de impressões digitais do dedo indicador direito de um indivíduo do sexo feminino ( $n^{\circ}$ 3), quando adulto (A) ou idoso (B). A área selecionada de $1 \mathrm{~cm}^{2}$ tem como centro uma minúcia que se encontra indicada pela seta... 18

Figura 9. Fotografias de impressões digitais (dedo indicador direito) do indivíduo do sexo feminino (no 3) das fases adulta (A) e idosa (B,C) para ilustrar a marcação de minúcias. Os pontos vermelhos indicam as minúcias, setas amarelas indicam linhas subsidiárias e seta azul indica linha albodactilar. 
Figura 10. Fotografias de impressões digitais de dedo indicador direito do mesmo indivíduo (sexo feminino, no 9), quando adulto (A) ou idoso (B). A linha diagonal traçada na imagem foi utilizada para a quantificação das cristas de fricção ....20

Figura 11. Fotografias dos datilogramas das fases adulta $(A, C)$ e idosa $(B, D)$ de um mesmo indivíduo do sexo masculino (no 20) para ilustrar a comparação entre os padrões datiloscópicos. As minúcias estão indicadas em vermelho e as linhas subsidiárias em amarelo. Minúcias ou linhas subsidiárias coincidentes (presentes em ambos os datilogramas) receberam a mesma identificação e as discrepantes receberam identificação única 21

Figura 12. Fotografias dos datilogramas obtidos de um indivíduo do sexo feminino (no 20) mostrando a fase adulta (A) e idosa (B). As setas indicam as linhas albodactilares que foram mais frequentes na fase idosa dos indivíduos. 26

Figura 13. Fotografias dos datilogramas do dedo indicador direito de um indivíduo do sexo masculino ( $n^{-1}$ 17) mostrando as fases, adulta (A) e idosa (B). As setas indicam áreas com redução na visibilidade das cristas, irregularidades no contorno e aproximação das linhas presentes nos datilogramas de 31 indivíduos idosos ..

Figura 14. Fotografias dos datilogramas dos dedos indicadores esquerdo dos indivíduos dos sexos masculino ( $n \div 4$ e 15) e feminino ( $n$ 우 16), nas fases, adulta (coluna A) e idosa (coluna B). Os padrões dos datilogramas dos idosos exibem as alterações descritas (coluna $\mathrm{C}$ ), na comparação com o seu respectivo padrão obtido na fase adulta. Nos três casos é descrita a ilegibilidade do tipo fundamental....

Figura 15. Datilogramas dos dedos dos indivíduos dos sexos feminino (no 12 e 13) e masculino (n- 17 e 18), nas fases, adulta (coluna A) e idosa (coluna B). Os padrões duvidosos obtidos dos idosos foram classificados a partir do padrão arquivado, coletado quando os indivíduos eram adultos

Figura 16. Fotografia da Individual datiloscópica do indivíduo do sexo masculino (no 4) exibindo amputação do $1^{\circ}$ dedo, polegar esquerdo, (seta) e anomalia do $2^{\circ}$ dedo, indicador esquerdo, (asterisco) 
Figura 17. Perfil individual referente ao total de cristas de fricção e de minúcias presentes numa área de $1 \mathrm{~cm}^{2}$ dos quirodáctilos indicadores direito de indivíduos do sexo masculino (A) e feminino (B), nas duas fases da vida, adulta e idosa. Os resultados da análise qualitativa indicam a grande variabilidade entre os indivíduos quanto ao total das características dos quirodáctilos 32

Figura 18. Total de cristas de fricção presentes nos datilogramas $\left(1 \mathrm{~cm}^{2}\right)$ obtidos dos indivíduos do sexo masculino (A) e do sexo feminino (B), nas fases adulta e idosa. Os resultados analisados pelo teste de Wilcoxon mostraram redução nas medianas do total de cristas em ambos os sexos. Estão mostrados os valores individuais. 33

Figura 19. Total de minúcias presentes nos datilogramas $\left(1 \mathrm{~cm}^{2}\right)$ obtidos dos indivíduos do sexo masculino (A) e do sexo feminino (B), nas fases adulta e idosa. Os resultados analisados pelo teste t pareado mostraram que o interstício temporal não afetou o total de minúcias nas impressões de ambas as fases e para ambos os sexos $(p>0,05)$. Estão mostrados os valores individuais 34

Figura 20. Total de linhas subsidiárias presentes nos datilogramas $\left(1 \mathrm{~cm}^{2}\right)$ obtidos dos indivíduos do sexo masculino (A) e do sexo feminino (B), nas fases adulta e idosa. Os resultados analisados pelo teste de Wilcoxon mostraram redução na mediana do total de linhas nos datilogramas do sexo feminino $(n=10)$, mas não para o masculino $(n=10)$. Estão mostrados os pontos individuais. 35

Figura 21. Total de linhas albodactilares presentes nos datilogramas $\left(1 \mathrm{~cm}^{2}\right)$ obtidos dos indivíduos do sexo masculino (A) e do sexo feminino (B), nas fases adulta e idosa. Os resultados analisados pelo teste de Wilcoxon mostraram aumento na mediana do total de linhas nos datilogramas do sexo feminino $(n=10)$, mas não para o masculino ( $n=10)$. Estão mostrados os pontos individuais 36

Figura 22. Total de cristas de fricção presentes nos datilogramas dos indivíduos do sexo masculino (A) ou feminino (B) agrupados em três diferentes classes de interstício temporal. Os resultados mostraram que os indivíduos com interstício temporal de 41 a 50 anos entre a fase adulta e idosa tiveram redução no total de cristas, assim como para o grupo feminino para as classes de 14 a 30 anos e para 41 a 50 anos $(p<0,05)$. Os indivíduos das demais classes não sofreram alteração no 
total de cristas $(p>0,05)$. Estão mostradas as medianas, quartis, valores máximos e mínimos. 38

Figura 23. Total de minúcias presentes nos datilogramas dos indivíduos do sexo masculino (A) ou feminino (B) agrupados em três diferentes classes de interstício temporal. Os resultados mostraram que na fase idosa o grupo dos homens com interstício temporal de 41 a 50 reduziram o total de minúcias na comparação com a fase adulta (Teste t pareado, $p=0,005$ ). Os demais indivíduos/classes, masculino ou feminino não sofreram alteração no total de minúcias da fase idosa na comparação com a fase adulta (teste $t$ pareado, $p>0,05$ ). Estão mostradas as médias e os desvios padrão. 40

Figura 24. Fotografia dos datilogramas das fases adulta $(A)$ e idosa $(B)$ do indivíduo do sexo masculino ( $\mathrm{n}^{\circ}$ 6) ilustrando minúcias (setas), (a) ausentes no datilograma do adulto e presente no datilograma do idoso; (b) presentes no registro do adulto e não visualizada pelo examinador no datilograma do idoso 41

Figura 25. Percentual de cristas de fricção/datilograma dos indivíduos distribuídos em diferentes classes de interstício temporal para a obtenção do padrão datiloscópico do idoso. Os resultados, analisados pelo teste de ANOVA, mostraram que o percentual de cristas de fricção visíveis não diferiu entre as classes para ambos os grupos, masculino ou feminino $(p>0,05)$. Estão mostradas as médias e os desvios padrão 42

Figura 26. Percentual de minúcias coincidentes nos datilogramas dos indivíduos distribuídos em diferentes classes de interstício temporal. Os resultados, analisados pelo teste de Kruskal-Wallis, mostraram que os percentuais de minúcias coincidentes não diferiram entre as classes para ambos os grupos, masculino ou feminino ( $p>0,05)$. Estão mostradas as médias e os desvios padrão 43

Figura 27. Percentual de linhas subsidiárias coincidentes nos datilogramas de adultos e idosos agrupados em classes de interstício temporal. Os resultados, analisados pelo teste Kruskal-Wallis mostraram que os percentuais de linhas subsidiárias não diferem entre si para ambos os grupos, masculino ou feminino ( $p>0,05)$, no entanto, houve redução na mediana desse percentual para o grupo feminino para o interstício temporal de 14 a 30 anos, na comparação com o grupo masculino. Estão representados os valores individuais 
Figura 28. Fotografias dos datilogramas dos indivíduos não identificados pela perda da nitidez das cristas de friç̧ão observada no padrão idoso. Nesses casos não foi possível encontrar correspondência nos prontuários arquivados

Figura 29. Fotografias dos datilogramas dos indivíduos não identificados pela perda da nitidez das cristas de friç̧ão e presença de linhas albodactilares no padrão idoso, que impossibilitou encontrar padrões correspondentes

Figura 30. Fotografias dos datilogramas dos indivíduos com padrão idoso satisfatório, porém não identificados devido a limitações no sistema de busca dos padrões arquivados 


\section{LISTA DE TABELAS}

Tabela 1. Percentual de homens e mulheres que exercem atividades laborais e/ou manuais danosas aos datilogramas

Tabela 2. Percentual de homens e mulheres afetados por patologias

crônicas

Tabela 3. Distribuição dos tipos fundamentais dos datilogramas nos diferentes quirodáctilos dos indivíduos do sexo masculino e feminino 28 


\section{LISTA DE SIGLAS, SÍMBOLOS E ABREVIATURAS}

ACE-V - Analysis, Comparison, Evaluation, Verification

AFIS - Automated Fingerprint Identification Sistem

$\mathrm{cm}^{2}$ - Centímetro quadrado

DM - Diabetes Mellitus

DPI - Dots Per Inch

DPT - Departamento de Polícia Técnica

F - Feminino

HAS - Hipertensão Arterial Sistêmica

HDL - High Density Lipoprotreins

II - Instituto de Identificação

II/PCDF - Instituto de Identificação da Polícia Civil do Distrito Federal

IML - Instituto Médico Legal

M - Masculino

$\mathrm{mg} / \mathrm{dl}$ - Miligrama por Decilitro

$\mathrm{mmHg}$ - Milímetro de Mercúrio

PCDF - Polícia Civil do Distrito Federal

SM - Síndrome Metabólica

SPD - Sistema Prontuário Digital

TIFF - Tagged Image File Format

UnB - Universidade de Brasília

VRP- Vertical Ridge Pattern 
1. INTRODUÇÃO 
Biometria é o método de identificação humana que se utiliza das características fisiológicas ou comportamentais específicas de cada indivíduo. Várias características individuais podem ser utilizadas em biometria, como a voz, a face, a retina, o DNA, sendo que as impressões digitais são as mais comumente empregadas (YAGER e AMIN, 2004). Nesse sentido, identidade é conceituada como o conjunto de características que individualizam uma pessoa, tornando-a essencialmente diferente de todos os demais (MARANHÃO, 2002). Devido à importante aplicação em sistemas de segurança esse método tem sido objeto de estudo em instituições públicas e privadas visando ao seu aprimoramento (YAGER e AMIN, 2004).

Os desenhos encontrados na pele espessa palmar e plantar são formados pelo padrão de cristas de fricção e sulcos, sendo que nas falanges distais esses são denominados desenhos digitais. As estruturas denominadas cristas de fricção formam linhas que aumentam o atrito com a pele, reduz a lisura e proporciona aumento da superfície de contato com um substrato (YAGER e AMIN, 2004); essas linhas podem ser contínuas ou interrompidas formando os pontos característicos ou minúcias que permitem a individualização (STÜCKER, GEIL, et al., 2001; YAGER e AMIN, 2004) (Figura 1). Além das cristas de fricção e das minúcias, ocasionalmente é possível encontrar linhas chamadas subsidiárias, que aparecem na região dos sulcos, que em geral são descontínuas e delgadas (STÜCKER, GEIL, et al., 2001; BARNES, MACEO, et al., 2011).

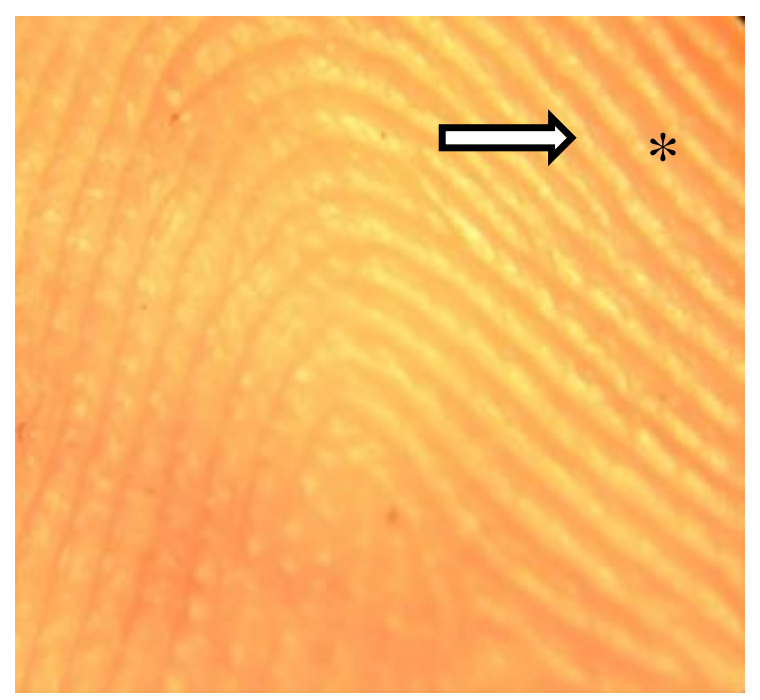

Figura 1. Imagem da superfície digital de um indivíduo mostrando os desenhos formados por cristas de fricção (seta) e sulcos, linhas mais escuras (asterisco), que caracterizam a pele espessa de mãos e pés (ampliado 20 vezes).

O datilograma ou impressão digital refere-se ao desenho digital impresso em um suporte (VANRELL, 2012), e impressão digital latente quando os desenhos digitais são apostos sobre uma determinada superfície e a impressão está "invisível" 
a olho nu e que requer métodos reveladores para sua aquisição. Em sendo assim, as linhas visíveis nos datilogramas correspondem às cristas de fricção existentes nas polpas digitais, enquanto que os espaços entre elas correspondem aos sulcos entre as cristas. Os desenhos digitais, ou dermatóglifos, resultam da interação entre a epiderme e a derme, em que projeções epidérmicas direcionadas à derme (cristas epidérmicas) provocam projeções dérmicas na epiderme (papilas dérmicas) aumentam a área de superfície e consequentemente maior área de atrito (cristas de fricção) (Figura 2).

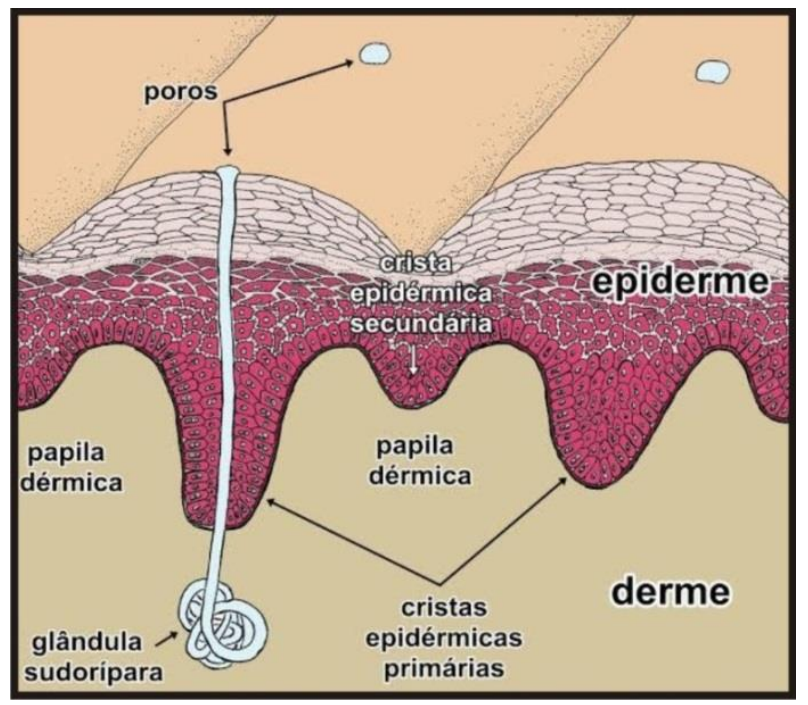

Figura 2. Esquema da pele mostrando a relação entre as cristas de fricção presentes na superfície epitelial e as papilas dérmicas que se projetam para a epiderme. Ilustração de Rodrigo Meneses de Barros (Mizokami, 2014).

As impressões registradas dos desenhos digitais formados conforme descrito podem ser classificados em tipos fundamentais ou também chamados de tipos primários, conforme o sistema de classificação de Galton-Henry ou de Vucetich (GALTON, 1895; RODRIGUEZ, 2004; BARNES, MACEO, et al., 2011); no Brasil, adota-se o sistema de Vucetich. Este sistema considera para a classificação datiloscópica três conjuntos de cristas, o central ou nuclear, o basal e o marginal, sendo que da confluência dos três conjuntos de cristas, pode-se formar uma figura de aspecto triangular denominada delta ou trirrádio (Figura 3).

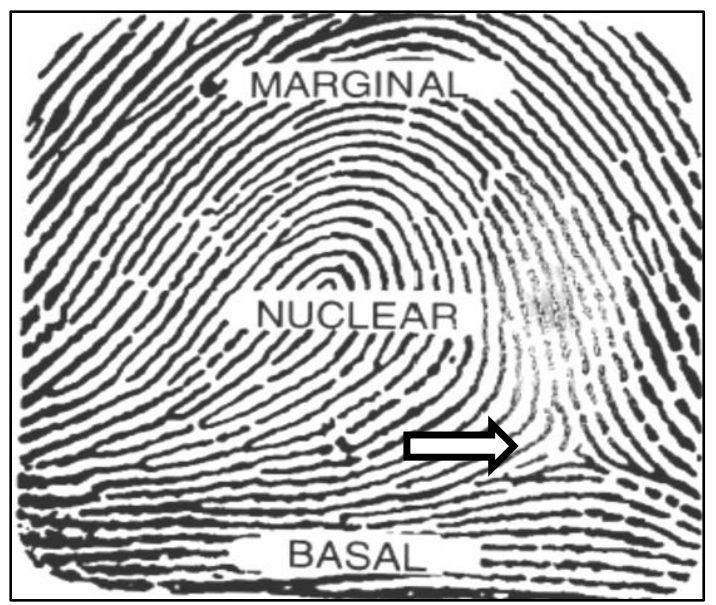

Figura 3. Impressão digital ilustrativa exibindo os três conjuntos de cristas de fricção utilizados no sistema de classificação de Vucetich. A seta indica um delta (VANRELL, 2012). 
Com base nos três conjuntos de cristas pode ser encontrado um delta, à direita ou à esquerda do observador, dois deltas ou ausência dele, assim sendo, são classificados quatro tipos fundamentais, presilha interna, presilha externa, verticilo e arco (APC, 2008b; VANRELL, 2012) (Figura 4). A ausência do delta e presença de linhas abauladas mais ou menos paralelas caracteriza o tipo fundamental denominado de arco. Classifica-se como presilha interna o datilograma que apresenta um delta à direita do observador e um núcleo constituído de uma ou mais linhas que partem da esquerda, vão ao centro, curvam-se e tendem voltar ao lado de origem formando as laçadas, já a presilha externa caracteriza-se por um delta à esquerda do observador e um núcleo constituído de uma ou mais linhas que partem da direita, vão ao centro, curvam-se e tendem voltar ao lado de origem formando as laçadas. A presença de pelo menos dois deltas, um à direita outro à esquerda do observador, caracteriza o tipo verticilo; seu núcleo pode ter configuração variada. Cada tipo fundamental possui também subclassificações que designa variações dos tipos primários. Além disso, os datilogramas que não se enquadram nos tipos fundamentais são denominados anômalos, cujas anomalias podem ser congênitas ou acidentais, ou mesmo decorrentes de cicatrizes ou doenças (APC, 2008b; VANRELL, 2012).
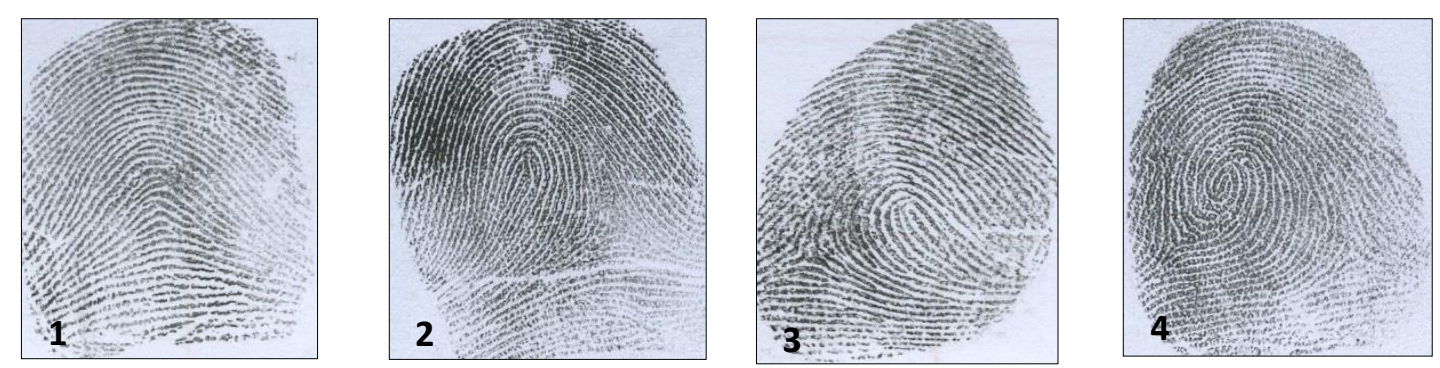

Figura 4. Tipos Fundamentais de datilogramas, segundo a classificação de Vucetich, o arco (1), presilha interna (2), presilha externa (3), ou verticilo (4) (II/PCDF).

A identificação humana é realizada nos centros periciais pela comparação entre duas impressões digitais, sendo uma impressão digital conhecida e registrada em documentos ou bancos de dados oficiais, que é denominada impressão padrão, e a impressão questionada que pode ser coletada em local de crime, de cadáver de identidade ignorada ou registrada de indivíduo com suspeita de falsidade ideológica. 
As impressões digitais questionadas são obtidas por técnicas diversas (empoamento e decalque, cianoacrilato, dentre outros) e posteriormente encaminhadas aos centros periciais. A comparação entre impressões é denominada confronto, este pode ser feito com auxílio de sistemas automatizados de identificação policial que se baseiam em algoritmos que consideram o número de linhas, a disposição dos pontos característicos (minúcias), a angulação e as correspondências entre a impressão padrão e impressão questionada (YAGER e AMIN, 2004); no Distrito Federal emprega-se o sistema denominado AFIS (Automated Fingerprint Identification System).

A identificação humana a partir dos datilogramas representa um método eficiente, prático e de baixo custo, embasado, sobretudo, pelos fundamentos que diferenciam os indivíduos (ZUGIBE e COSTELLO, 1986; KAHANA, GRANDE, et al., 2001; FRANCA, 2011; VANRELL, 2012). Dentre esses fundamentos destacam-se a unicidade, perenidade, praticabilidade e a classificabilidade dos desenhos digitais, conforme explicitado em diferentes publicações forenses (GUTIÉRREZ, GALERA, et al., 2007; VANRELL, 2012).

A unicidade implica na especificidade de determinados elementos ou caracteres existentes em um indivíduo que pode ser percebida pela apresentação de impressões digitais distintas inclusive entre gêmeos univitelinos (OKAJIMA, 1970). Esse pressuposto se fundamenta na influência de múltiplos fatores que influenciam para a formação dos desenhos digitais, e foi ilustrado por cálculos matemáticos demonstram a probabilidade próxima de zero da ocorrência de duas impressões idênticas (KÜCKEN, 2007; PAGE, TAYLOR e BLENKIN, 2011).

A perenidade se refere à manutenção dos datilogramas ao longo da vida, não são transitórios, mas desaparecem com a decomposição dos tecidos moles decorrente dos processos transformativos cadavéricos (APC, 2008a; VANRELL, 2012).

A praticabilidade refere-se a um processo não complexo de registro dos datilogramas, que comumente envolve o entintamento e aposição dos dedos em papel branco ou via captura eletrônica por meio de escâner óptico ou mesmo a revelação de impressões digitais deixadas em determinada superfície por um indivíduo a partir da utilização de agentes físicos ou químicos. 
A classificabilidade é o requisito metodológico para o arquivamento dos registros, que é o resultado de uma avaliação dos datilogramas na população para a elaboração de uma classificação aplicável ao ser humano; o método empregado no Brasil foi desenvolvido por Vucetich em 1896 (RODRIGUEZ, 2004; BARNES, MACEO, et al., 2011), conforme reportado anteriormente.

Além dos fundamentos descritos acima, existe um pressuposto que afirma que as impressões digitais são imutáveis, ou seja, que os desenhos digitais são conservados ao longo da vida. Apesar do conceito da imutabilidade ainda persistir na papiloscopia, é comum na prática pericial a observação de alterações nos desenhos digitais de indivíduos idosos, como a perda da nitidez dos datilogramas, o surgimento de linhas subsidiárias e a presença de linhas albodactilares, que são áreas ou linhas brancas decorrentes de enrugamentos da pele ou da perda do seu tônus; disso decorrem interrupções ou o desaparecimento de trechos das cristas de fricção causando falhas nos datilogramas que prejudicam a identificação das minúcias (Comunicação Pessoal).

Corroborando os achados da prática pericial, os estudos realizados na década de 60 e 70 por Plotinik e Pinkus (1958) e Okajima (1979) sugeriram que a derme papilar de indivíduos idosos pode apresentar papilas dérmicas desorganizadas e em maior número do que a derme papilar de indivíduos jovens. Misumi e Akiyoshi (1984) analisaram as papilas dérmicas com microscopia eletrônica de varredura e verificaram que essas estruturas variam em formatos e tamanho, sendo que essas variações não são dependentes da área em que estão presentes; o número de papilas tende a aumentar com a idade tanto pela transformação de papilas primárias em secundárias como pelo surgimento de novas papilas, o que corrobora com as pesquisas das décadas anteriores e indica a remodelação dérmica em função da idade. Os achados de Stücker, et al. (2001) mostraram que as minúcias presentes nos desenhos digitais não se alteram ao longo da vida, mas apesar disso, eles afirmaram que as linhas interpapilares ou subsidiárias podem ser consideradas como uma parte do datilograma em evolução e, à medida que aumenta a idade do indivíduo, aumenta também a ocorrência de linhas subsidiárias entre as cristas de fricção.

Consonante com os achados relatados acima, sabe-se que a pele humana é formada por diferentes tecidos biológicos que estão sujeitos ao processo normal de envelhecimento que provoca alterações morfológicas e fisiológicas em suas 
estruturas, por exemplo, o surgimento de linhas subsidiárias e/ou do aumento no número de papilas dérmicas (OKAJIMA, 1979; MODI, ELLIOTT, et al., 2007; BARNES, MACEO, et al., 2011).

O envelhecimento da pele pode estar associado a mudanças dos níveis hormonais que ocorrem ao longo da vida. A epiderme é um tecido epitelial estratificado queratinizado cujos queratinócitos se originam na camada germinativa (basal) e migram para os demais estratos até sua descamação na camada córnea. O tecido conjuntivo no qual a epiderme está fixada compreende a derme, a qual é composta das camadas papilar e reticular com importante papel na termoregulação e suprimento nutricional da epiderme por meio de sua rede vascular; nessa camada os fibroblastos são responsáveis pela secreção das proteínas da matriz extracelular (colágeno, elastina, proteoglicanos e outras) que promovem a resistência e a elasticidade da pele, além de proporcionar a resiliência da pele (MAKRANTONAKI e ZOUBOULIS, 2007). Com o envelhecimento, ocorre um achatamento na junção dérmico-epidermica redução da vascularização e na quantidade de células, decréscimo da atividade de fibroblastos com a redução da quantidade de colágeno e elastina (FARAGE, MILLER, et al., 2013). Barnes et al. (2011) propõem que na epiderme, observa-se que a proliferação dos queratinócitos reduz, entretanto os efeitos da idade na epiderme são menos proeminentes do que na derme, proporcionando a manutenção dos dermatóglifos verificados na pele espessa.

O desenvolvimento da Síndrome Metabólica (SM) tem sido relatado é comum na população adulta (PEREIRA, SAMPAIO, et al., 2012). A ocorrência dessa síndrome tem sido constatada em $25 \%$ a $35 \%$ da população mundial, com maior frequência em mulheres (BORTOLETTO, DE SOUZA, et al., 2014). A síndrome metabólica pode ser definida como fatores de risco para doenças crônicas, principalmente o diabetes mellitus e as doenças cardiovasculares. O diagnóstico é realizado pela ocorrência de três ou mais condições, a obesidade abdominal (circunferência da cintura acima de $102 \mathrm{~cm}$ no sexo masculino e $88 \mathrm{~cm}$ no sexo feminino); hipertrigliceridemia (superior ou igual a $150 \mathrm{mg} / \mathrm{dl}$ ); baixas concentrações de HDL-colesterol (menor que 40mg/dl no sexo masculino e menor que $50 \mathrm{mg} / \mathrm{dl}$ no sexo feminino); pressão arterial sistólica acima ou igual a $130 \mathrm{mmHg}$ e pressão arterial diastólica acima de $85 \mathrm{mmHg}$; e hiperglicemia de jejum (superior ou igual a $110 \mathrm{mg} / \mathrm{dl}$ ) (FARIAS, PEREIRA e ROSA, 2010). No Brasil, a prevalência dessa síndrome é de $29,8 \%$ para a população geral e $81 \%$ em idosos devido ao 
decréscimo gradual da eficiência do organismo e pode estar relacionada à combinação de fatores tais como obesidade central, resistência à insulina, inflamação, fatores genéticos e ambientais, dentre os quais, a dieta hiperglicêmica e a inatividade física são os principais relatados. (BORTOLETTO, DE SOUZA, et al., 2014).

Associado ao envelhecimento é possível que as variações nos datilogramas de um mesmo indivíduo decorram de patologias que afetam a nutrição e oxigenação tecidual, como a hipertensão arterial sistêmica (HAS) e o diabetes mellitus (DM).

Sabe-se que o risco de hipertensão é aumentado para os indivíduos com histórico familiar dessa patologia. Devido ao fator genético, tem-se estudado a correlação entre dermatóglifos e hipertensão arterial para detecção precoce de pessoas com predisposição genética para desenvolvimento dessa doença. Os resultados mostraram maior incidência da hipertensão em pessoas que apresentam arco, verticilo sinuoso e presilha interna, além de maior contagem do número de cristas de fricção comparado às pessoas normais (LAHIRI, BANDYOPADHYAY, et al., 2013). Godfrey et al. (1993) observaram a prevalência do tipo fundamental verticilo para adultos com pressão arterial elevada. Entretanto, tais resultados ainda não estão esclarecidos, uma vez que ainda não foi demonstrada a associação da HAS com o desenvolvimento dos datilogramas (WIJERATHNE, MEIER, et al., 2015).

No diabetes, é comum a redução da densidade capilar possivelmente relacionada à redução do número de fibroblastos (HERNÁNDEZ, TORRES, et al., 1999; BUCKLEY e BOSSEN, 2013). Alguns estudos observaram uma relação positiva entre maior média do número de linhas nos datilogramas e a ocorrência do diabetes mellitus na meia idade (RAVINDRANATH e THOMAS, 1995; KAHN, GRAFF, et al., 2009). Considerando que o diabetes pode resultar de um número restrito de células formadoras das ilhotas de Langerhans, especialmente as células beta, o aumento no número de linhas nos quirodáctilos poderia refletir circunstâncias presentes até a primeira metade da gestação (KAHN, GRAFF, et al., 2009).

Outros estudos indicam uma correlação entre a esquizofrenia e a redução do número de linhas nos dermatóglifos possivelmente mediada pelo estresse durante 0 desenvolvimento fetal (AVILA, SHERR, et al., 2003). Nesse sentido, outras pesquisas demonstraram a associação de assimetria dos tipos fundamentais de dermatóglifos existentes nos quirodáctilos homólogos das duas mãos, o que resultou 
em maior número de assimetrias para portadores de transtornos do pensamento do que para pessoas hígidas (DE BRUIN, DE NIJS, et al., 2012). Esses achados reforçam a ideia de se utilizar os tipos fundamentais como possíveis marcadores ou indicadores de risco da instabilidade prénatal e desenvolvimento da esquizofrenia e eventos psicóticos, uma vez que o desenvolvimento cerebral se inicia no mesmo momento embrionário da formação das cristas de fricção e se formam originalmente do mesmo ectoderma (AVILA, SHERR, et al., 2003).

Considerando que as mãos humanas estão associadas a múltiplas funções e que a pele que a reveste possui diferentes tecidos e especificidades, é possível que atividades laborais danosas, como as que envolvem o uso de substâncias químicas (limpeza, indústria química etc) ou de ferramentas (construção civil, agricultura, carpintaria, artesanato etc), reflitam em um processo de reparação tecidual que proporcione a sua remodelação gerando modificações nos dermatóglifos (STÜCKER, GEIL, et al., 2001), mas é possível também que, em função de lesões repetitivas e do envelhecimento, haja prejuízo do processo de reparação tecidual (MAKRANTONAKI e ZOUBOULIS, 2007).

Sabidamente, a ação dos elementos ambientais como a temperatura e a umidade podem afetar a funcionalidade do tegumento e proporcionar o surgimento de patologias. De forma preventiva, o uso de cremes hidratantes ou cosméticos associados pode favorecer a preservação da pele e, consequentemente, dos desenhos digitais. Nesse contexto, especula-se que os datilogramas das mulheres sejam mais preservados ao longo da vida pelo hábito delas no uso de tais produtos em comparação aos homens.

Pondera-se como fundamental que os objetos de identificação (impressões digitais) apresentem qualidade técnica para a individualização segura (ZUGIBE e COSTELLO, 1986), e que é comum na prática pericial que as impressões digitais obtidas de indivíduos idosos apresentem perda de qualidade, portanto, faz-se necessário identificar quais são as alterações que comprometem essa qualidade. No entanto, até o momento, não há estudos que avaliem o perfil dos datilogramas de um mesmo indivíduo ao longo da vida, ou mesmo que descrevam quais são as alterações longitudinais sofridas pelos desenhos digitais.

No Brasil, além dos registros biométricos criminais, a existência do documento civil de identidade favorece a construção de uma base de dados civil que pode ser empregada em estudos longitudinais. Os dados biométricos são obtidos 
por meio da coleta das impressões digitais dos dez dedos de ambas as mãos, e ainda são registrados altura, fotografia facial, cor dos olhos, da pele e dos cabelos, sinais, tatuagens e cicatrizes, e dados qualificativos do indivíduo baseados em documento oficial registrado em cartório. De acordo com a legislação brasileira, a Carteira de Identidade é expedida com base no processo de identificação datiloscópica, sendo que os Prontuários Civis (impressão padrão) são arquivados nos institutos de identificação (BRASIL, 1983).

Considerando que ao longo do processo de envelhecimento ocorram variações nos desenhos digitais, é possível que haja incongruências nos algoritmos dos sistemas automatizados que podem afetar o processo de individualização no confronto de impressões questionadas com o padrão datiloscópico coletado em idade jovem. Logo, a manutenção e atualização dos padrões arquivados, bem como a determinação das variações morfométricas datiloscópicas podem ser importantes para aprimoramento dos especialistas em papiloscopia e para melhoramento dos algoritmos dos sistemas de identificação no âmbito civil e criminal. 
2. OBJETIVOS 


\section{1. OBJETIVO GERAL}

Determinar variações qualitativas e quantitativas longitudinais em impressões digitais coletadas de indivíduos em idade adulta e idosa.

\subsection{OBJETIVOS ESPECÍFICOS}

- Classificar o tipo fundamental e sua frequência nos 10 dedos das mãos;

- Quantificar o número de cristas de fricção, minúcias, linhas subsidiárias e linhas albodactilares visíveis nos datilogramas de indivíduos em idade adulta e idosa;

- Identificar e comparar a presença de cristas de fricção, minúcias, linhas subsidiárias e linhas albodactilares nos datilogramas de indivíduos em idade adulta e idosa;

- Comparar os datilogramas com fins à identificação datiloscópica;

- Verificar a correlação entre a identificação civil com as atividades laborais, o uso de cosméticos e patologias;

- Avaliar qualitativamente a nitidez e a integridade das impressões digitais registradas de indivíduos em idade adulta e idosa. 
3. MATERIAIS E MÉTODOS 


\subsection{Delineamento do estudo}

O presente estudo descritivo trata da comparação quantitativa e qualitativa de impressões digitais coletadas de indivíduos idosos com os seus padrões coletados quando eram adultos e que se encontram arquivados nos bancos oficiais, conforme delineamento esquematizado na figura 5 .

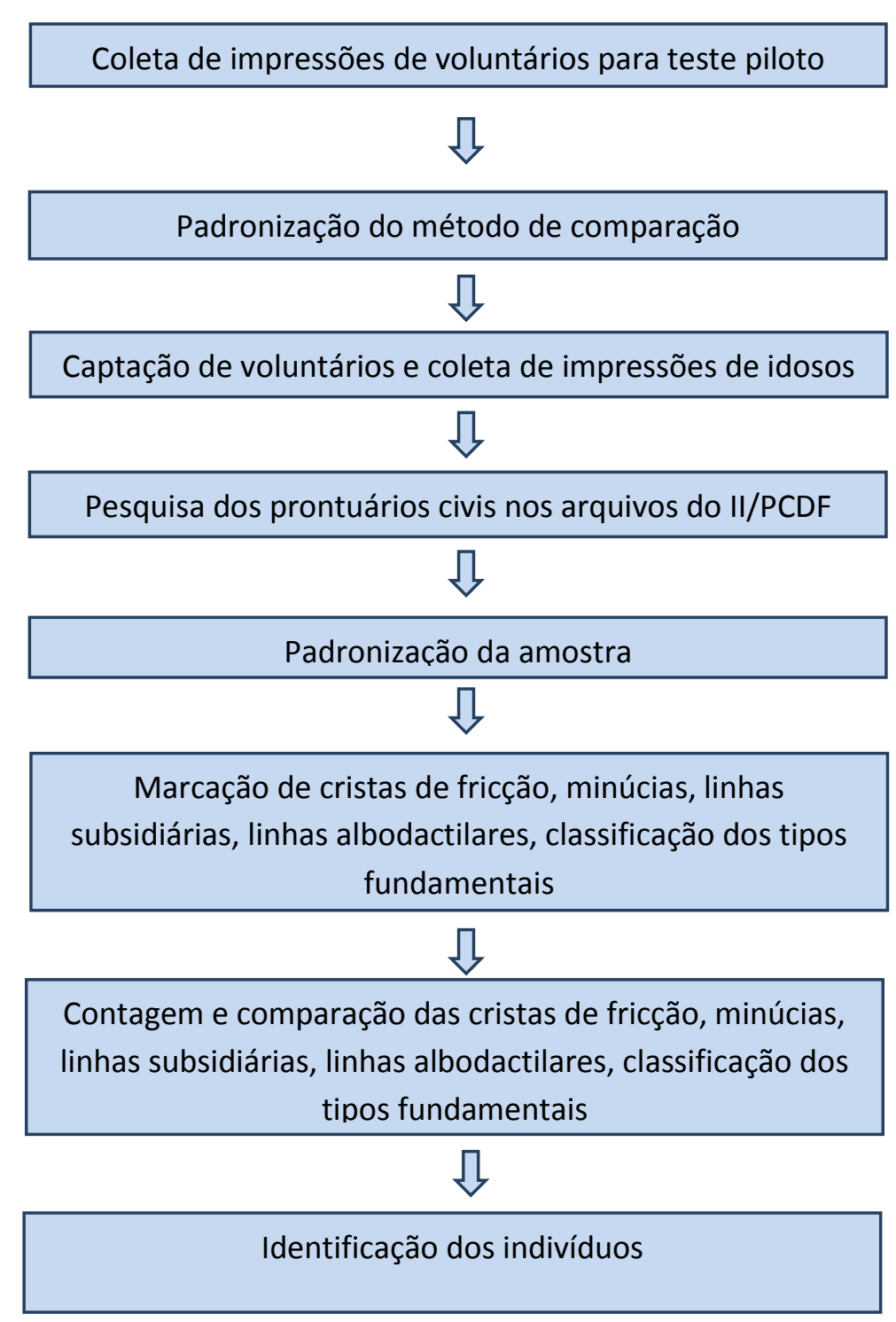

Figura 5. Fluxograma exibindo o delineamento do estudo experimental da comparação qualitativa e quantitativa de impressões de adultos e idosos.

\subsection{Tipo de estudo}

Trata-se de um estudo longitudinal e descritivo que busca comparar impressões digitais coletadas de indivíduos idosos com os seus padrões arquivados nos bancos oficiais para determinar possíveis variações qualitativas e quantitativas 
em função do processo de envelhecimento. Este estudo foi realizado em parceria com o Instituto de Identificação da Polícia Civil do Distrito Federal (II - PCDF).

\subsection{Normas Éticas}

O projeto de pesquisa foi submetido ao Comitê de Ética em Pesquisa da Faculdade de Medicina da Universidade de Brasília (Protocolo ㄲo 65/2011) e foi desenvolvido somente após aprovação pelo referido Comitê (Anexo 1). Considerando a parceria, a Polícia Civil do Distrito Federal autorizou o acesso ao banco de dados para a execução deste projeto, conforme Ofício № 112/2012 Departamento de Polícia Técnica, de 18 de maio de 2012 (Anexo 2).

Durante o desenvolvimento deste estudo obedeceu-se à regulamentação para realização de pesquisa envolvendo seres humanos, composta pela Declaração de Helsinque (WMA, 2013) e pela Resolução 196/96 do Ministério da Saúde (BRASIL, 1996).

\subsection{Indivíduos}

Os indivíduos voluntários participantes da pesquisa foram esclarecidos quanto à aplicabilidade e objetivo do estudo, a não remuneração por sua participação, ao direito de desistência de participação a qualquer tempo, ao sigilo dos dados e garantia da privacidade, ao uso exclusivo dos dados para este estudo, conforme autorização prévia em Termo de Consentimento Livre e Esclarecido (Apêndice A).

O estudo foi realizado mediante a coleta de impressões digitais de 40 indivíduos voluntários, 20 homens e 20 mulheres, idosos (idade igual ou superior a 60 anos) e cujo padrão datiloscópico havia sido coletado quando em idade adulta e estava arquivado no banco de dados II/PCDF; a diferença entre a maior e a menor idade era igual ou superior a 14 anos dos registros.

Para descrever o perfil epidemiológico dos indivíduos, cada participante foi entrevistado para a coleta em questionário do nome, data de nascimento, histórico de doenças, uso de medicamentos, hábitos manuais, atividade laboral ao longo da 
vida e atual, bem como do uso de cosméticos para pele (Apêndice B ). Foram considerados como hábitos potencialmente danosos aos datilogramas aqueles relacionados com serralheria, construção, mecânica, agricultura, horticultura, jardinagem, limpeza doméstica, uso de produtos químicos sem luvas de proteção, artesanato, costura, crochetagem e tricotagem.

\subsection{Obtenção das impressões digitais de idosos}

A coleta da impressão digital de indivíduos idosos foi feita por um perito em papiloscopia pelo método convencional para permitir a comparação dessas impressões com aquelas coletadas em anos anteriores. Esse método consiste no entintamento das polpas digitais de dez dedos de cada indivíduo e registro dos datilogramas em uma ficha de papel cartão branco, denominada individual datiloscópica, previamente identificada com nome do participante, número da amostra, data e nome do perito que a coletou. As fichas individuais utilizadas apresentavam coloração diferenciada em razão do gênero, sendo preto para sexo masculino e vermelho para sexo feminino; a tinta empregada foi a Fingerprint ink (Sirchie ${ }^{\circledR}$,Finger Print Laboratories Inc, Nova lorque, Estados Unidos). Durante a coleta das impressões foram evitados o uso de pressão e entintamento excessivos. Posteriormente ao registro em papel, as impressões datiloscópicas individuais foram submetidas ao processo de digitalização com uma resolução de 500 dpi com uso do sistema Epson Perfection V700 Photo Scanner® (Figura 6) e então, as imagens foram convertidas para o formato Tagged Image File Format (TIFF).

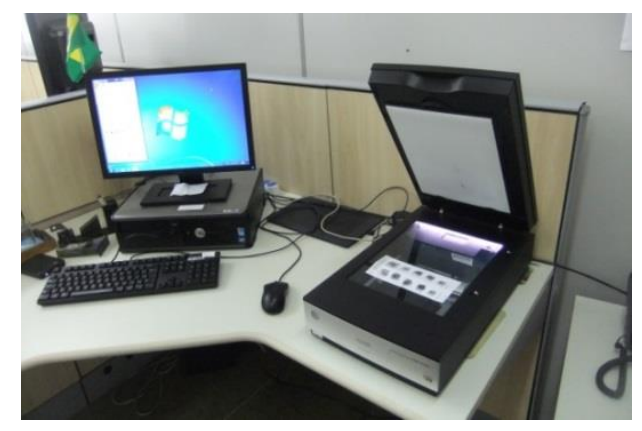

Figura 6. Sistema de fotodocumentação utilizado para a digitalização das impressões digitais pertencente ao Instituto de Identificação do Distrito Federal.

\subsection{Pesquisa dos prontuários civis para a obtenção das impressões digitais para o estudo comparativo}

Para localizar a impressão digital dos indivíduos adultos correspondentes às impressões atuais obtidas dos idosos foi feita uma pesquisa dos prontuários civis por 
meio da busca dos dados qualificativos de cada indivíduo ou do número de registro geral; essas impressões coletadas em anos anteriores pelo método convencional que posteriormente foram digitalizadas em 500 dpi encontram-se armazenadas nos prontuários civis do Sistema de Prontuário Digital (SPD) e em arquivos físicos segundo sua ordem numérica de arquivamento. Depois de localizados, os prontuários civis e o datilograma padrão do indicador direito foram salvos em formato TIFF e a data de qualificação exibida no prontuário foi utilizada para cálculo do interstício temporal dos registros datiloscópicos.

\subsection{Determinação dos tipos fundamentais e padronização das imagens}

Após obtenção dos registros dos indivíduos, os datilogramas dos dez dedos foram classificados quanto ao tipo fundamental datiloscópico, conforme classificação de Vucetich, sendo (1) Arco, quando há ausência de delta e linhas mais ou menos paralelas; (2) Presilha Interna, quando o delta apresenta-se à direita do observador e uma ou mais linhas formam laçadas na região do núcleo; (3) Presilha Externa, quando o delta encontra-se à esquerda do observador e uma ou mais linhas formam laçadas na região do núcleo; e (4) Verticilo, quando há presença de pelo menos dois deltas.

Para fins de cálculo da frequência dos tipos fundamentais, as eventuais dúvidas e hipóteses foram sanadas pela classificação existente no datilograma padrão da fase adulta dos indivíduos que se encontram arquivados no II/PCDF.

Para o estudo comparativo foi selecionado o padrão datiloscópico digitalizado, adulto e idoso, do dedo indicador direito de cada indivíduo. Em seguida, os datilogramas foram exportados para o programa CorelDRAW ${ }^{\circledR} X 7$ e as imagens foram calibradas quanto ao tamanho e rotação para assegurar a correspondência das áreas a serem analisadas. A partir da imagem em tamanho real foi feito 0 redimensionamento proporcional dos datilogramas tendo como referência a marcação da distância entre dois pontos característicos visíveis em ambas as impressões. Em seguida, as imagens foram rotacionadas até que seus pontos de referência correspondentes estivessem alinhados em relação ao seu maior eixo e horizontalmente aos seus eixos colineares (Figura 7). As imagens foram sobrepostas para assegurar o alinhamento vertical em relação a um único eixo. 


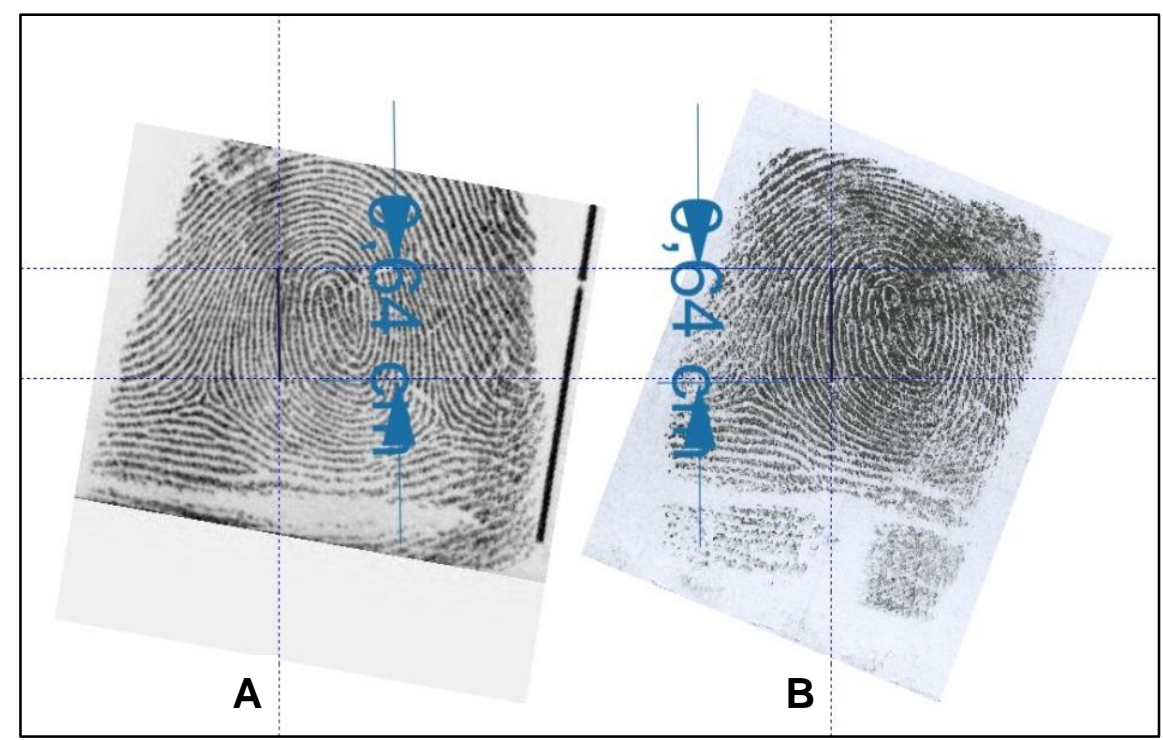

Figura 7. Imagem dos datilogramas coletados do mesmo indivíduo do sexo masculino ( $n$ - 19) em idades distintas, fase adulta (A) e idosa (B). Ambas as imagens foram rotacionadas e alinhadas nos eixos vertical e horizontal para manter a equivalência das distâncias entre dois pontos característicos correspondentes.

Para permitir o estudo comparativo, uma área de $1 \mathrm{~cm}^{2}$ em cada par de imagens, das fases adulta e idosa, foi delimitada. A seleção da área teve como base a minúcia mais central possível visível nas duas impressões correspondentes, de forma que o quadrado delimitado estivesse completamente preenchido por linhas (Figura 8). Em seguida, as áreas selecionadas nas imagens foram cortadas e salvas em formato TIFF para análise e marcação das minúcias no programa CoreIDRAW ${ }^{\circledR}$ X7.
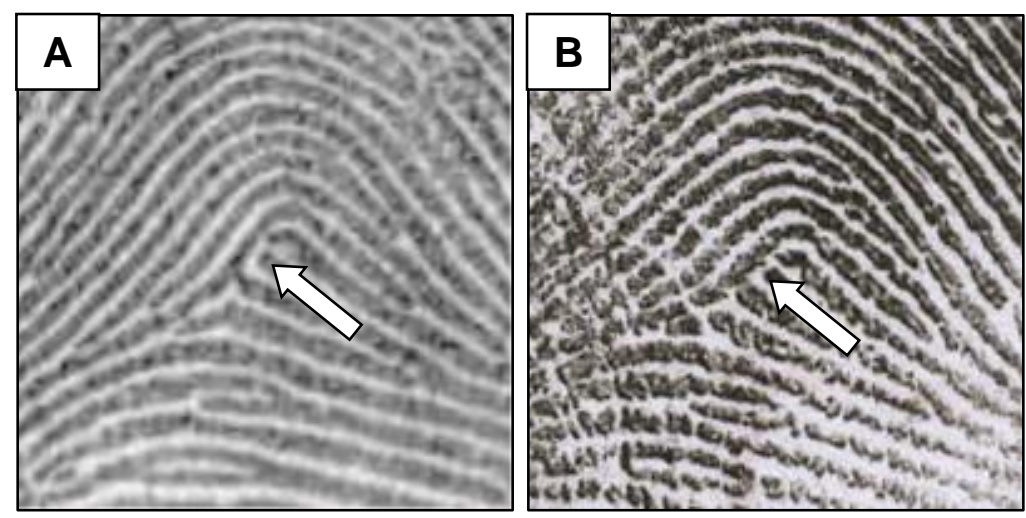

Figura 8. Fotografias de impressões digitais do dedo indicador direito de um indivíduo do sexo feminino ( $\left.\mathrm{n}^{\circ} \mathrm{3}\right)$, quando adulto (A) ou idoso (B). A área selecionada de $1 \mathrm{~cm}^{2}$ tem como centro uma minúcia que se encontra indicada pela seta. 


\subsection{Marcação das minúcias e linhas subsidiárias}

Para a comparação entre os padrões datiloscópicos (adulto e idoso) as imagens de $1 \mathrm{~cm}^{2}$ seccionadas das impressões digitais foram repassadas separadamente a um especialista em identificação para a marcação de minúcias e linhas subsidiárias, em dias distintos, de forma que os pares correspondentes não fossem analisados no mesmo dia; a correspondência entre as impressões era desconhecida, bem como a identidade dos indivíduos. Foi solicitado ao especialista que marcasse todas as minúcias visíveis na área de $1 \mathrm{~cm}^{2}$ e, em separado, a indicação das linhas subsidiárias e linhas albodactilares. Para fins de marcação, as mínúcias caracterizadas por pequenos pontos (ilhotas) e fragmentos de linhas isolados foram incluídas na contagem geral de minúcias.

Para determinar a ocorrência de linhas subsidiárias, os critérios adotados foram os mesmos aplicados por Stücker et al. (2001), ou seja, foram consideradas as linhas localizadas no espaço correspondente aos sulcos (inter-crista), que são caracterizadas por serem delgadas e frequentemente interrompidas e por não apresentarem poros das glândulas sudoríparas; tais estruturas deveriam ocorrer no espaço de pelo menos três linhas vizinhas (Figura 9).
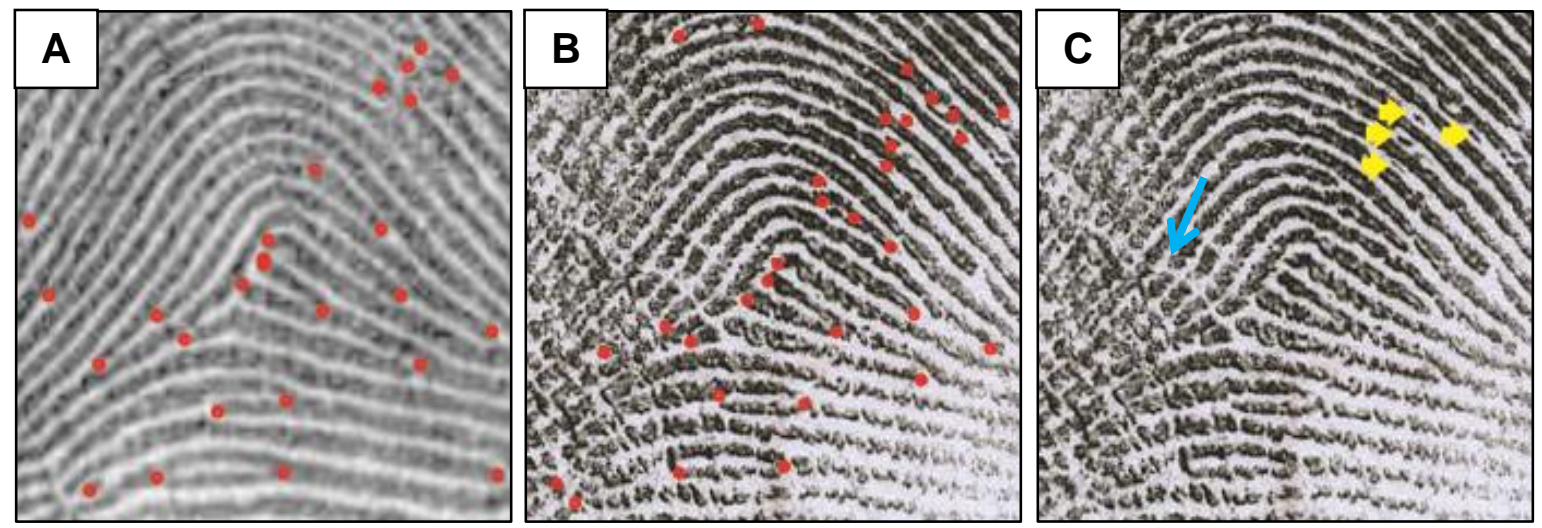

Figura 9. Fotografias de impressões digitais (dedo indicador direito) do indivíduo do sexo feminino $\left(n^{\circ}-3\right)$ das fases adulta $(A)$ e idosa $(B, C)$ para ilustrar a marcação de minúcias. Os pontos vermelhos indicam as minúcias, setas amarelas indicam linhas subsidiárias e seta azul indica linha albodactilar.

\subsection{Quantificação das cristas de fricção}

Para a quantificação do total de linhas digitais presentes na área de $1 \mathrm{~cm}^{2}$, previamente selecionada como descrito acima nas duas impressões de cada 
individuo, traçou-se uma linha diagonal ao quadrado a partir do ângulo superior esquerdo e seu oposto inferior direito, conforme demonstrado na figura 10. Em seguida, as linhas concorrentes à diagonal foram quantificadas de forma que fosse visível a sua continuidade e o espaço entre elas; minúcias isoladas ou pequenos fragmentos de linhas tangentes à diagonal foram desconsiderados.
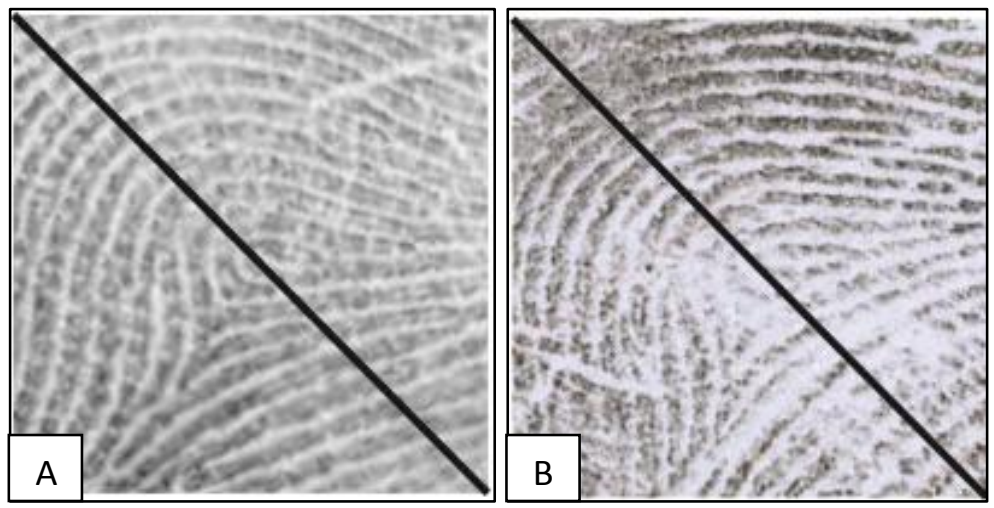

Figura 10. Fotografias de impressões digitais de dedo indicador direito do mesmo indivíduo (sexo feminino, $\mathrm{n}^{\circ}$ 9), quando adulto (A) ou idoso (B). A linha diagonal traçada na imagem foi utilizada para a quantificação das cristas de fricção.

\subsection{Comparação entre os padrões datiloscópicos}

Para a comparação dos datilogramas das fases adulta e idosa de um mesmo indivíduo, primeiramente foram marcados os pontos característicos/minúcias em vermelho e as linhas subsidiárias em amarelo como descrito anteriormente. Cada ponto característico assinalado pelo especialista foi enumerado de forma que o primeiro número indica o indivíduo, a letra indica o sexo ( $\mathrm{M}$ ou F) e o segundo número indica a minúcia ou a linha subsidiária (nesse caso acompanhada da letra S). Pontos característicos coincidentes receberam a mesma identificação e foram utilizados para determinar os percentuais de coincidências entre minúcias e linhas subsidiárias (Figura 11). 

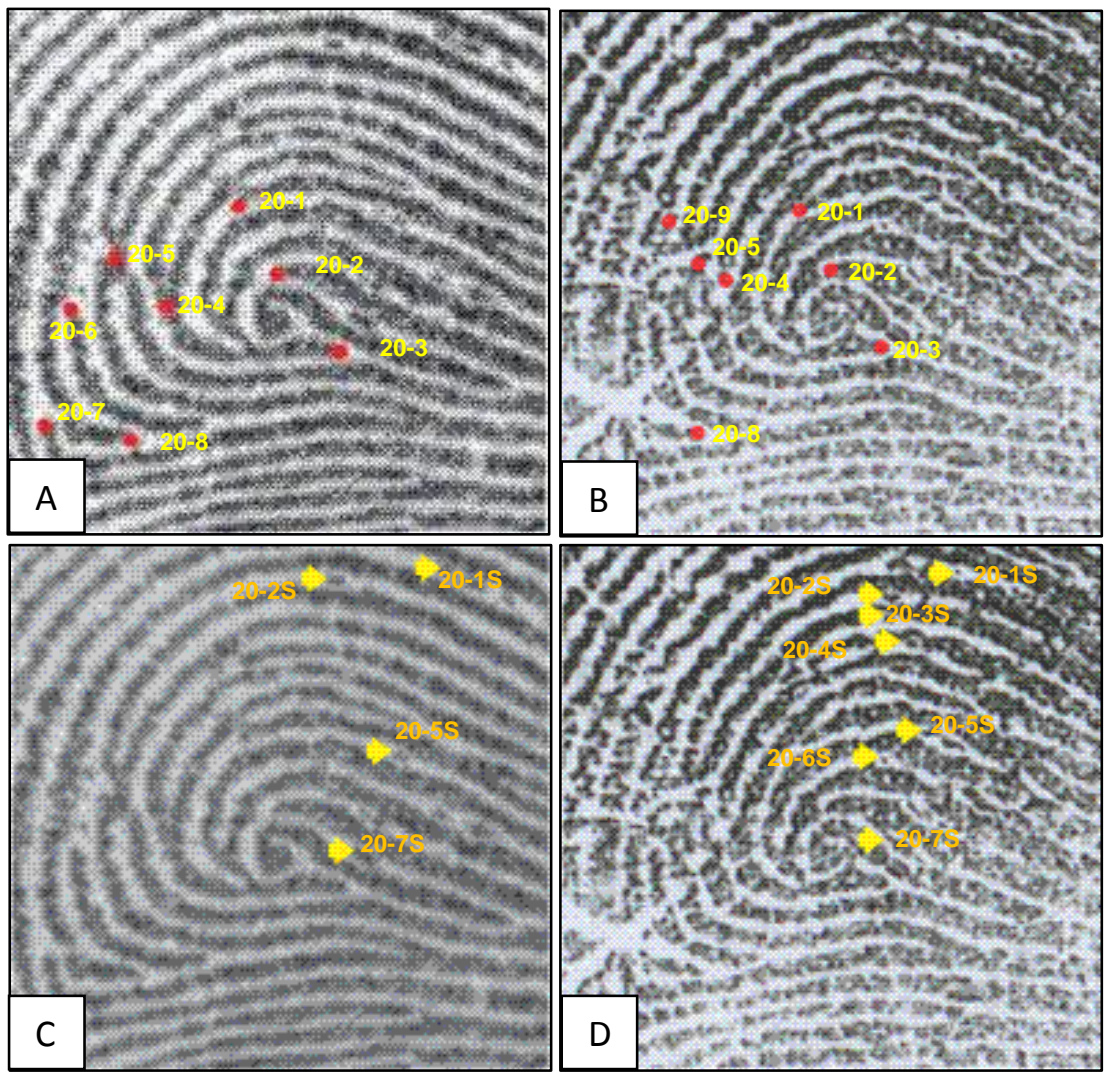

Figura 11. Fotografias dos datilogramas das fases adulta $(A, C)$ e idosa $(B, D)$ de um mesmo indivíduo do sexo masculino ( $\left.n^{\circ} 20\right)$ para ilustrar a comparação entre os padrões datiloscópicos. As minúcias estão indicadas em vermelho e as linhas subsidiárias em amarelo. Minúcias ou linhas subsidiárias coincidentes (presentes em ambos os datilogramas) receberam a mesma identificação e as discrepantes receberam identificação única.

Para o estudo comparativo do par de impressões de um mesmo indivíduo criou-se uma planilha para contagem dos pares de pontos coincidentes e dos pontos discrepantes, em que quando as minúcias estavam presentes em ambas as impressões atribuía-se o valor igual a 1 (um) e quando a minúcia estava em apenas uma das impressões atribuía-se o valor igual a 0 (zero); a ocorrência de linhas subsidiárias foi analisada da mesma maneira. Finalizada a comparação na área 
previamente definida de $1 \mathrm{~cm}^{2}$, foram quantificados os totais de minúcias coincidentes e discrepantes, de linhas subsidiárias e de linhas albodactilares.

\subsection{Identificação dos indivíduos}

Para avaliar se o padrão datiloscópico dos idosos permitiria a identificação civil, todos os datilogramas foram repassados a um perito em identificação datiloscópica do II/PCDF. No processo de identificação foi feita: 1) Busca automatizada por padrões compatíveis, utilizando o sistema AFIS (Automatic Fingerprint Identification System) com a ferramenta VRP (Vertical Ridge Processing) na qual o próprio sistema considera as áreas a serem pesquisadas e assinala as minúcias automaticamente; 2) Busca automatizada associada à análise do perito com aplicação do protocolo de pesquisa do II/PCDF, sua seleção subjetiva de ferramentas e filtros, marcação e exclusão de minúcias, ajuste da localização do núcleo para pesquisa das mesmas impressões (padrão ouro); 3) Confronto direto do datilograma do idoso com seu padrão adulto arquivo, tendo como base conhecimento/suspeita prévia da identidade do indivíduo. Para a análise por esses métodos foram consideradas características específicas dos datilogramas como 0 tipo fundamental, a quantidade de cristas de fricção, minúcias e linhas subsidiárias.

Considerou-se "padrão ouro" o método de pesquisa em que há a associação da análise do especialista somada ao processamento do sistema automatizado de busca nos arquivos, quando a identidade de quem produziu as impressões é desconhecida e a busca é feita na totalidade do arquivo, sendo "1" impressão questionada para "n" armazenadas no banco de dados.

\subsection{Análise estatística}

A normalidade das variáveis foi analisada empregando-se o teste de Kolmogorov-Smirnov e a igualdade das variâncias pelo teste de Bartlett. Para a comparação entre mais de dois grupos utilizou-se os testes de ANOVA ou KruskalWallis quando os dados apresentavam distribuição normal ou não normal, respectivamente. Para a comparação entre duas amostras dependentes foram utilizados os testes t-pareado ou Wilcoxon para dados com distribuição paramétrica ou não paramétrica, respectivamente. Para duas amostras independentes com distribuição paramétrica ou não paramétrica foram utilizados os testes $t$ ou MannWhitney, respectivamente. Para o estudo de correlação dos dados não paramétricos 
foi utilizado o teste de Sperman. As diferenças entre as variáveis comparadas serão consideradas estatisticamente significantes quando a probabilidade bi-caudal da sua ocorrência devida ao acaso (erro tipo l) foi menor que $5 \%(p<0,05)$. 


\subsection{PERFIL DOS INDIVÍDUOS}

O estudo analisou 40 individuais datiloscópicas coletadas de indivíduos com idade acima de 60 anos, 20 homens e 20 mulheres que possuíam seus padrões datiloscópicos registrados, quando na fase em que eram adultos, arquivados no Instituto de Identificação da Polícia Civil do Distrito Federal (II/PCDF). Para descrever o perfil dos indivíduos foram coletados relativos à idade, às atividades laborais e/ou manuais ao longo da vida e à presença ou ausência de patologias crônicas e ao uso de cosméticos para pele das mãos.

Depois de compiladas as informações coletadas dos participantes identificou-se que o grupo de estudo foi formado por indivíduos com 67,4 $\pm 5,6$ anos de idade e os seus respectivos padrões datiloscópicos armazenados no II/PCDF

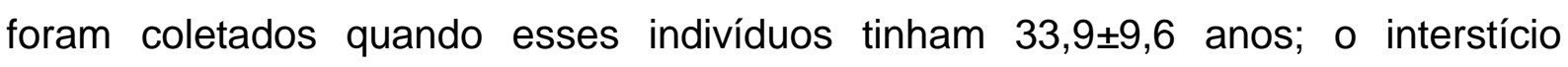
temporal foi de $33,5 \pm 9,4$ (Apêndice $C$ ).

Quanto às atividades laborais e/ou manuais o grupo de estudo foi formado por indivíduos cuja maioria $(26 ; 65 \%$ ) exerceu ou ainda exerce atividades consideradas como danosas aos datilogramas (serralheria, construção civil, mecânica, agricultura, horticultura, jardinagem, limpeza doméstica, artesanato, costura, crochetagem e tricotagem), sendo 8 homens e 18 mulheres. O restante do grupo $(14 ; 35 \%)$ exerceu ou exerce atividades laborais consideradas não prejudiciais aos datilogramas (serviços administrativos e bancários, comércio e ensino); desses 2 são do sexo feminino e 12 do sexo masculino (Tabela 1).

Tabela 1. Quantidade de homens e mulheres que exercem atividades laborais e/ou manuais danosas aos datilogramas.

\begin{tabular}{c|cccccc}
\hline Gênero & $\begin{array}{c}\text { Limpeza } \\
\text { Doméstica }\end{array}$ & $\begin{array}{c}\text { Construção } \\
\text { civil }\end{array}$ & $\begin{array}{c}\text { Agricultura, } \\
\text { jardinagem }\end{array}$ & $\begin{array}{c}\text { Mecânica, } \\
\text { serralheria }\end{array}$ & $\begin{array}{c}\text { Artesanato, costura, } \\
\text { crochetagem e } \\
\text { tricotagem }\end{array}$ \\
\hline Masculino & 3 & 1 & 2 & 2 & 0 \\
\hline Feminino & 9 & 0 & 1 & 0 & 8 \\
\hline
\end{tabular}

Dentre as principais patologias relatadas pelo grupo estudado a hipertensão arterial foi a mais comum acometendo 7 mulheres e 8 homens, seguida pelo 
diabetes mellitus (8 mulheres e 2 homens). Outras patologias também como cardiopatias, neoplasias, doenças articulares, psiquiátricas, hormonais, dentre outras foram identificadas entre os participantes (Tabela 2). Quanto ao uso de cosméticos para a pele, 22 indivíduos do grupo de estudo (55\%) relataram seu uso, sendo esse hábito comum a 19 mulheres e 3 homens.

Tabela 2. Percentual de homens e mulheres afetados por patologias crônicas.

\begin{tabular}{|c|c|c|c|c|c|c|c|}
\hline Gênero & $\begin{array}{c}\text { Hipertensão } \\
\text { arterial } \\
\text { sistêmica }\end{array}$ & $\begin{array}{l}\text { Diabetes } \\
\text { Mellitus }\end{array}$ & Cardiopatias & $\begin{array}{l}\text { Doenças } \\
\text { articulares }\end{array}$ & Neoplasia & $\begin{array}{c}\text { Distúrbios } \\
\text { psiquiátricos }\end{array}$ & $\begin{array}{c}\text { Doenças } \\
\text { hormonais }\end{array}$ \\
\hline Masculino & $40 \%$ & $10 \%$ & $5 \%$ & $15 \%$ & $20 \%$ & 0 & 0 \\
\hline Feminino & $35 \%$ & $40 \%$ & $10 \%$ & $20 \%$ & $10 \%$ & $15 \%$ & $15 \%$ \\
\hline
\end{tabular}

\subsection{ESTUDO DE CORRELAÇÃO}

Para os estudos de correlação foram considerados a determinação de identidade/qualidade satisfatória dos datilogramas, a partir do padrão ouro de identificação, relacionada à prática de atividades laborais danosas aos datilogramas, o uso ou não de cosméticos pelos indivíduos, bem como a presença ou não de patologias relacionadas a distúrbios vasculares que podem comprometer a integridade da pele como o diabetes mellitus (DM) ou a hipertensão arterial sistêmica (HAS).

Considerando a distribuição não paramétrica dos dados o teste de Sperman mostrou que a identificação dos indivíduos não apresenta para o grupo estudado correlação com as atividades danosas ( $p=0,301)$, o mesmo foi observado para as análises específicas para os grupos isoladamente, do sexo masculino $(p=0,519)$ ou feminino $(p=0,074)$.

Para o uso ou não de cosméticos os resultados mostraram que não há correlação com a identificação dos indivíduos do grupo estudado (Teste de Sperman, $p=0,344)$, assim como não há para os grupos de homens ou mulheres analisados isoladamente (Homens, $p=0,374$; Mulheres, $p=0,429$ ).

Semelhantemente aos resultados anteriores que também foram analisados pelo teste de Sperman, a identificação dos indivíduos não apresentou no grupo estudado correlação com a presença do DM $(p=0,117)$ ou HAS $(p=0,730)$, ou 
mesmo para os grupos em separado, do sexo masculino (DM, $p=0,482$; HAS, $p=0,669$ ) ou do sexo feminino (DM, $p=0,103$; HAS, $p=0,858$ ).

\subsection{DESCRIÇÃO DOS DATILOGRAMAS}

Os datilogramas dos dez dedos de cada indivíduo idoso foram foram avaliados quanto à qualidade e posterioermente classificadas para a determinação dos tipos fundamentais, conforme Vucetich (1904).

\section{A. Qualidade das impressões}

Os resultados da análise qualitativa mostraram que na comparação com 0 padrão armazenado no II/PCDF, as impressões coletadas dos idosos apresentam perda da nitidez das cristas de fricção. Quanto aos pontos característicos a avaliação qualitativa mostrou que os datilogramas dos idosos, na comparação com seus correspondentes adultos, havia o desaparecimento, surgimento e/ou alterações pontuais na conformidade de cristas, minúcias e linhas subsidiárias; a presença de linhas subsidiárias mais largas também foi observada nos datilogramas dos idosos na comparação com os adultos. Além dessas, as linhas albodactilares foram mais frequentes nas impressões dos idosos resultando na fragmentação das cristas de fricção e consequentemente a perda da nitidez da impressão como demonstrado na figura 12.
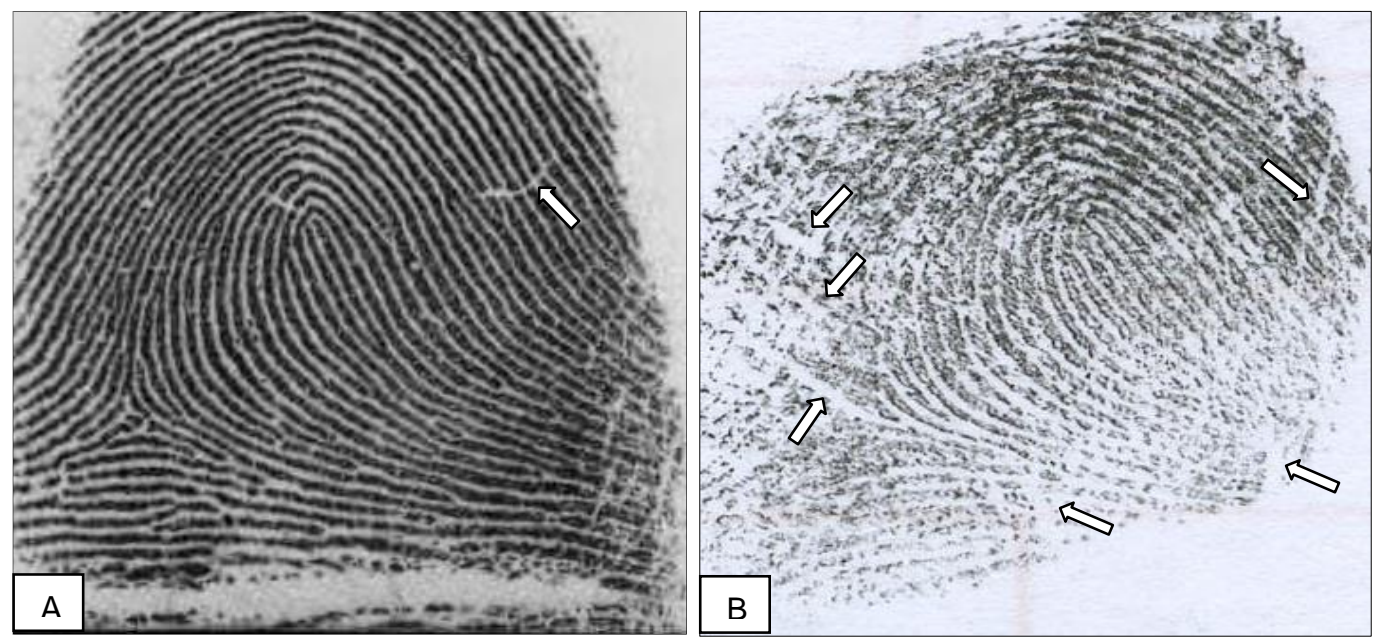

Figura 12. Fotografias dos datilogramas obtidos de um indivíduo do sexo feminino (no 20) mostrando a fase adulta (A) e idosa (B). As setas indicam as linhas albodactilares que foram mais frequentes na fase idosa dos indivíduos. 
Qualitativamente, as cristas de friç̧ão nos datilogramas obtidos na fase idosa de 31 indivíduos (15 homens e 16 mulheres) apresentaram cristas de friç̧ão com menor nitidez, na comparação com a fase adulta. Isso ocorreu pela diminuição da largura dos sulcos entre as cristas e pela deficiência dos seus contornos (Figura 13); nos demais indivíduos as cristas de fricção estavam nítidas.

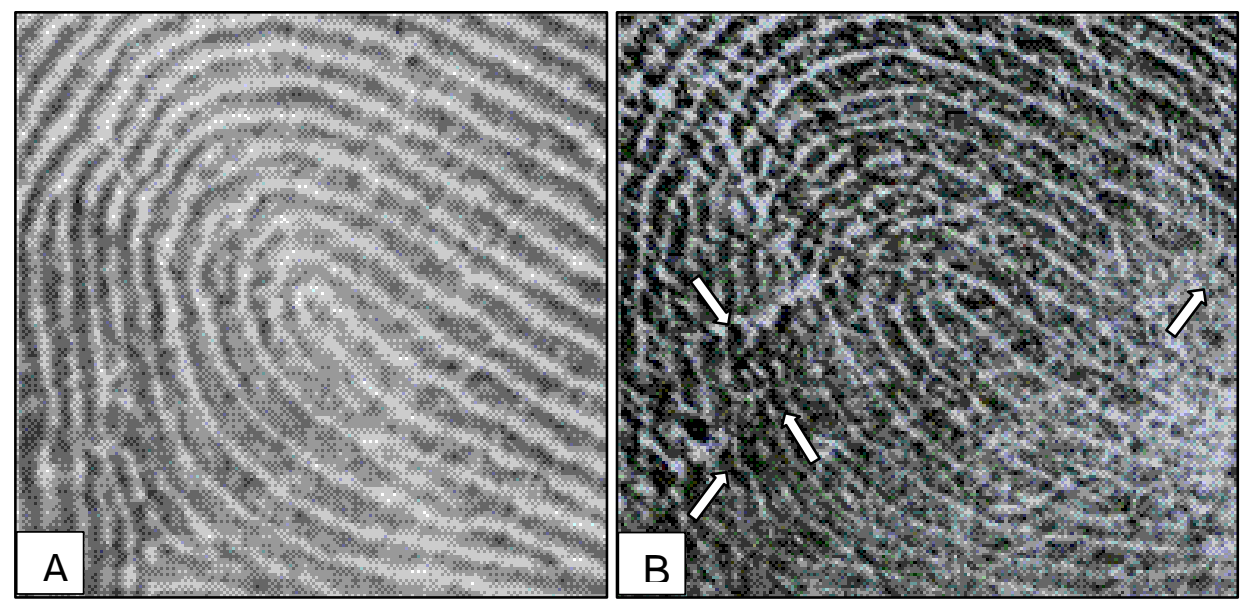

Figura 13: Fotografias dos datilogramas do dedo indicador direito de um indivíduo do sexo masculino ( $n^{\circ}$ 17) mostrando as fases, adulta (A) e idosa (B). As setas indicam áreas com redução na visibilidade das cristas, irregularidades no contorno e aproximação das linhas presentes nos datilogramas de 31 indivíduos idosos.

\section{B. Classificação dos tipos fundamentais}

Quanto aos tipos fundamentais dos dez dedos de cada indivíduo os resultados mostraram que dos 400 datilogramas classificados, foi observado $34 \%$ verticilo, $30 \%$ presilha externa, $27 \%$ presilha interna, $8 \%$ arco, $1 \%$ anomalia/cicatriz (Tabela 3).

Especificamente, no grupo masculino houve predominância dos verticilos $(44,5 \%)$, seguido da presilha externa $(27,5 \%)$, presilha interna $(23,5 \%)$ e arco $(3 \%)$, enquanto que para as mulheres foi observado maior percentual de presilha externa (33\%), presilha interna $(29,5 \%)$, verticilo $(23,5 \%)$ e arco (13,5\%). A distribuição dos tipos fundamentais para os quirodáctilos de ambas as mãos, direita e esquerda, são mostradas na tabela 3. 
Tabela 3. Distribuição dos tipos fundamentais dos datilogramas nos diferentes quirodáctilos dos indivíduos do sexo masculino e feminino.

\begin{tabular}{|c|c|c|c|c|c|c|c|c|c|c|c|c|c|c|c|c|c|c|c|c|}
\hline \multirow{3}{*}{ Tipos } & \multicolumn{10}{|c|}{$\begin{array}{c}\text { Sexo masculino } \\
\text { Dedos direito (D) e esquerdo (E) }\end{array}$} & \multicolumn{10}{|c|}{$\begin{array}{c}\text { Sexo feminino } \\
\text { Dedos direito (D) e esquerdo (E) }\end{array}$} \\
\hline & \multicolumn{2}{|c|}{ Polegar } & \multicolumn{2}{|c|}{ Indicador } & \multicolumn{2}{|c|}{ Médio } & \multicolumn{2}{|c|}{ Anelar } & \multicolumn{2}{|c|}{ Mínimo } & \multicolumn{2}{|c|}{ Polegar } & \multicolumn{2}{|c|}{ Indicador } & \multicolumn{2}{|c|}{ Médio } & \multicolumn{2}{|c|}{ Anelar } & \multicolumn{2}{|c|}{ Mínimo } \\
\hline & $D$ & $E$ & $D$ & $E$ & $D$ & $E$ & $D$ & $E$ & $D$ & $E$ & $D$ & $E$ & $D$ & $E$ & $D$ & $E$ & $D$ & $E$ & $D$ & $E$ \\
\hline Verticilo & 14 & 13 & 11 & 9 & 6 & 6 & 10 & 9 & 4 & 5 & 8 & 10 & 4 & 5 & 2 & 2 & 7 & 5 & 1 & 1 \\
\hline $\begin{array}{l}\text { Presilha } \\
\text { externa }\end{array}$ & 6 & 0 & 5 & 3 & 14 & 0 & 10 & 0 & 16 & 1 & 9 & 0 & 9 & 4 & 16 & 0 & 12 & 0 & 16 & 0 \\
\hline $\begin{array}{l}\text { Presilha } \\
\text { interna }\end{array}$ & 0 & 5 & 2 & 5 & 0 & 12 & 0 & 11 & 0 & 14 & 1 & 8 & 3 & 3 & 0 & 13 & 0 & 14 & 1 & 16 \\
\hline Arco & 0 & 1 & 2 & 1 & 0 & 2 & 0 & 0 & 0 & 0 & 2 & 2 & 4 & 7 & 2 & 5 & 1 & 1 & 2 & 1 \\
\hline Anomalias & 0 & 0 & 0 & 2 & 0 & 0 & 0 & 0 & 0 & 0 & 0 & 0 & 0 & 1 & 0 & 0 & 0 & 0 & 0 & 0 \\
\hline Amputação & 0 & 1 & 0 & 0 & 0 & 0 & 0 & 0 & 0 & 0 & 0 & 0 & 0 & 0 & 0 & 0 & 0 & 0 & 0 & 0 \\
\hline Total & 20 & 20 & 20 & 20 & 20 & 20 & 20 & 20 & 20 & 20 & 20 & 20 & 20 & 20 & 20 & 20 & 20 & 20 & 20 & 20 \\
\hline
\end{tabular}

Do total dos datilogramas, $1 \%$ nos homens e $0,5 \%$ nas mulheres (masculino/no 4 e 15; feminino/n16) eram anômalas/cicatriz, em que o desarranjo das cristas inviabilizou a classificação pelo datilograma obtido da fase idosa,; para o indivíduo do sexo masculino de no 15 o datilograma idoso refletiu a presença de cicatrizes já observadas no datilograma da fase adulta (Figura 14). 


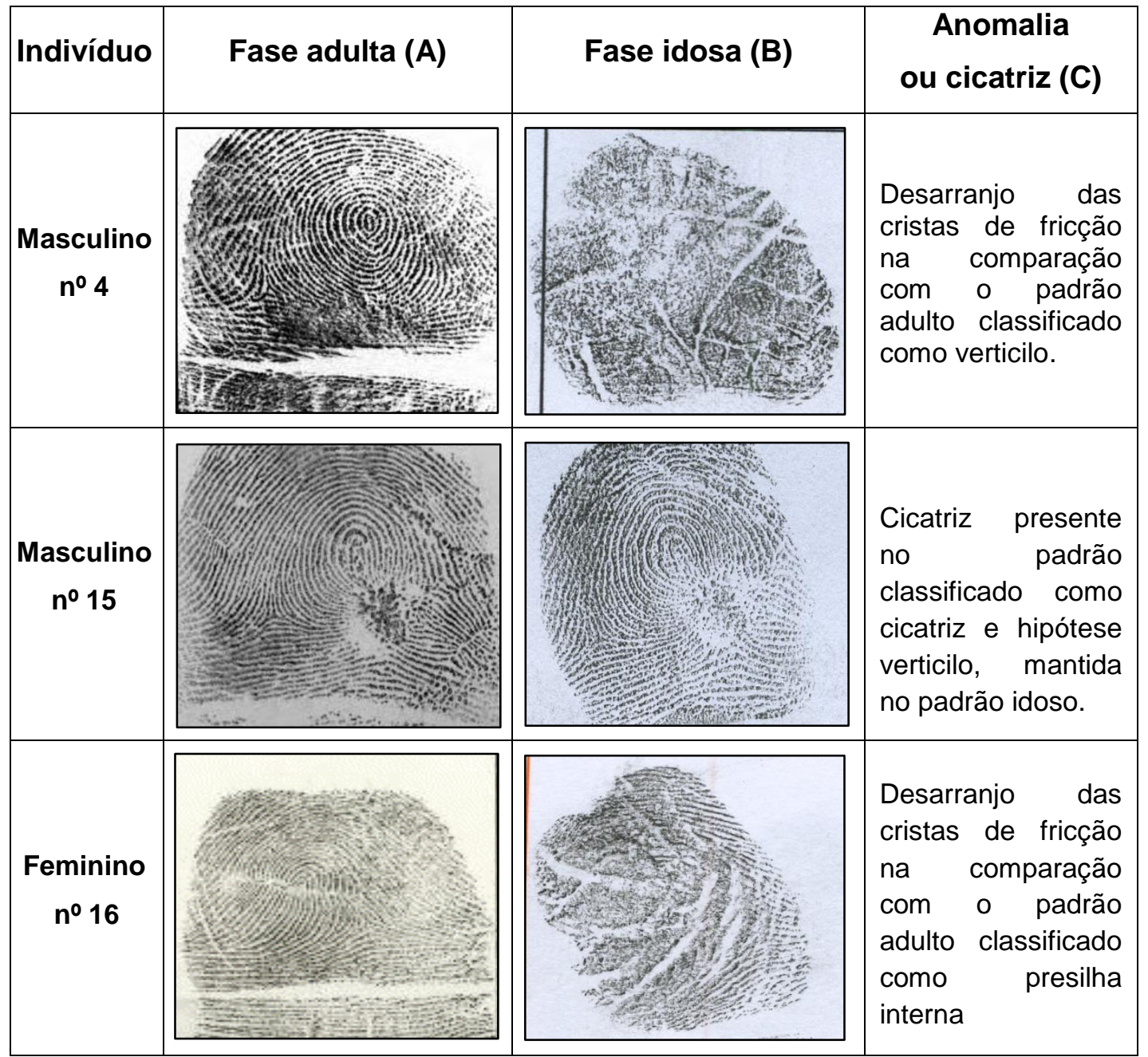

Figura 14. Fotografias dos datilogramas dos dedos indicadores esquerdo dos indivíduos dos sexos masculino ( $\mathrm{n}^{\circ} 4$ e 15) e feminino ( $\mathrm{n}-16$ ), nas fases, adulta (coluna A) e idosa (coluna B). Os padrões dos datilogramas dos idosos exibem as alterações descritas (coluna $\mathrm{C}$ ), na comparação com o seu respectivo padrão obtido na fase adulta. Nos três casos é descrita a ilegibilidade do tipo fundamental.

Além dos datilogramas anômalos (ilegíveis), a desorganização das linhas e a perda de nitidez gerou, no momento da análise, uma classificação duvidosa para 12 datilogramas, no entanto, as dúvidas foram sanadas pela consulta ao padrão adulto existente no prontuário arquivado no II/PCDF. A figura 15 ilustra a confirmação do padrão duvidoso dos indivíduos idosos a partir do padrão arquivado. 


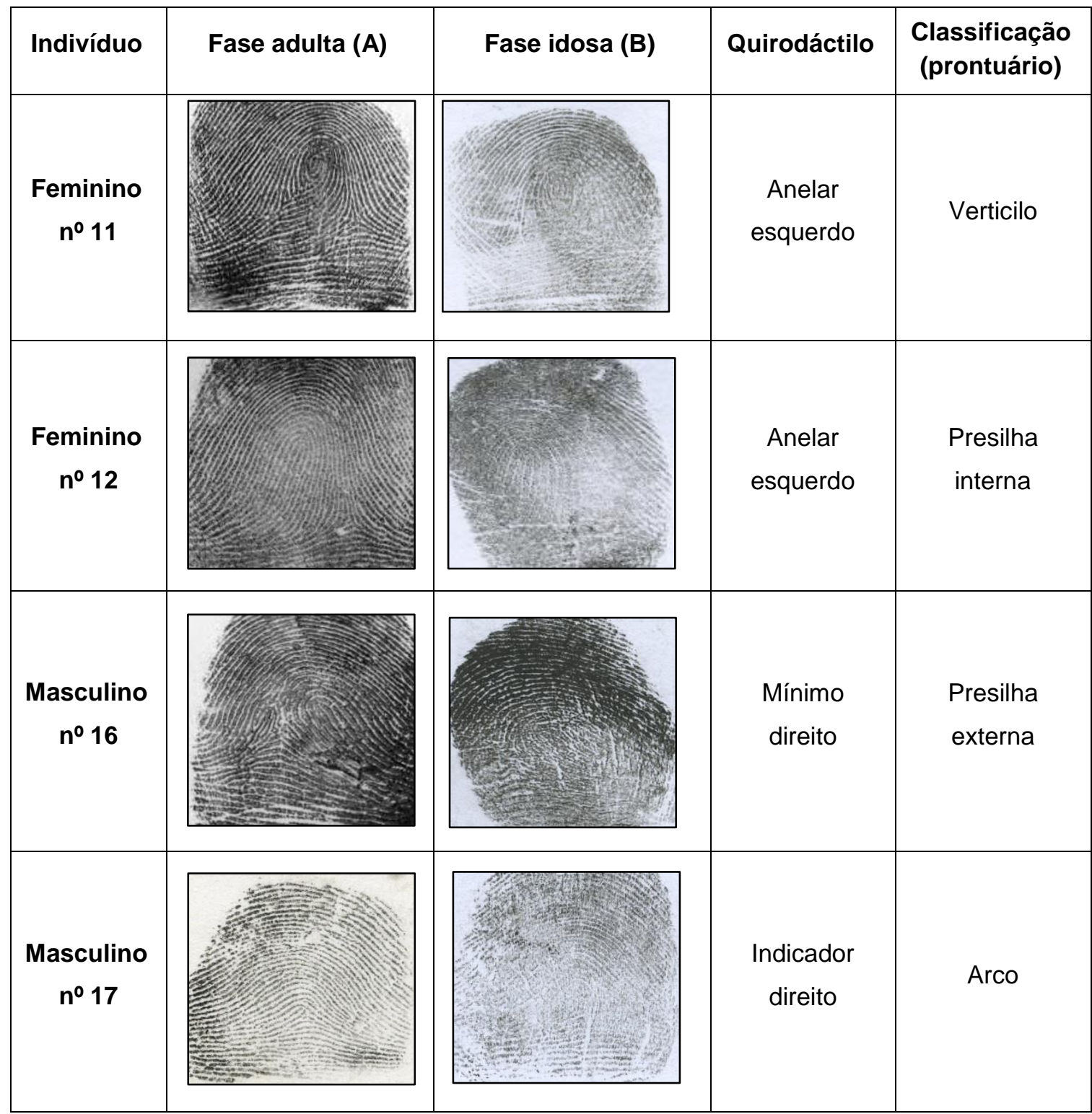

Figura 15. Datilogramas dos dedos dos indivíduos dos sexos feminino ( $n^{\circ} 11$ e 12) e masculino ( $n^{\circ} 16$ e 17), nas fases, adulta (coluna A) e idosa (coluna B). Os padrões duvidosos obtidos dos idosos foram classificados a partir do padrão arquivado, coletado quando os indivíduos eram adultos.

Considerando o cálculo da frequência, a classificação do tipo fundamental do polegar esquerdo do indivíduo do sexo masculino (no 4) não foi possível devido à amputação parcial desse quirodáctilo na altura da falange média igualmente presente no padrão arquivado da fase adulta, bem como a classificação do datilograma do indicador esquerdo deste indivíduo em idade idosa (Figura 16). 


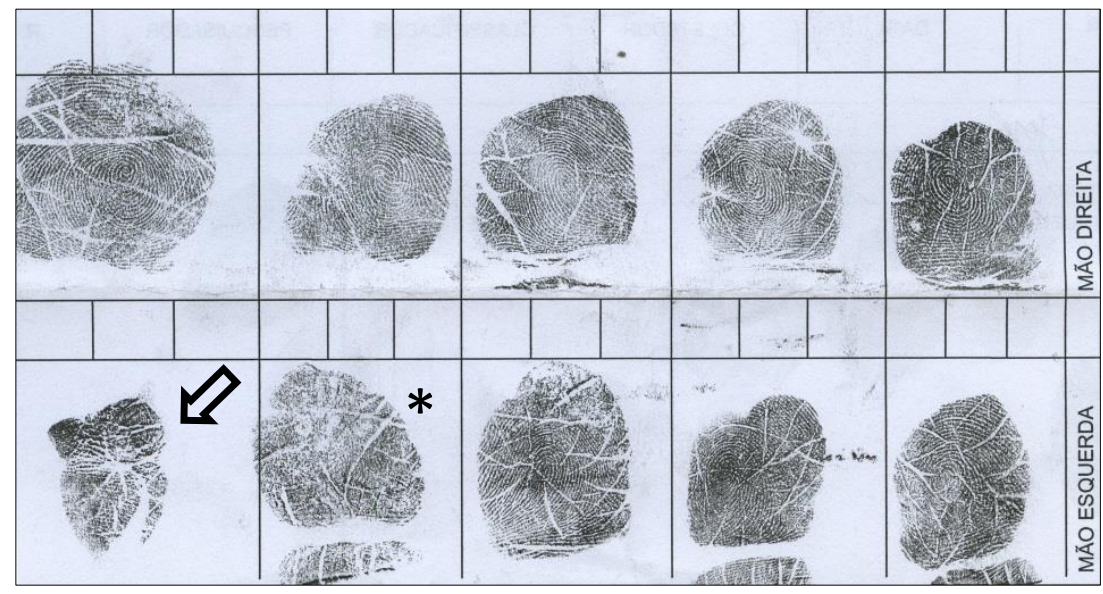

Figura 16: Fotografia da Individual datiloscópica do indivíduo do sexo masculino (no 4) exibindo amputação do $1^{\circ}$ ํㅓㅇ dedo, polegar esquerdo, (seta) e anomalia do $2^{\circ}$ dedo, indicador esquerdo, (asterisco).

\section{Perfil individual dos datilogramas quanto ao total de cristas e minúcias}

Para o estudo comparativo entre as impressões coletadas nas fases adulta $e$ idosa (estudo longitudinal) foi selecionado, nos datilogramas do dedo indicador direito de cada indivíduo, uma área de $1 \mathrm{~cm}^{2}$ para avaliar o total de cristas de fricção, de linhas subsidiárias, de minúcias e linhas albodactilares presentes nos datilogramas.

O estudo mostrou que os indivíduos de ambos os sexos apresentam grande variabilidade quanto ao número de cristas de fricção e de minúcias presentes na fase idosa, quando comparado com a fase adulta (Figura 17). 


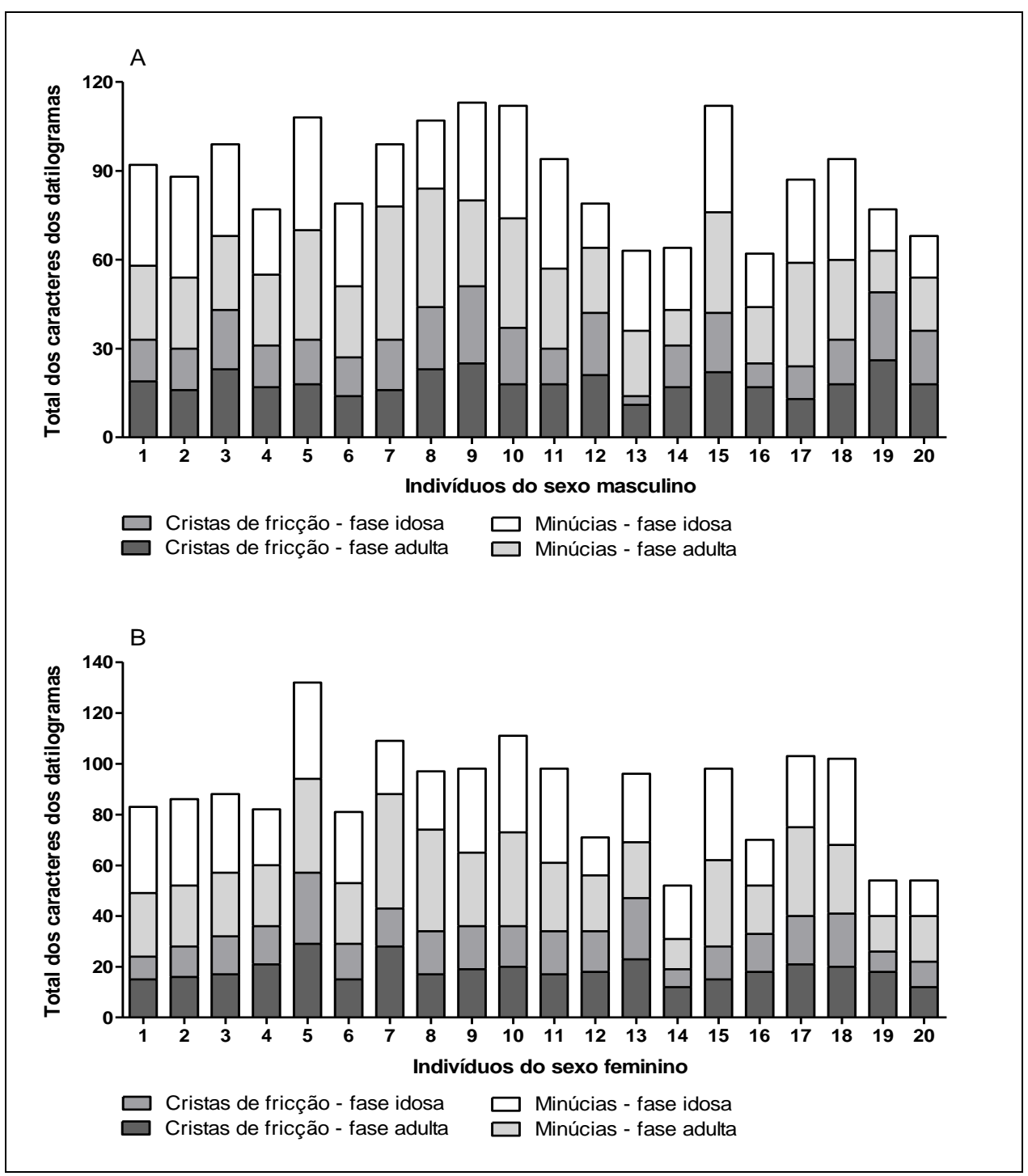

Figura 17. Perfil individual referente ao total de cristas de fricção e de minúcias presentes numa área de $1 \mathrm{~cm}^{2}$ dos quirodáctilos indicadores direito de indivíduos do sexo masculino (A) e feminino (B), nas duas fases da vida, adulta e idosa. Os resultados da análise qualitativa indicam a grande variabilidade entre os indivíduos quanto ao total das características dos quirodáctilos.

\subsection{DETERMINAÇÃO DO TOTAL DE CRISTAS DE FRICÇÃO, MINÚCIAS E LINHAS SUBSIDIÁRIAS}

Para o estudo morfométrico dos caracteres dos datilogramas foram consideradas as áreas de $1 \mathrm{~cm}^{2}$ previamente demarcadas conforme descrito anteriormente. 


\section{A. Determinação do total de cristas de fricção}

Quanto ao total de cristas de fricção para o grupo de estudo, os resultados analisados pelo teste de Wilcoxon mostraram que os datilogramas obtidos na fase idosa apresentam redução na mediana do total de cristas de fricção. Especificamente, para os homens a mediana do total de cristas reduziu de 18,0 na fase adulta para 15,0 na fase idosa $(p=0,0007)$ (Figura $18 \mathrm{~A}$ ), enquanto que para as mulheres a redução foi de 17,5 para 15,0 nas fases adulta e idosa, respectivamente $(p=0.0036)$ (Figura $18 \mathrm{~B})$.

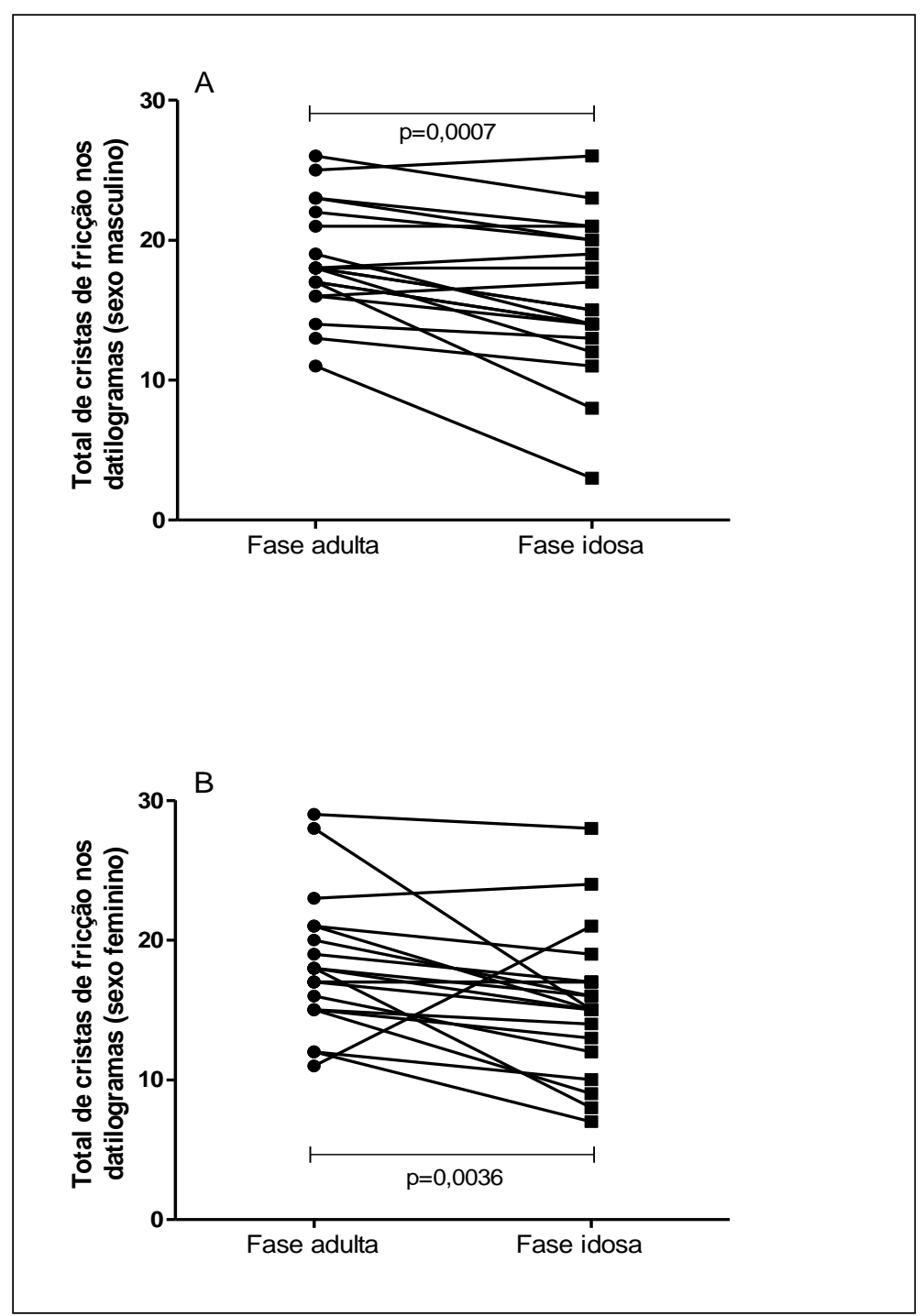

Figura 18. Total de cristas de fricção presentes nos datilogramas $\left(1 \mathrm{~cm}^{2}\right)$ obtidos dos indivíduos do sexo masculino (A) e do sexo feminino (B), nas fases adulta e idosa. Os resultados analisados pelo teste de Wilcoxon mostraram redução nas medianas do total de cristas em ambos os sexos. Estão mostrados os valores individuais. 


\section{B. Determinação do total de minúcias}

A comparação entre os padrões, adulto $x$ idoso, dos datilogramas mostrou que o interstício temporal não alterou a mediana (Adulto $=25$; Idoso $=22$ ) ou a média $\pm \mathrm{DP}$ (Adulto $=27,0 \pm 8,7$; Idoso $=27,3 \pm 8,3$ ) do total de minúcias presentes nos datilogramas para o grupo de homens (Mann-Whitney, $p>0,05$ ) ou mulheres (Teste $t$ pareado, $p>0,05$ ), respectivamente (Figura 19).

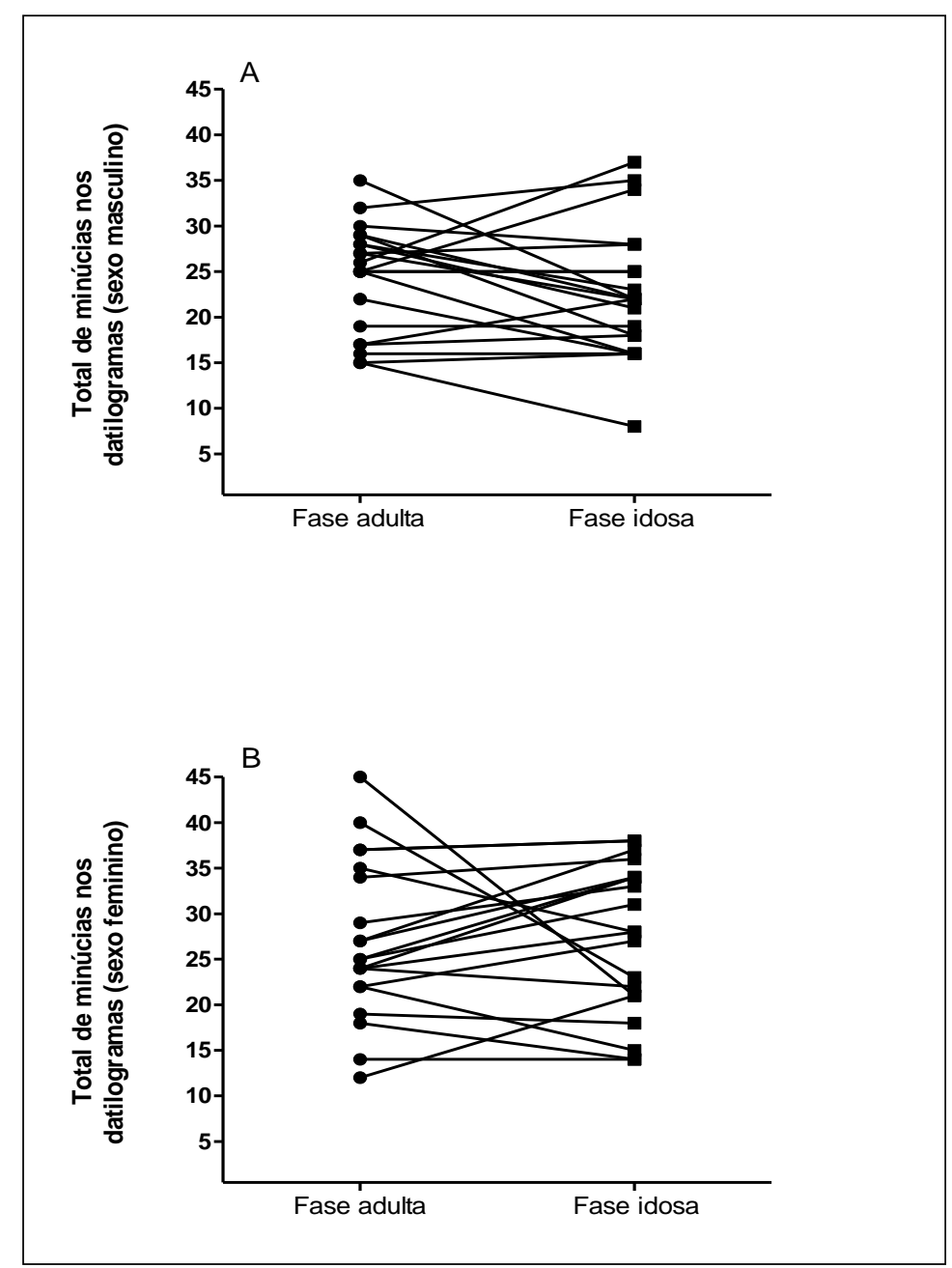

Figura 19. Total de minúcias presentes nos datilogramas $\left(1 \mathrm{~cm}^{2}\right)$ obtidos dos indivíduos do sexo masculino (A) e do sexo feminino (B), nas fases adulta e idosa. Os resultados analisados pelo teste $t$ pareado mostraram que o interstício temporal não afetou o total de minúcias nas impressões de ambas as fases e para ambos os sexos $(p>0,05)$. Estão mostrados os valores individuais. 


\section{Determinação do total de linhas subsidiárias}

Para o total de linhas subsidiárias os resultados mostraram que os datilogramas do sexo masculino não apresentaram diferenças entre as duas fases de idade (adulta $x$ idosa) $(p=0,138)$. Entretanto, para o sexo feminino a mediana do total de linhas subsidiárias na fase idosa foi menor $(0,08)$ do que o encontrado na fase adulta $(1,15)$ (Teste de Wilcoxon, $p=0,0033$ ) (Figura 20).

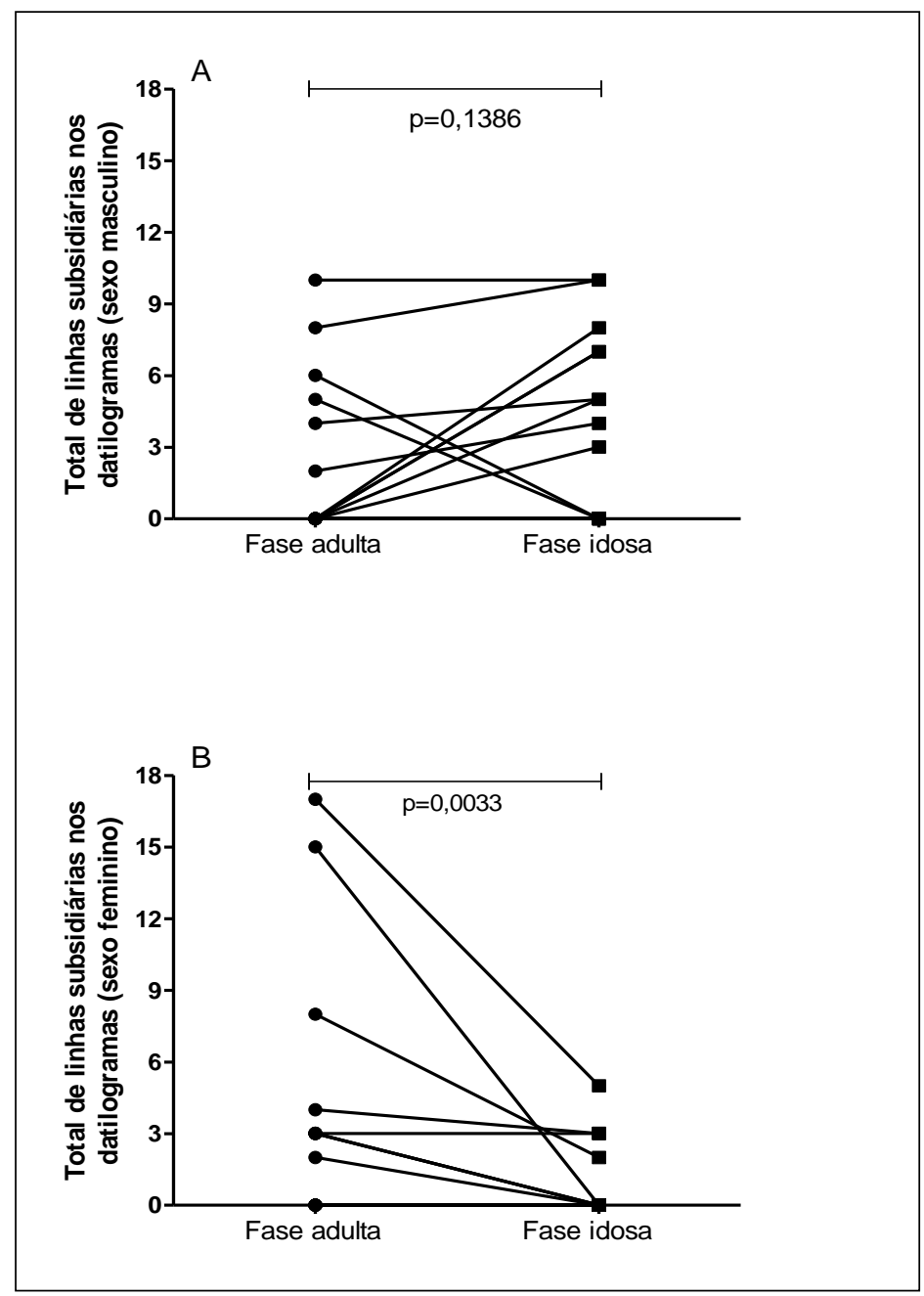

Figura 20. Total de linhas subsidiárias presentes nos datilogramas $\left(1 \mathrm{~cm}^{2}\right)$ obtidos dos indivíduos do sexo masculino (A) e do sexo feminino (B), nas fases adulta e idosa. Os resultados analisados pelo teste de Wilcoxon mostraram redução na mediana do total de linhas nos datilogramas do sexo feminino $(n=10)$, mas não para o masculino $(n=10)$. Estão mostrados os pontos individuais. 


\section{Determinação do total de linhas albodactilares}

Para o total de linhas albodactilares os resultados, analisados pelo teste de Wilcoxon, mostraram que em ambos os grupos houve aumento nas medianas nos datilogramas dos idosos na comparação com a fase adulta de 0,0 para 2,0 para os homens ( $p=0,0008)$ e de 0,5 para 3,5 para as mulheres ( $p=0,0004)$ (Figura 21).

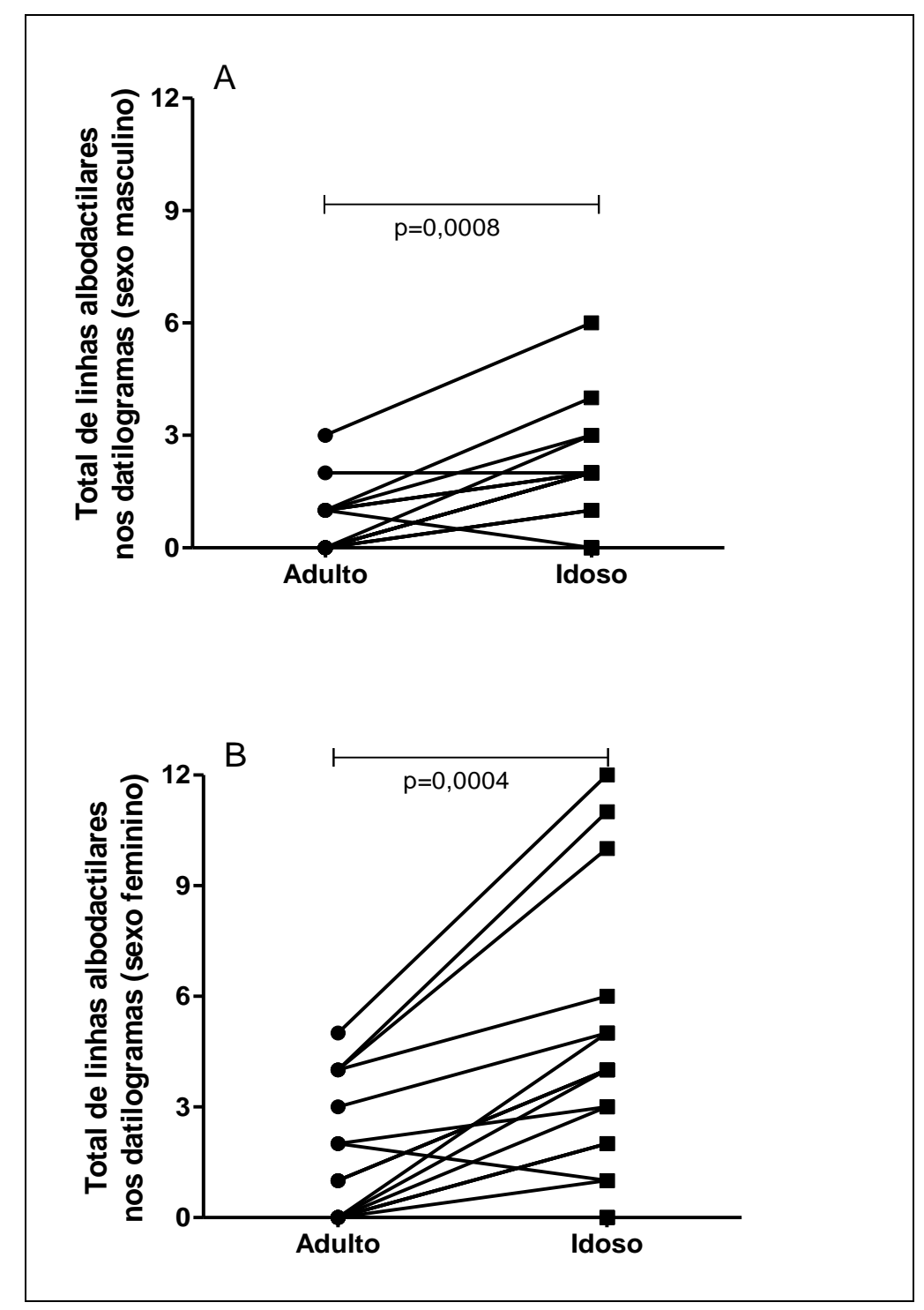

Figura 21. Total de linhas albodactilares presentes nos datilogramas $\left(1 \mathrm{~cm}^{2}\right)$ obtidos dos indivíduos do sexo masculino (A) e do sexo feminino (B), nas fases adulta e idosa. Os resultados analisados pelo teste de Wilcoxon mostraram aumento na mediana do total de linhas nos datilogramas do sexo feminino $(n=10)$ e para o masculino $(n=10)$. Estão mostrados os pontos individuais. 


\subsection{AVALIAÇÃO DOS DATILOGRAMAS EM DIFERENTES INTERSTíCIOS TEMPORAIS}

Para avaliar se o tempo transcorrido entre a coleta do datilograma da fase adulta e da fase idosa afetou as características dos datilogramas, os indivíduos de ambos os sexos foram agrupados em três classes distintas de interstício temporal de 14 a 30 anos (masculino, $n=8$; feminino, $n=7$ ), 31 a 40 anos (masculino, $n=5$; feminino, $n=6$ ) ou 41 a 50 anos (masculino, $n=6$; feminino, $n=7$ ).

\section{A. Avaliação das cristas de fricção no interstício temporal}

Os resultados obtidos para as três classes de interstício temporal mostraram que no grupo do sexo masculino o tempo transcorrido de 41 a 50 anos causou uma redução na média $\pm D P$ do total de cristas de fricção de $18,0 \pm 3,6$ na fase adulta para $16,6 \pm 5,0$ (Teste $t$ pareado, $\mathrm{p}=0,0063$ ); as demais classes de 14 a 30 (adulto = $18,0 \pm 3,6$ e idoso $=16,6 \pm 5,0$ ) ou 31 a 40 anos não alteraram o total de cristas, sendo de adulto $=19,4 \pm 2,8$ e idoso $=16,2 \pm 5,2$ (Teste $t$ pareado, $p>0,05$ ) (Figura $22 \mathrm{~A}$ ).

Para o grupo feminino os resultados mostraram que a redução no total de cristas foi observada no interstício de 14 a 30 anos, sendo de 18,6 55,6 na fase adulta para $13,9 \pm 3,8$ na fase idosa (Teste t pareado, $p=0,0171$ ), enquanto que para

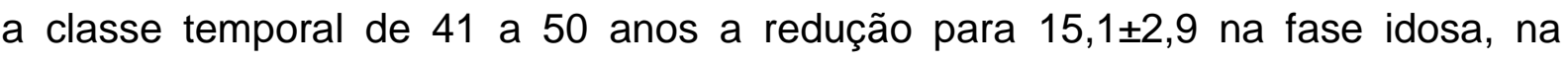
comparação com fase adulta $(17,7 \pm 1,9)$ ficou dentro do nível de significância do teste estatí́stico (Wilcoxon, $\mathrm{p}=0,0533$ ); o interstício de 31 a 40 anos não alterou o total de cristas (adulto $=17,7 \pm 1,9$; idoso $=15,1 \pm 2,9$ ) (Teste t pareado, $p>0,05$ ) (Figura $22 \mathrm{~B})$. 
Figura

22.

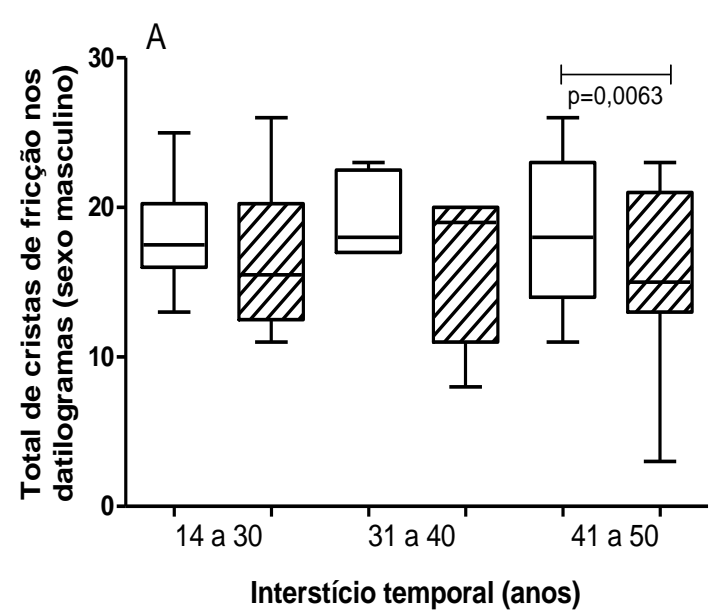

$\mathbb{Z}$ Fase adulta

Fase adulta

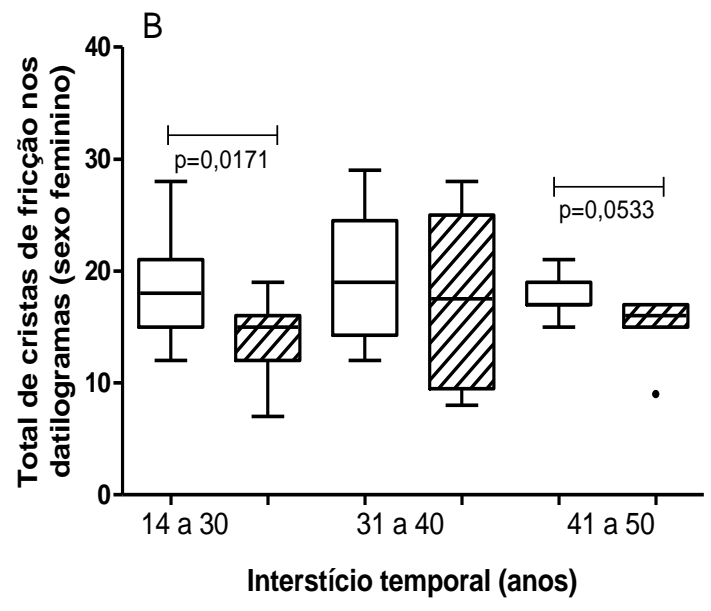

Fase idosa

Fase adulta

Total de cristas de fricção presentes nos datilogramas dos indivíduos do sexo masculino (A) ou feminino (B) agrupados em três diferentes classes de interstício temporal. Os resultados mostraram que os indivíduos com interstício temporal de 41 a 50 anos entre a fase adulta e idosa tiveram redução no total de cristas, assim como para o grupo feminino para as classes de 14 a 30 anos e para 41 a 50 anos $(p<0,05)$. Os indivíduos das demais classes não sofreram alteração no total de cristas $(p>0,05)$. Estão mostradas as medianas, quartis, valores máximos e mínimos. 


\section{B. Avaliação das minúcias no interstício temporal}

Os resultados mostraram que para o grupo masculino o interstício temporal de 14 a 30 (Adulto=24,0 $\pm 6,28 ; \quad$ Idoso $=25,6 \pm 7,4$ ) ou de 31 a 40 anos (Adulto=24,8 $\pm 5,1$; Idoso=21,8 $\pm 4,9$ ) não foi suficiente para alterar o total de minúcias (Teste t pareado, $p>0,05$ ), no entanto, para um lapso temporal de 41 a 50 anos houve redução na média $\pm \mathrm{DP}$ do total de minúcias nos datilogramas da fase adulta $(24,4 \pm 7,0)$ na comparação com a fase idosa $(17,6 \pm 4,9)$ (Teste t pareado, $p=0,005$ ) (Figura 23 A e 24).

Para o grupo do sexo feminino os resultados analisados pelo teste t pareado mostraram que em nenhuma das classes de interstício temporal os indivíduos tiveram alterações no total de minúcias nos datilogramas da fase idosa (de 14 a 30 anos $=28,0 \pm 8,1$; de 31 a 40 anos $=25,8 \pm 10,1$; de 41 a 50 anos $=27,9 \pm 7,9$ ) na comparação com a fase adulta (de 14 a 30 anos $=29,4 \pm 11,5$; de 31 a 40 anos $=23,7 \pm 7,9$; de 41 a 50 anos $=27,4 \pm 5,9$ ) (Teste t pareado, $p>0,05$ ) (Figura $23 \mathrm{~B}$ ). 

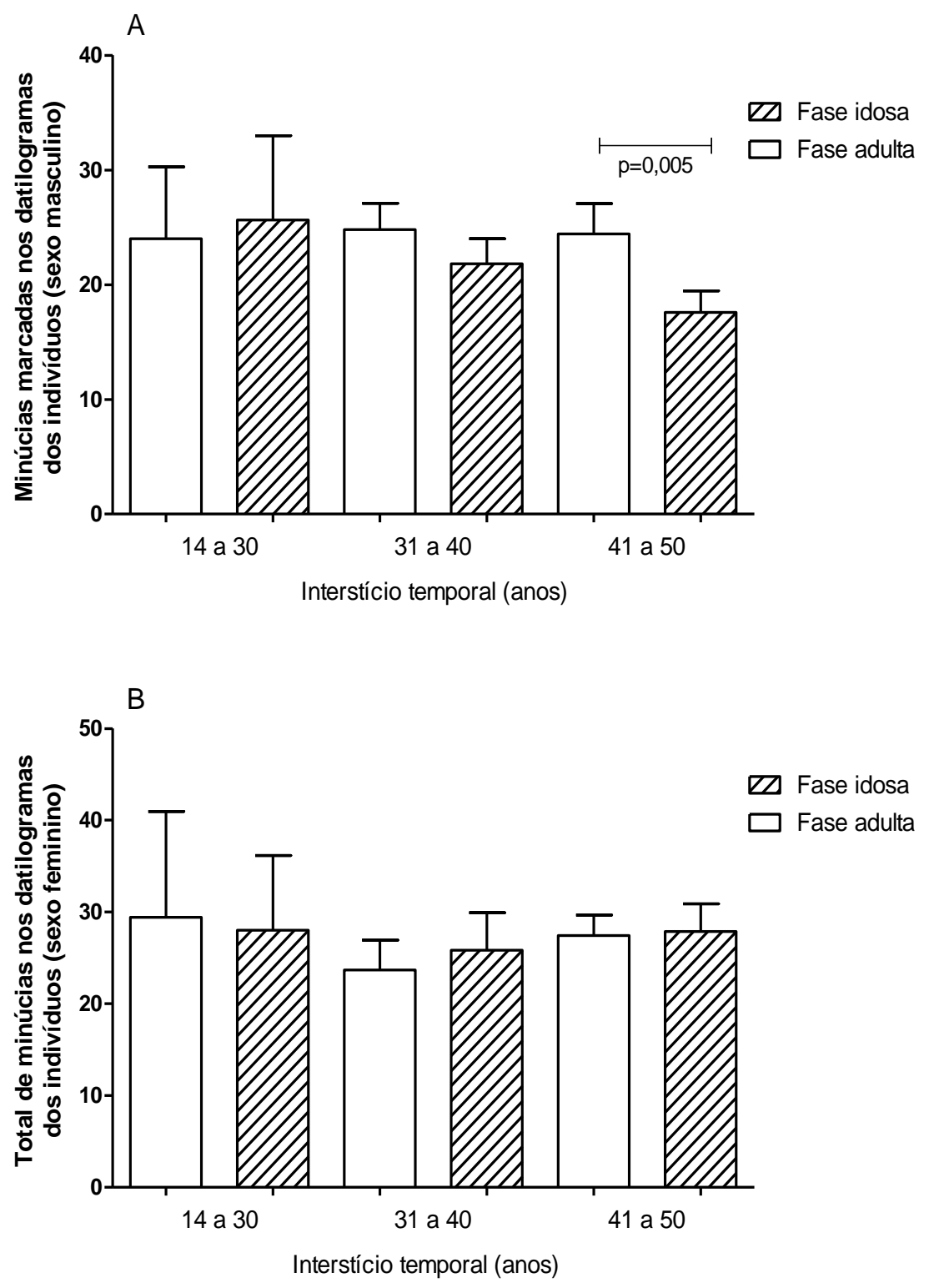

Figura 23. Total de minúcias presentes nos datilogramas dos indivíduos do sexo masculino (A) ou feminino (B) agrupados em três diferentes classes de interstício temporal. Os resultados mostraram que na fase idosa o grupo dos homens com interstício temporal de 41 a 50 anos reduziram o total de minúcias na comparação com a fase adulta (Teste t pareado, $p=0,005$ ). Os demais indivíduos/classes, masculino ou feminino não sofreram alteração no total de minúcias da fase idosa na comparação com a fase adulta (teste t pareado, $p>0,05)$. Estão mostradas as médias e os desvios padrão. 


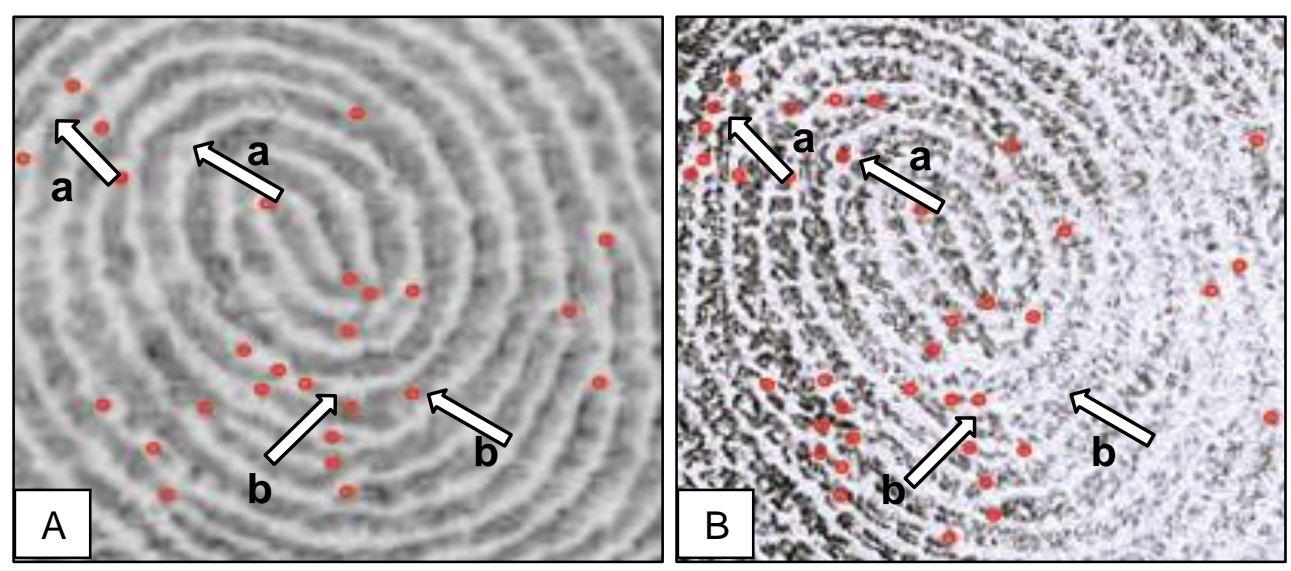

Figura 24. Fotografia dos datilogramas das fases adulta $(A)$ e idosa $(B)$ do indivíduo do sexo masculino ( $\mathrm{n}^{\circ}$ 6) ilustrando minúcias (setas), (a) ausentes no datilograma do adulto e presente no datilograma do idoso; (b) presentes no registro do adulto e não visualizada pelo examinador no datilograma do idoso.

\subsection{AVALIAÇÃO DOS PERCENTUAIS DE COINCIDÊNCIAS ENTRE OS PADRÕES DATILOSCÓPICOS}

Para determinar se o tempo transcorrido entre a coleta dos padrões datiloscópicos afetou o percentual de coincidências entre as impressões de um mesmo indivíduo, os valores obtidos de cristas de fricção, minúcias e linhas subsidiárias foram comparados em cada classe de interstício temporal. Os percentuais de cristas de fricção visíveis e os percentuais de coincidências para as minúcias e linhas subsidiárias foram calculados tomando-se como base os resultados do padrão datiloscópico obtidos na fase adulta.

\section{A. Percentual de cristas de fricção visíveis}

Para o grupo de estudo, os resultados mostraram que o percentual de cristas de fricção visíveis nos datilogramas dos indivíduos não foi afetado pelos diferentes interstícios temporais, isso foi observado para os indivíduos de ambos os sexos (ANOVA, $p>0,05$ ) (Figura 25). 


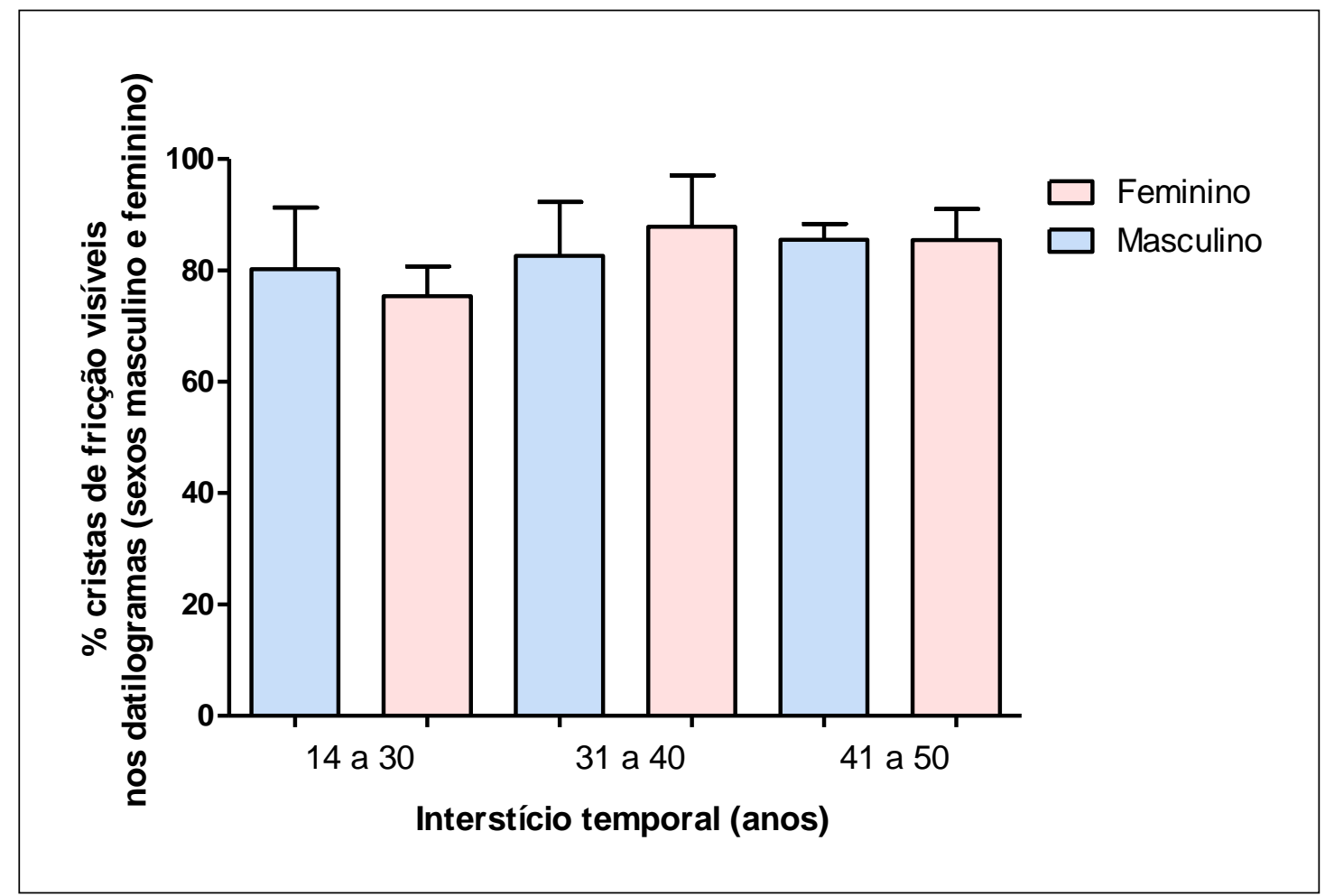

Figura 25. Percentual de cristas de fricção/datilograma dos indivíduos distribuídos em diferentes classes de interstício temporal para a obtenção do padrão datiloscópico do idoso. Os resultados, analisados pelo teste de ANOVA, mostraram que o percentual de cristas de fricção visíveis não diferiu entre as classes para ambos os grupos, masculino ou feminino ( $p>0,05)$. Estão mostradas as médias e os desvios padrão.

\section{B. Percentual de minúcias coincidentes}

Para o grupo de estudo, os resultados mostraram que as medianas dos percentuais de minúcias coincidentes não diferiram entre as classes de interstício temporal, tanto para o grupo masculino (de 14 a 30 anos=62,2; de 31 a 40 anos=69,0; de 41 a 50 anos=50,0) como para o feminino (de 14 a 30 anos=61,5; de 31 a 40 anos=57,5; de 41 a 50 anos=60,0) (Kruskal-Wallis, p>0,05) (Figura 26). 


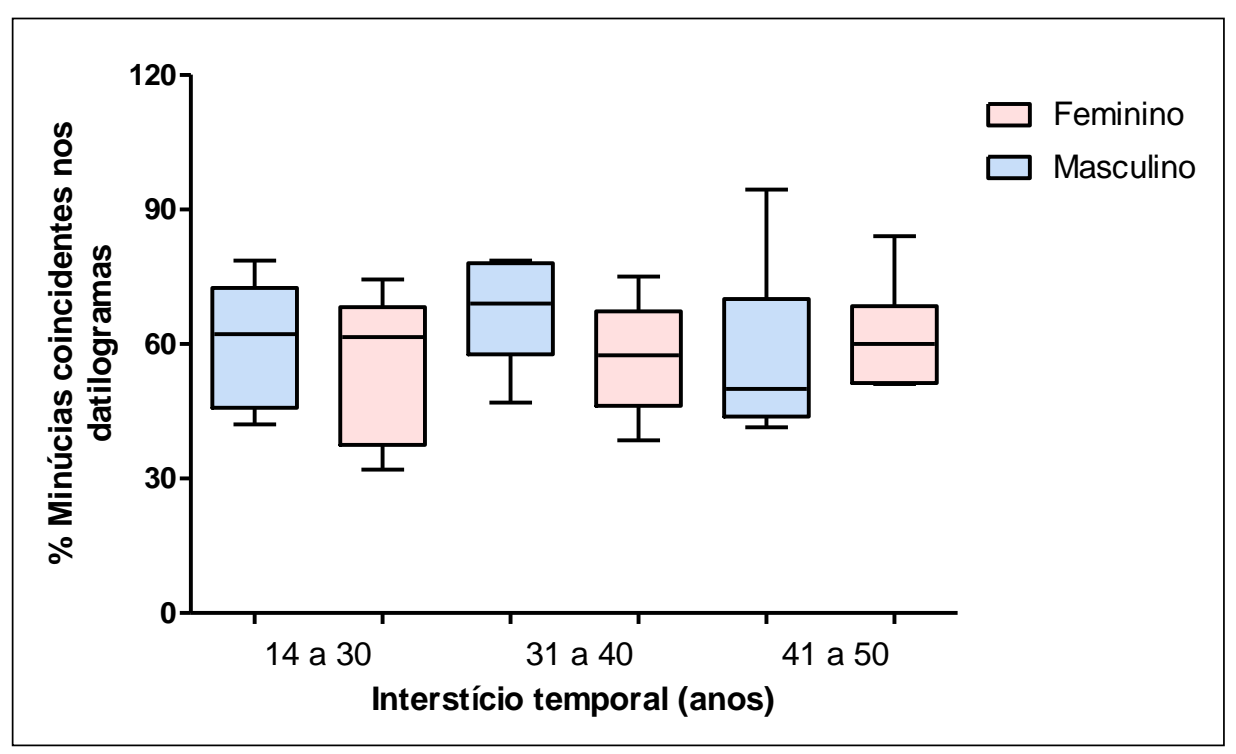

Figura 26. Percentual de minúcias coincidentes nos datilogramas dos indivíduos distribuídos em diferentes classes de interstício temporal. Os resultados, analisados pelo teste de Kruskal-Wallis, mostraram que os percentuais de minúcias coincidentes não diferiram entre as classes para ambos os grupos, masculino ou feminino $(p>0,05)$. Estão mostradas as médias e os desvios padrão.

\section{Percentual de linhas subsidiárias coincidentes}

Quanto ao percentual de linhas subsidiárias encontradas em ambos os datilogramas, da fase adulta e idosa, para as diferentes classes de interstício temporal os resultados analisados pelo teste de Kruskal-Wallis mostraram que as medianas das classes para o grupo masculino (83,3 para 14 a 30 anos; 100,0 para 31 a 40 anos; 0,0 para 41 a 50 anos) não diferiram entre si ( $p>0,05$ ); o mesmo foi observado para o grupo feminino (0,0 para 14 a 30 anos; 68,8 para 31 a 40 anos; $42,9$ para 41 a 50 anos) ( $>0,05)$ (Figura 27$)$.

Os resultados mostraram também que houve redução na mediana do percentual de linhas subsidiárias na primeira classe de interstício temporal (14 a 30 anos) para o grupo feminino, na comparação com o masculino (Wilcoxon, $p=0,0283$ ) (Figura 27). 


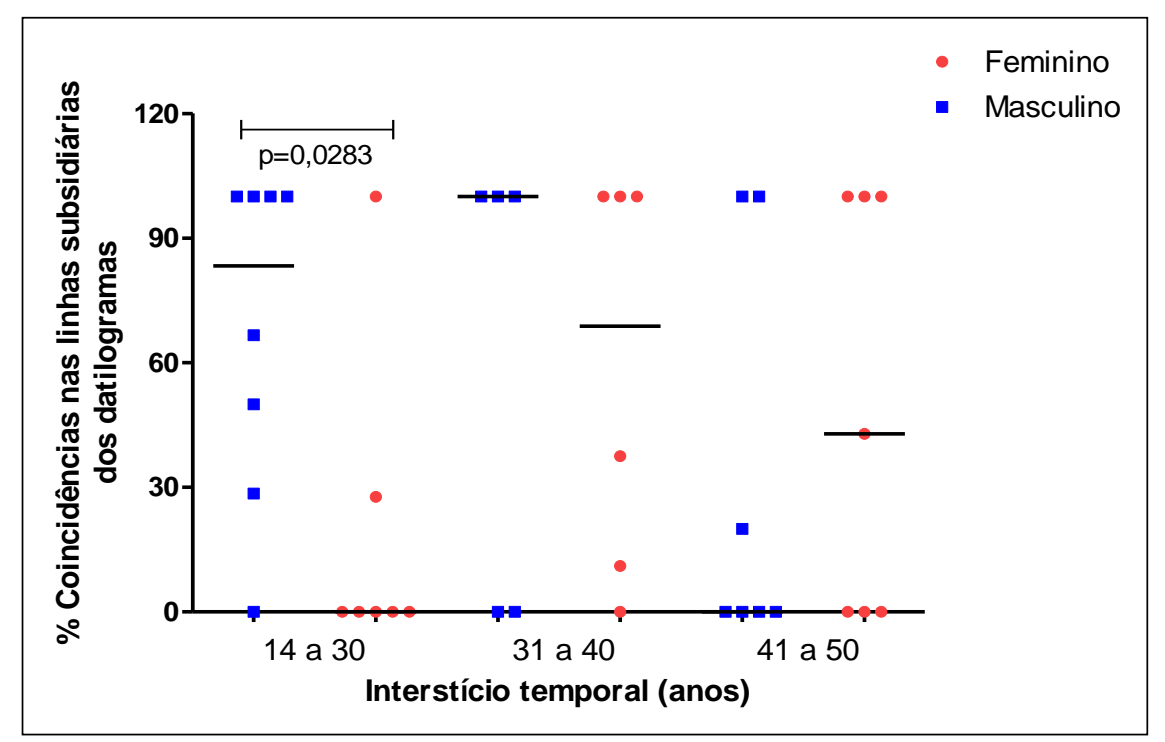

Figura 27. Percentual de linhas subsidiárias coincidentes nos datilogramas de adultos e idosos agrupados em classes de interstício temporal. Os resultados, analisados pelo teste Kruskal-Wallis mostraram que os percentuais de linhas subsidiárias não diferem entre si para ambos os grupos, masculino ou feminino ( $p>0,05)$, no entanto, houve redução na mediana desse percentual para o grupo feminino para o interstício temporal de 14 a 30 anos, na comparação com o grupo masculino. Estão representados os valores individuais.

\subsection{IDENTIFICAÇÃO DOS INDIVÍDUOS}

Para avaliar se o padrão datiloscópico dos idosos permitiria a identificação civil, todos os datilogramas foram repassados a um perito em identificação datiloscópica do II/PCDF para proceder: 1) à busca automatizada por padrões compatíveis; 2) à busca automatizada associada à análise do perito (padrão ouro); 3) ao confronto direto baseado no conhecimento/suspeita prévia da identidade do indivíduo.

Dada a busca automatizada no sistema AFIS com a ferramenta VRP, resultou na identificação de 23 indivíduos (57,5\%, sendo 13 homens e 10 mulheres), restando 17 indivíduos sem identificação por esse método (sexo masculino, no 5, 6, 7, 12, 13, 14, 17; sexo feminino, oㅡ 2, 4, 6, 7, 8, 12, 14, 16, 18, 19).

Para a busca automatizada associada à análise do perito, a identificação civil foi possível para 28 indivíduos (70,0\%, sendo 16 homens e 12 mulheres), restando 12 indivíduos sem identificação (sexo masculino, ํo 5, 12, 16, e 17; sexo feminino, oㅡ 2, 4, 8, 12, 14, 16, 18 e 19). 
Pelo confronto direto do datilograma baseado no conhecimento/suspeita prévia da identidade foi possível a identificação de 36 indivíduos (90\%, sendo 19 homens e 17 mulheres), restando não identificados 4 indivíduos (sexo masculino, no 17; sexo feminino, ํㅡㄴ 2, 12 e 16).

Pela análise dos padrões datiloscópicos das fases adulta e idosa, considerando o método da busca automatizada associada à análise do perito (padrão ouro), foi possível determinar as prováveis causas relacionadas a não identificação.

Primeiramente, a análise qualitativa mostrou que para os indivíduos do sexo masculino ( $n^{\circ} 16$ e 17) e feminino (no 12, 16 e 19) a impossibilidade de identificação se deveu à perda da nitidez das cristas de fricção conforme demonstrado na figura 28.

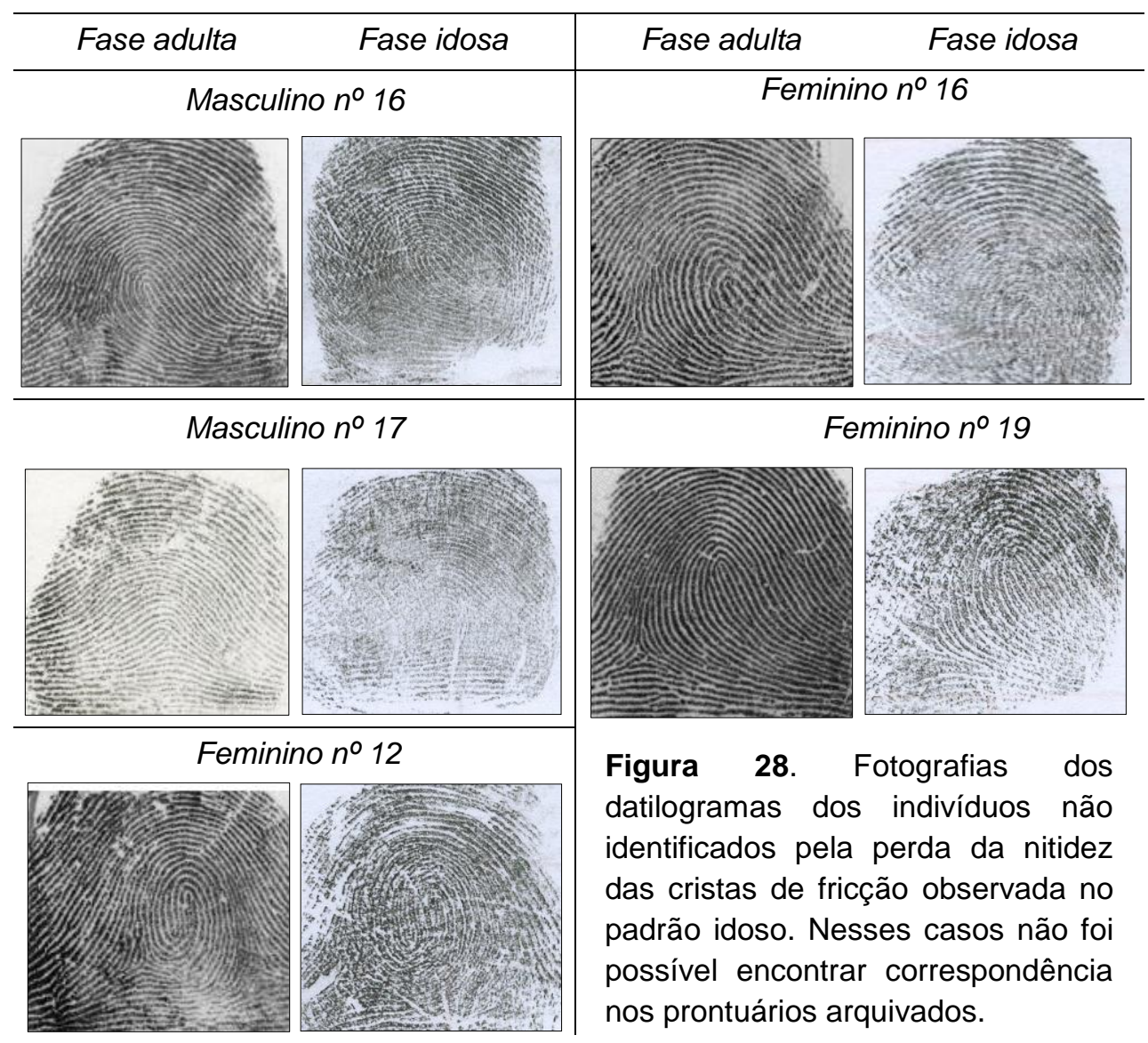

Pela perda da nitidez das cristas de fricção associada à presença maior número de linhas albodactilares a identificação não foi possível para 3 indivíduos (sexo masculino, oํ 12; sexo feminino ํo 2 e 14) (Figura 29). 


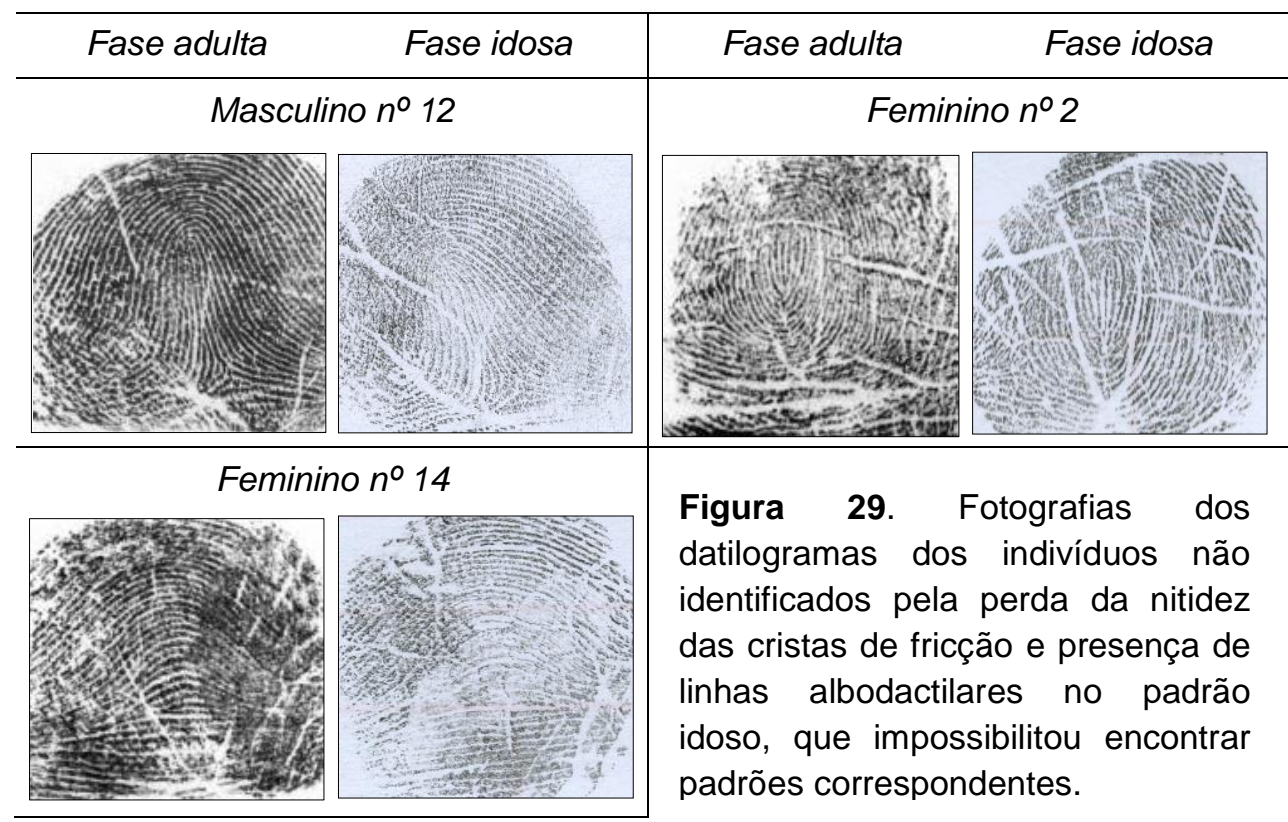

Dado a limitação por causas indeterminadas e próprias do sistema de busca automatizada que foi utilizada em dois dos métodos, a identificação foi impossibilitada para 4 indivíduos, sendo 3 do sexo feminino ( $n^{\circ} 4,8$ e 18) e 1 do sexo masculino (no 5) (Figura 30).

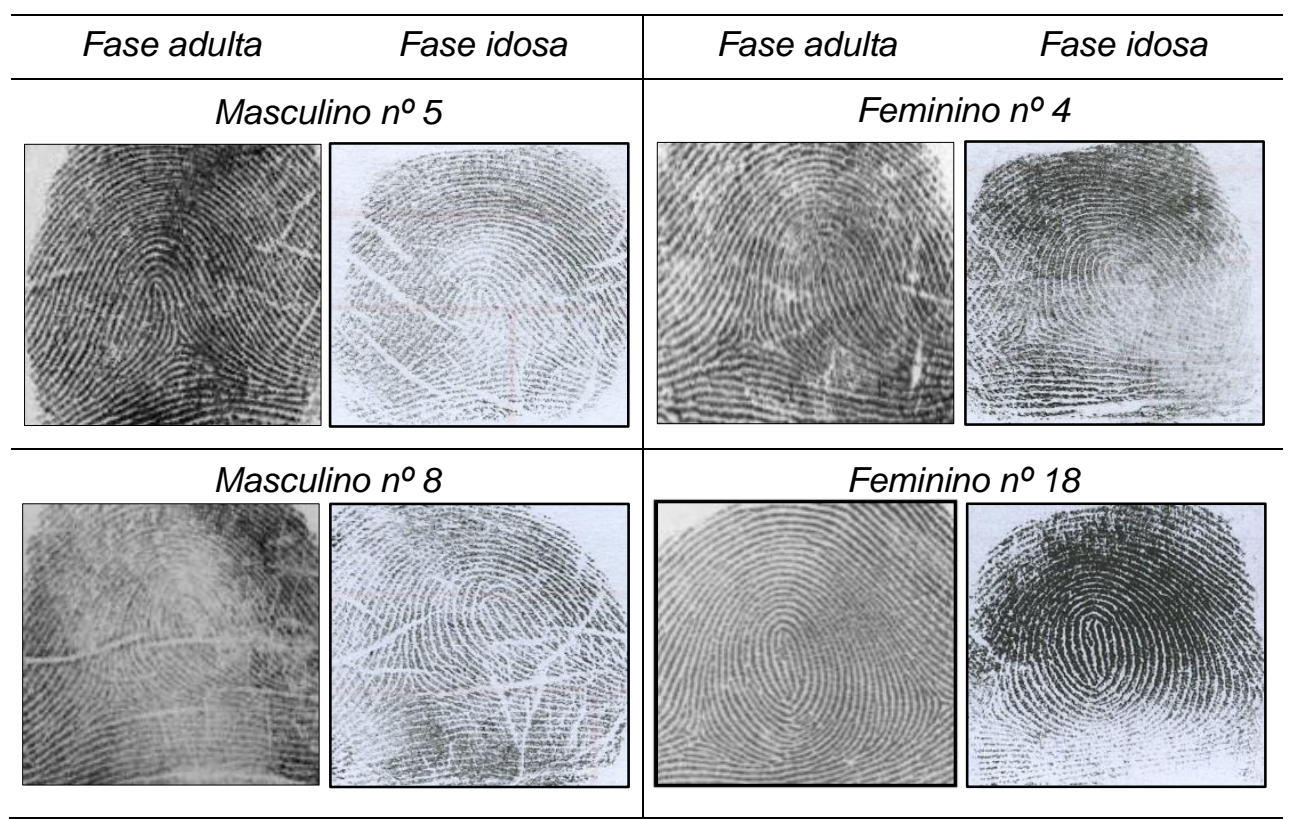

Figura 30. Fotografias dos datilogramas dos indivíduos com padrão idoso satisfatório, porém não identificados devido a limitações no sistema de busca dos padrões arquivados. 


\subsection{Considerações sobre a obtenção dos datilogramas}

O grupo de estudo, composto por critério de conveniência, teve como determinante a existência do padrão datiloscópico, de cada indivíduo idoso, registrado no banco de dados do Instituto de Identificação da PCDF para permitir a comparação qualitativa e quantitativa das impressões digitais obtidas em idade adulta e idosa do mesmo indivíduo; considerando esse confronto, o estudo buscou minimizar as variáveis relacionadas ao método de registro dos datilogramas.

Atualmente no II/PCDF o registro dos datilogramas se dá por meio de captura eletrônica das impressões digitais em equipamento de escaneamento óptico, em tempo real. No entanto, considerando que o padrão datiloscópico dos indivíduos, quando em idade adulta, foi registrado primeiramente em papel para posteriormente ser digitalizado, esse estudo reproduziu esse método para evitar as variáveis relacionadas ao método de captura do datilograma. Sendo assim, os dedos dos indivíduos idosos foram entintados e apostos em papel branco para o registro das individuais datiloscópicas por um especialista.

O método de registro, entintamento convencional ou captura eletrônica, pode influenciar na nitidez e/ou espessura das linhas/cristas. Essas alterações podem influenciar, por exemplo, na percepção de minúcias, pontas de linhas podem aparecer como bifurcações, ou ainda na própria disposição do desenho quando exercidas pressões diferentes ao realizar o registro da mesma polpa digital. Além disso, no caso de desenhos digitais pouco proeminentes, comumente observados em indivíduos em idade avançada, o método de registro pode ser determinante quanto à possibilidade ou não da identificação papiloscópica. Essas limitações indicam a possibilidade do uso de métodos alternativos de registro no caso de indivíduos idosos, em que os desenhos digitais são pouco nítidos. Métodos como a microadesão, utilizada na identificação de cadáveres, realizada com o uso de pó pericial e fita adesiva para o registro do datilograma, já demonstram resultados superiores em casos de desenhos pouco proeminentes em decorrência dos fenômenos transformativos (MIZOKAMI, 2014). Novas formas de captura que não exponham a polpa digital à pressões, como a fotografia, ainda que não resolvam a totalidade dos problemas, podem ser úteis.

A quantidade de tinta utilizada no momento do entintamento convencional e a pressão utilizada no momento do registro na individual datiloscópica ou no 
equipamento de varredura óptica são fatores relevantes na obtenção de datilogramas com qualidade técnica para análise. Essas variáveis relacionadas ao técnico especialista tendem a ser minimizadas pelo treinamento a que cada um deles se submete antes de ser designado ao serviço.

\subsection{O perfil dos indivíduos e a qualidade dos datilogramas}

O estudo avaliou os datilogramas de indivíduos idosos, homens e mulheres, com idade média de $67,4 \pm 5,6$ anos e os comparou com seus respectivos padrões coletados quando esses indivíduos eram adultos (33,9 $9 \pm 9,6$ anos). Nossos resultados mostraram que o interstício temporal de $33,5 \pm 9,4$ anos para o grupo diminuiu a qualidade dos datilogramas e impossibilitou a identificação mediante confronto pelo padrão ouro (busca automatizada associada à análise do perito) para $30 \%$ dos indivíduos. Esses resultados são corroborados pela constatação da perda da nitidez dos datilogramas observadas pelos especialistas na prática pericial (BLOMEKE, MODI e ELLIOT, 2008; BARNES, MACEO, et al., 2011), e que podem estar relacionadas a alterações morfológicas estruturais da pele decorrentes do processo normal de envelhecimento, de fatores extrínsecos (ambientais e atividades laborais) ou de patologias.

\subsubsection{A influência do envelhecimento}

Alguns estudos realizados com pele fina mostram que o envelhecimento causa diminuição das camadas do epitélio, perda de papilas dérmicas e redução da interdigitação entre as camadas dérmica e epidérmica (MAKRANTONAKI e ZOUBOULIS, 2007; WAAIJER, GUNN, et al., 2012.; FARAGE, MILLER, et al., 2013). Essas alterações reduzem a elasticidade e a sustentação dos tecidos, além do aumento da fragilidade e o surgimento de lesões e manchas, uma vez que os mecanismos de reparação do DNA nuclear e mitocondrial estão prejudicados no envelhecimento (MAKRANTONAKI e ZOUBOULIS, 2007). Também, tem sido reportado que o envelhecimento diminui a umidade e a oleosidade da pele, a vascularização, a proliferação celular e a produção da substância fundamental amorfa (glicosaminoglicanos e ácido hialurônico) (FARAGE, MILLER, et al., 2013). Os ligamentos cruzados de colágeno se estabilizam enquanto que os feixes de fibras colágenas se fragmentam e se desorganizam; a elastina apresenta maior grau 
de calcificação, com consequente degradação de fibras elásticas (MAKRANTONAKI e ZOUBOULIS, 2007; WAAIJER, GUNN, et al., 2012.; FARAGE, MILLER, et al., 2013).

Quando foram avaliados os datilogramas das mulheres observou-se uma piora na qualidade das impressões, na comparação com os dos homens (4), pois para 8 (oito) delas a identificação pelo confronto não foi possível. Esse resultado pode refletir as particularidades do envelhecimento das mulheres, sobretudo devido às alterações hormonais advindas da menopausa. É conhecido que as mulheres possuem significativamente mais receptores de estrógeno na pele do que os homens e a influência dos hormônios sexuais sobre esse órgão tem sido demonstrada (FARAGE, MILLER, et al., 2013). Considerando que, basicamente os dois tipos de pele, a fina e a espessa, apresentem composição histológica semelhante, é possível inferir que as alterações cronológicas que ocorrem na pele fina também ocorram na pele espessa. Na pele fina senil, ocorre acentuada fragmentação das fibras elásticas que permanecem frouxamente dispersas com redução do entrelaçamento com as fibras colágenas, bem como menor compactação dos feixes colágenos (ORIÁ, FERREIRA, et al., 2003). Considerando que a derme papilar é também formada por tecido conjuntivo é possível que o arranjo descrito para a pele senil reflita no aumento das linhas albodactilares que correspondem a dobras ou sulcos na pele espessa retratadas nos datilogramas.

As alterações em decorrência do envelhecimento do indivíduo são menos notadas na pele espessa do que na pele fina e, apesar da perenidade das cristas de fricção, algumas mudanças são percebidas. Para Barnes et al. (2011) as cristas de friç̧ão tendem a achatar devido à combinação da atrofia da epiderme e remodelação das papilas dérmicas. Embora a remodelação dos tecidos esteja presente ao longo da vida, ela varia de acordo com a superfície corporal. À medida que a pele envelhece e, em função do estresse, tensão, pressão ou atrito, as papilas dérmicas ramificam-se e novas papilas se formam para aumentar a adesão entre a epiderme e a derme, refletindo assim no aumento das cristas epidérmicas secundárias (MISUMI e AKIYOSHI, 1984). A interação entre os tecidos que compõem a pele, ao longo do processo de envelhecimento, pode ter reflexos nas alterações observadas nesse estudo.

Nossos resultados mostraram que as alterações mais frequentes nos datilogramas dos idosos que impossibilitaram a identificação pelo confronto foram a 
perda da nitidez e o surgimento de linhas albodactilares, o que dificultou a continuidade e visualização das cristas de fricção e das minúcias. As linhas albodactilares correspondem às áreas de depressão nos desenhos digitais, que no momento da coleta da impressão não são entintadas e assim registra-se uma impressão fragmentada. Considerando que o enrugamento/deformação da pele pode estar associado à perda dos elementos que compõem os tecidos da pele (células e matriz extracelular) (Barnes, et al. 2011), que é próprio do processo de envelhecimento, é possível que o aumento das linhas albodactilares resulte da perda da resiliência da pele, que é a propriedade de retornar à forma original após ter sido submetida a uma deformação elástica. Embora sejam perceptíveis em qualquer faixa etária, as linhas albodactilares quando numerosas podem dificultar a verificação dos tipos fundamentais e a localização de uma minúcia em relação às demais. Neste estudo verificou-se qualitativamente maior número dessas linhas nos datilogramas dos idosos, na comparação com a fase adulta, o que colaborou para a piora na qualidade das impressões. Diferentemente das cristas de fricção as linhas albodactilares não atendem ao fundamento da perenidade e por esse motivo, elas não são consideradas como características distintivas, embora possam ser utilizadas como guia no momento do cotejo papiloscópico.

\subsubsection{A influência dos fatores extrínsecos}

Sabidamente, os fatores ambientais como a temperatura e umidade do ar afetam os tecidos biológicos. Em indivíduos jovens, os processos de reparação tecidual são eficazes e tendem a contrabalancear os efeitos nocivos causados pelas variações de temperatura e umidade, uma vez que estão preservadas as células responsáveis pela manutenção da funcionalidade do epitélio e da matriz extracelular. No entanto, associado ao envelhecimento, a redução qualitativa e quantitativa da matriz extracelular causa a diminuição da água de solvatação, que comumente está adsorvida na matriz amorfa, bem como diminui a oleosidade natural da pele (BLOMEKE, MODI e ELLIOT, 2008). Em conjunto, essas alterações são refletidas na perda de qualidade da pele, inclusive as encontradas nas mãos e pés.

O uso de substâncias químicas podem afetar a pele e, consequentemente, a qualidade dos datilogramas. Nossos resultados mostraram que 9 (nove) mulheres e 3 (três) homens utilizam algum tipo de substância química que pode causar dano aos dermatóglifos, sobretudo aqueles utilizados em limpeza doméstica (sabões, 
amaciantes, solventes e etc). Considerando o maior número de mulheres não identificadas pelo confronto, na comparação com os homens, é possível que o uso de substâncias químicas danosas tenha se refletido na piora da qualidade de seus datilogramas, pelo prejuízo ao processo de reparação tecidual pela exposição prolongada ao agente lesivo.

Ainda considerando os fatores ambientais, o uso de cremes hidratantes ou cosméticos, comumente associado ao sexo feminino, pode favorecer a preservação da pele e minimizar os efeitos do envelhecimento. Embora para a papiloscopia apenas o efeito sobre a pele espessa seja relevante, é possível que a utilização contínua ou rotineira dessas substâncias influencie na preservação de desenhos digitais com linhas íntegras e com contornos nítidos. Nesse contexto, especula-se que os datilogramas das mulheres tenham menor qualidade originalmente, independente da idade, com relevo das cristas menos proeminentes e assim permanecem ao longo da vida, uma vez que, sabidamente, elas fazem mais uso da cosmetologia do que os homens. No entanto, contrariamente à maior utilização da cosmetologia, as mulheres utilizam-se mais de substâncias químicas lesivas à pele do que os homens, conforme demonstrado.

Dentre os indivíduos estudados, nossos resultados mostraram que 9 (nove) mulheres e 5 (cinco) homens exercem algum tipo de atividade laboral que se utiliza de ferramentas ou métodos danosos, com reflexos, sobretudo, na pele das mãos. Considerando a perda qualitativa nos datilogramas dos idosos é possível que o exercício dessas atividades cause lesões teciduais repetitivas, que quando em jovens são reparadas, uma vez que os processos reparadores são funcionais, mas que quando no envelhecimento, leve ao surgimento de cicatrizes ou falhas nos datilogramas.

Apesar da constatação de que atividades manuais afetam a qualidade das impressões (BADAWI, MAHFOUZ, et al., 2006), nosso estudo não demonstrou correlação entre atividades laborais danosas e ausência de identificação, possivelmente pela limitação amostral. Apesar disso, verificou-se qualitativamente que as impressões de alguns indivíduos que exerciam a atividade danosa apresentavam perda da nitidez. Somado à atividade danosa especialmente relatada no grupo das mulheres, o uso de cosméticos para pele pode ter agido de forma a preservar as estruturas da pele. 


\subsubsection{A influência das patologias}

As principais patologias crônicas sistêmicas relatadas nesse estudo foram a hipertensão arterial e diabetes mellitus, doenças comumente verificadas na faixa etária estudada. Com o fim de buscar alguma correlação entre a perda da qualidade dos datilogramas com patologias comuns na idade senil, considerou-se hipoteticamente a influência da hipertensão arterial e a diabetes mellitus sobre as estruturas da pele e reflexos sobre os dermatóglifos, uma vez que em ambas as afecções existem um comprometimento vascular que afeta a homeostasia tecidual $\mathrm{e}$ foram as mais frequentes no grupo de homens (50\%) e mulheres (75\%).

De acordo com o Ministério da Saúde, estima-se que na população brasileira com idade acima de 65 anos a prevalência da hipertensão em 59,2\% e do diabetes em 22,9\% (MINISTÉRIO DA SAÚDE, 2012). Considerando que a hipertensão arterial causa $O$ enrijecimento das paredes vasculares e degeneração da microvasculatura e que, no diabetes é comum a destruição tecidual em função de aumento nos níveis séricos de glicose (DANIEL, RETO e FRED, 2002), esperava-se identificar uma correlação positiva entre essas patologias e os achados de perda de qualidade dos datilogramas. No entanto, nossos resultados não confirmaram essa correlação para o grupo, ou mesmo para homens ou mulheres.

Embora nenhum indivíduo tenha relatado patologias propriamente dermatológicas que pudessem afetar diretamente os dermatóglifos como a psoríase e a dermatite atópica (DRAHANSKY, DOLEZEL, et al., 2012), é possível que alterações decorrentes da hipertensão e da diabetes mellitus possam indiretamente afetar as características da pele espessa. Logo, sugere-se que o aumento amostral e comparação a um grupo controle em estudos posteriores possa demonstrar a influência dessas patologias na pele das polpas digitais e estabelecer elementos preditivos de alterações datiloscópicas, a verificação de uso de medicamentos controladores dos distúrbios e, para certificação dos dados, sugere-se a necessidade de exames de diagnóstico das patologias em complemento à informação relatada pelos indivíduos.

\subsection{Considerações sobre a frequência dos tipos fundamentais}

$\mathrm{Na}$ análise dos tipos fundamentais foi observada a prevalência de verticilos e presilhas. Os resultados obtidos no presente estudo foram semelhantes aos registros criminais brasileiros (ARAÚJO, BOSSOIS e SANTANA, 2003), no qual a 
incidência de verticilo foi $31,16 \%$, presilha interna $(30,84 \%)$, presilha externa $(29,21 \%)$, arco $(7,50 \%)$ e anomalias somadas às amputações e cicatrizes $(1,5 \%)$. Entretanto, o resultado divergiu de estudos da população indiana (AMINI, 2009; MODI e PRAJAPATI, 2013; MEHTA e MEHTA, 2015) e espanhola (GUTIERREZREDOMERO, E., et al., 2011), nas quais predominam as presilhas, seguidas dos verticilos. Esses achados corroboram a influência dos fatores genéticos na formação das impressões digitais. Considerando que o desenvolvimento das polpas digitais reflete a interação de enorme variação genética, diversos estudos têm sido desenvolvidos com intuito de verificar a caracterização e predominância dos dermatóglifos em relação às variedades étnicas populacionais (GUTIÉRREZ, GALERA, et al., 2007; FOURNIER, 2013; GUTIÉRREZ-REDOMERO, SÁNCHEZANDRÉS, et al., 2013; MEHTA e MEHTA, 2015). No tocante à população brasileira, a miscigenação é historicamente um fator relevante que pode dificultar a caracterização de um padrão dermatoglífico (FREITAS, 2008).

Os tipos fundamentais encontrados mostraram diferença de frequência quanto ao gênero, sendo que para os homens há o predomínio dos verticilos $(44,5 \%)$ e para as mulheres as presilhas externas $(33,0 \%)$. Os resultados do grupo estudado são corroborados pelos achados de Araújo et al. (2003) para brasileiros. Sugere-se que estudos de prevalência dos tipos fundamentais e seus subtipos sejam importantes para determinar o perfil datiloscópico dos indivíduos nas diferentes regiões brasileiras e, quem sabe, fornecer os subsídios para acelerar o processo de identificação. Por esse mesmo motivo, é importante a realização de estudos adicionais.

\subsection{Considerações acerca dos parâmetros qualitativos no confronto}

Os dermatóglifos permitem a identificação humana devido à unicidade dos seus arranjos que compõem os tipos fundamentais, e da presença e disposição das minúcias (YAGER e AMIN, 2004). Em concordância com outros achados, nos datilogramas dos indivíduos idosos foi observada perda da nitidez das cristas de fricção, menor definição dos contornos das linhas/cristas e redução dos espaços correspondentes aos sulcos (BLOMEKE, MODI e ELLIOT, 2008; XIE, YANG, et al., 2012). 
No processo de identificação, a determinação do tipo fundamental de cada datilograma, sempre que possível, normalmente é o primeiro passo na comparação de dois datilogramas. De fato, em muitos casos de fragmentos de impressões a classificação fundamental é prejudicada, porém não impede completamente a realização da pesquisa no banco de dados por meio dos sistemas automatizados. Embora a indeterminação do tipo fundamental não seja causa impeditiva da pesquisa automatizada, a visualização do tipo fundamental é um facilitador e auxilia a análise do especialista na busca de coincidências no momento da comparação e estabelecimento de sua decisão quanto à identificação (FOURNIER, 2013; LIU, CHAMPOD, et al., 2015).

No estudo, foi observado que a maioria dos indivíduos idosos apresentou manutenção de sua classificação primária, ainda que o desenho apresentasse menor qualidade. Entretanto, conforme ilustrado nos resultados, 2 indivíduos (Fig. 14) sofreram alterações nos seus datilogramas ao longo do tempo, de tal forma que a determinação do tipo fundamental ficou prejudicada; nesses casos houve o exercício de atividades laborais danosas que possivelmente favoreceram o desarranjo das cristas de fricção a ponto de impedir sua classificação. Para fins de classificação estes dois datilogramas ("transformados" no interstício temporal) foram incluídos no rol dos anômalos, mesmo que o padrão adulto não tenha apresentado a anomalia. No indivíduo de no 15 (Fig. 14) constatou-se a presença de uma cicatriz em ambos os padrões (adulto e idoso), nesse caso, pela sua dimensão e profundidade a cicatriz provocou uma remodelação tecidual irreversível que permaneceu até a idade idosa do indivíduo.

Seguindo esse processo transformativo, outros 12 datilogramas apresentaram alterações em seus caracteres, em menor grau, o que tornou a classificação duvidosa, mas com possibilidade de dedução ou estabelecimento de hipóteses dos tipos fundamentais pelo arranjo e disposição das cristas. As alterações exibidas possivelmente acarretariam em falhas para o processo de identificação, ocasionando um possível falso negativo na busca do banco de dados. Dentre esses, seis indivíduos (no , 17, 19 do sexo masculino; e oำ11, 12, 14, 20 feminino) relataram o exercício de hábitos laborais danosos à pele, o que sugere que, ainda que não atuem de forma direta e determinante, essas atividades podem influenciar a baixa qualidade dos datilogramas. 
Observa-se na prática pericial datilogramas de indivíduos de diversas idades, de ambos os gêneros, em que a classificação dos tipos fundamentais é dificultada. Dado a presença de anomalias ou transformações de outra natureza, é possível perceber que a baixa qualidade das impressões digitais é multifatorial e atinge todas as faixas etárias, em sendo assim, impressões digitais com qualidade muito baixa podem manifestar uma característica individual e não ter, necessariamente, relação com o envelhecimento ou outras alterações ocorridas ao longo da vida.

\subsection{Considerações sobre os parâmetros quantitativos dos dermatóglifos no interstício temporal}

A determinação das variações nos dermatoglifos durante 0 interstício temporal de 33,5 $\pm 9,4$ anos, bem como a distribuição dos indivíduos em classes de interstício temporal ( 14 a 30,31 a 40 ou 41 a 50 anos), considerou o total de cristas de fricção, de minúcias e de linhas subsidiárias em uma área de $1 \mathrm{~cm}^{2}$ da impressão digital do dedo indicador direito obtida de cada indivíduo (fase adulta ou idosa). Nossos resultados mostraram que o interstício temporal afetou o número de cristas de fricção, de minúcias e de linhas subsidiárias presentes na fase idosa, quando comparado com a fase adulta.

\subsubsection{Total de cristas de fricção}

Quanto ao número de cristas nossos resultados mostraram que houve redução no total de linhas/cristas visíveis para os dermatóglifos de idosos (40 indivíduos), sendo o mesmo verificado para os homens (20 indivíduos) e para as mulheres (20 indivíduos), na comparação com o padrão adulto. Especificamente, para o grupo de homens a redução do total de cristas de friç̧ão ocorreu nos indivíduos cujo tempo transcorrido entre a obtenção dos dois padrões datiloscópicos foi de 41 a 50 anos, já para as mulheres a redução se deu para os indivíduos das classes de 14 a 30 e de 41 a 50 anos. Esse resultado corrobora a análise qualitativa na prática pericial, quanto à perda de nitidez dos datilogramas, e sugere que essas alterações ocorrem devido ao envelhecimento dos indivíduos.

A quantificação dos caracteres dos dermatóglifos é objeto de estudo em várias pesquisas com fins de delinear os perfis populacionais e para fornecer os 
subsídios para inferir etnia, gênero, lateralidade das mãos, posição dos dedos relativos à autoria de determinada impressão digital (GUTIERREZ-REDOMERO, E., et al., 2011; NITHIN, MANJUNATHA, et al., 2011; FOURNIER, 2013). Tocante a isso, os estudos realizados com indivíduos da Espanha e Argentina (GUTIÉRREZREDOMERO, ALONSO, et al., 2008), (GUTIÉRREZ-REDOMERO, SÁNCHEZANDRÉS, et al., 2013) mostraram que as cristas de fricção, avaliadas nos dez dedos, são mais numerosas e delgadas em mulheres do que em homens. Contrariamente a isso, nossos resultados mostraram que o total de cristas de fricção não difere entre homens e mulheres quando avaliadas apenas no dedo indicador direito. É possível que o total de cristas varie entre os dedos de um mesmo indivíduo ou que os resultados obtidos nesse estudo sejam replicados para os demais dedos, confirmando a diferença entre esse estudo e os de Gutierrez-Redomero (2011 e 2013). De qualquer forma é importante que novos estudos esclareçam as características específicas da população brasileira.

\subsubsection{Total de minúcias}

Nossos resultados mostraram que o número total de minucias visualizadas nos dermatóglifos dos idosos não diferiu dos seus respectivos padrões correspondentes da fase adulta. No entanto, quando avaliamos os indivíduos agrupados em classes de interstício temporal nossos resultados mostraram que os indivíduos do sexo masculino, cujo tempo transcorrido entre a obtenção dos dois padrões datiloscópicos foi de 41 a 50 anos, diminuíram o total de minúcias no padrão idoso.

Os achados de Stücker et al. (2001) mostraram que as minúcias presentes nos desenhos digitais não se alteram ao longo da vida, mas considerando que o processo de envelhecimento afeta os tecidos da pele é possível que haja o desaparecimento e o surgimento de novas minúcias. Além do envelhecimento, outros fatores podem ter contribuído para essa diferença, por exemplo, danos à superfície da pele e a subjetividade da marcação das minúcias. Embora não tenha sido possível determinar o papel das minúcias na identificação pelo confronto, baseado em algoritmos que consideram as linhas e as minúcias, a ausência da identificação de 12 indivíduos pode indicar que o conjunto de alterações qualitativas e quantitativas contribuiu para isso. Nosso resultado também reforça a tese de que, apesar da existência de discrepâncias entre os padrões datiloscópicos de idosos e 
adultos, a presença de coincidências favorece a determinação de identidade pelo confronto, como verificado para 28 indivíduos.

\subsubsection{Total de linhas subsidiárias}

$\mathrm{Na}$ análise do total de linhas subsidiárias, o grupo masculino estudado não apresentou diferença significativa entre as medianas, já no grupo feminino os datilogramas da fase adulta apresentaram maior mediana total de linhas quando comparadas aos seus correspondentes idosos. A baixa qualidade e insuficiente nitidez das cristas podem ter influenciado na redução do apontamento dessas estruturas. Em estudo não pareado sobre a caracterização de linhas subsidiárias, Stücker et al. (2001) observaram aumento da frequência de linhas subsidiárias em adultos na comparação com jovens, isso foi observado tanto para homens como para as mulheres, sendo que especificamente para as mulheres houve redução no total de linhas subsidiárias após 60 anos, possivelmente pela redução da visibilidade. Considerando que o nosso estudo comparou datilogramas de um mesmo indivíduo (estudo pareado) a redução da mediana do total de linhas subsidiárias, observado para o grupo feminino, reflete a influência do tempo/envelhecimento nos datilogramas, assim como foi observado nos estudos não pareados de Stücker et al. (2001). É possível que a perda da nitidez das cristas de friç̧ão observada no envelhecimento prejudique a identificação das linhas subsidiárias. Apesar de apresentar maior perenidade nos datilogramas, não há consenso quanto à sua utilização das linhas subsidiárias como caractere distintivo; alguns especialistas as utilizam para estabelecer coincidências, mas justificam sua ausência pela transitoriedade dos datilogramas. Estudos complementares são essenciais para verificar sua influência na confiabilidade do seu uso no cotejo papiloscópico.

\subsection{Considerações sobre os parâmetros quantitativos dos dermatóglifos por classes de interstício temporal}

O agrupamento dos indivíduos em três classes do tempo transcorrido entre a coleta dos padrões datiloscópicos ( 14 a 30, 31 a 40 ou 41 a 50 anos) permitiu avaliar se o tempo influenciou os percentuais dos três parâmetros do confronto entre os 
padrões datiloscópicos de ambas as fases, adulta $x$ idosa. (cristas de fricção visíveis, coincidências entre minúcias, linhas subsidiárias).

\subsubsection{Percentual de cristas de fricção visíveis}

Nossos resultados mostraram que o percentual de cristas de fricção visíveis nos datilogramas dos indivíduos não foi afetado pelos diferentes interstícios temporais, para o grupo de homens ou de mulheres. Como reportado anteriormente, a análise qualitativa mostrou que os datilogramas dos idosos apresentaram perda da nitidez das cristas para o grupo de estudo, mas quando se avaliou o percentual de cristas visíveis, pelo agrupamento desses indivíduos em classes de interstício temporal, não foi possível determinar diferenças entre essas classes. Neste parâmetro de avaliação, considerou-se o total de cristas visíveis nos datilogramas da fase idosa como sendo uma fração do total presente no datilograma padrão da fase adulta (100\%). Assim sendo, os indivíduos apresentaram visibilidade das cristas de fricção aproximada de $80 \%$, nas três classes de interstício temporal. Isso indica que as variações de tempo avaliadas (14 a 30, 31 a 40 ou 41 a 50 anos) não afetam o percentual de visibilidade das cristas de fricção.

Os resultados mostraram que, embora tenha ocorrido perda da nitidez das cristas, não houve comprometimento completo da identificação dos indivíduos pelo padrão ouro, mas somente para 12 deles. Assim, observa-se que a identificação papiloscópica permanece viável para a identificação de indivíduos idosos, no entanto, nossos resultados indicam a necessidade de aprimoramento dos métodos de registro, de edição de imagem e de pesquisa automatizada.

Na prática profissional, esse resultado auxilia a construção do conhecimento técnico do especialista em papiloscopia, de forma que desenvolva uma capacidade crítica em seu processo avaliativo no sentido de abstrair as possíveis discrepâncias existentes quando da contagem de linhas em datilogramas com menor nitidez, como no caso de idosos, considerando, é claro, a existência de outras coincidências seguras para a decisão final no momento da identificação. Um menor percentual de cristas de fricção visíveis dificulta a classificação do tipo fundamental, ao limitar a área para identificação dos caracteres distintivos formados pelas minúcias e, ao impedir que as minúcias localizadas sejam correlacionadas às demais no confronto entre o datilograma padrão e o questionado. 
Nosso resultado mostra que o estudo das alterações morfométricas das cristas de friç̧ão podem ser úteis no estabelecimento de algoritmos compensadores das falhas ou distorções dos datilogramas para aprimorar os sistemas automatizados (YAGER e AMIN, 2004; CHOI, CHOI e KIM, 2011). Atualmente, os sistemas são baseados no reconhecimento e disposição das minucias, entretanto a inserção de características relativas às cristas de fricção permitiria melhorar a acurácia no processo de identificação. O estudo de Drahansky et al. (2012) sobre indivíduos com patologias de pele espessa propõem um algoritmo para o melhoramento das imagens, em que a remoção de todo o ruído de informação do datilograma (linhas e de plano de fundo), baseado em medidas estimadas da largura das cristas e dos sulcos, bem como na inclinação das bordas superior e inferior das linhas, permitiria ao sistema automatizado a elaboração do "esqueleto" do datilograma e a complementação das falhas/linhas ausentes.

O estudo morfométrico dos datilogramas de indivíduos idosos pode auxiliar o desenvolvimento de sistemas automatizados com maior acurácia, além de incluir a idade como um fator relevante a ser considerado no momento do confronto para justificar possíveis distorções ou discrepâncias entre os datilogramas, ou mesmo para orientar a aplicação da identificação biométrica para indivíduos idosos.

\subsubsection{Percentual de minúcias coincidentes}

Para determinar o percentual de minúcias coincidentes inicialmente foram marcadas as minúcias nos datilogramas dos indivíduos e posteriormente ao confronto dos datilogramas da fase idosa com seu respectivo padrão adulto determinou-se dentre o total os percentuais de coincidências e de discrepâncias. Nossos resultados mostraram que as medianas dos percentuais de minúcias coincidentes não diferiram entre as classes de interstício temporal (14 a 30, 31 a 40 ou 41 a 50 anos). Apesar de o confronto indicar que nas três classes de interstício temporal os percentuais de minúcias coincidentes superam os $50 \%$, a identificação pelo padrão ouro foi possível para 28 indivíduos, logo, os demais indivíduos não identificados apontam para importância das discrepâncias entre os datilogramas das fases adulta e idosa de um mesmo indivíduo.

A ocorrência de minúcias discrepantes entre ambos os padrões de um mesmo indivíduo sugere que o processo de envelhecimento pode causar alterações nos datilogramas, como a interrupção de linhas que antes eram contínuas ou 
mesmo o surgimento de linhas subsidiárias que interferem no espaço intercristas podendo aproximá-las e impedir a visualização de minúcias e o contorno das cristas. No entanto, é possível que em alguns casos, a ocorrência de discrepância se dê por falhas de identificação de determinada minúcia e não necessariamente por alterações estruturais da pele, uma vez que o analista está sujeito ao erro intrínseco considerado no momento da marcação das minúcias (DROR e CHARLTON, 2006). Esses erros podem decorrer primeiramente de falhas humanas (proposital, negligência, inabilidade, cognição, psicológica, operacional ou tecnológica), de falhas instrumentais ou de falhas algorítmicas dos sistemas automatizados (DROR e CHARLTON, 2006).

Considerando que os tipos fundamentais podem expressar maior ou menor número de minúcias, conforme os estudos de Gutiérrez et al. (2007) é possível que nos datilogramas em que as minúcias são menos frequentes como é o caso dos arcos, a perda da nitidez das cristas de fricção favoreça a indeterminação de identidade.

\subsubsection{Percentual de linhas subsidiárias coincidentes}

Quanto ao percentual de linhas subsidiárias os resultados mostraram que as medianas para o grupo masculino ou para o feminino não diferiram entre si. No entanto, houve redução na mediana do percentual de linhas subsidiárias na primeira classe de interstício temporal (14 a 30 anos) para o grupo feminino, na comparação com o masculino, sendo que para essa classe as mulheres ou os homens apresentaram $0 \%$ ou $100 \%$ de coincidências entre as linhas subsidiárias. Esse resultado reflete a menor quantidade de linhas subsidiárias encontrada para o grupo de mulheres, sobretudo para aquelas cujos padrões datiloscópicos, adulto e idoso, foram obtidos no tempo transcorrido entre 14 e 30 anos.

Os achados de Stücker et al. (2001) sugerem que as linhas interpapilares ou subsidiárias podem ser consideradas como uma parte do datilograma em evolução e, à medida que aumenta a idade do indivíduo, aumenta também sua ocorrência, no entanto, no presente estudo os achados para o grupo de mulheres foram diferentes, com redução na visualização de tais estruturas. Logo, é possível que a diminuição do número de linhas subsidiárias reflita outras alterações observadas, como a diminuição no total de cristas de fricção pela perda da nitidez das impressões do 
grupo feminino, o que causou a não identificação de 8 mulheres, ou seja, $66 \%$ do total de 12 não identificados.

\subsection{Considerações sobre a identificação dos indivíduos}

Os métodos empregados no cotidiano da identificação humana em órgãos de segurança pública do Brasil são baseados em três níveis de complexidade das características dos datilogramas, que são consideradas pelo especialista na identificação. No primeiro nível é avaliado o arranjo das cristas de fricção, para classificar o tipo fundamental, mas que não é suficiente para a individualização. $\mathrm{Na}$ sequência, o segundo nível avalia os traços que as linhas/cristas formam na definição de minúcias, (bifurcação, pontas de linhas e interrupções abruptas) e em seguida, o terceiro nível compreende a análise morfométrica dos datilogramas (largura e formato das cristas e de poros, etc) cujas características corroboram o fundamento da unicidade e por vezes são empregados pelos especialistas em suas análises (ASHBAUGH, 1991; FOURNIER, 2013).

Nesse estudo as análises consideraram os três níveis de complexidade, tendo em vista a obtenção de dados morfométricos que embasaram a comparação pareada dos indivíduos e a determinação das alterações no interstício temporal. No entanto, para avaliar os métodos de busca de padrões datiloscópicos para o confronto, foram utilizados três diferentes métodos, em que, nos dois primeiros o especialista ignorava o conhecimento prévio da identidade do indivíduo. Assim, o primeiro método utilizou-se exclusivamente do sistema automatizado AFIS, no segundo método o perito analisou e selecionou áreas e minucias nos datilogramas previamente à pesquisa automatizada (padrão ouro) e o terceiro se deu pelo confronto direto das impressões questionadas com o padrão arquivado a partir do conhecimento prévio da identidade do indivíduo.

Dado o confronto dos datilogramas, nossos resultados mostraram que a busca automatizada no sistema AFIS resultou na identificação de $57,5 \%$ dos indivíduos, enquanto que pelo padrão ouro foi possível determinar a identidade de $70 \%$ deles e pelo confronto direto foram identificados $90 \%$ do total de indivíduos do grupo.

O uso do sistema AFIS é eficaz na busca automatizada por padrões compatíveis, no universo dos datilogramas arquivados no banco de dados, uma vez 
que esse sistema utiliza-se de um conjunto de filtros de melhoramento da imagem para a análise dos caracteres. No entanto, apesar de eficiente essa ferramenta permitiu a determinação de identidade de pouco mais da metade dos indivíduos idosos (57,5\%), enquanto que a atuação do especialista somada à ação do sistema automatizado (padrão ouro) resultou em 28 identificações (70\%). Este resultado evidencia a importância do papel do perito no processo de reconhecimento dos caracteres distintivos de cada impressão, das áreas escolhidas e os melhoramentos por ele efetivados através de ferramentas e filtros que o sistema disponibiliza.

Como a totalidade da amostra estava incluída no banco de dados empregado na presente pesquisa, teoricamente o resultado deveria ser de identificação dos 40 indivíduos. No entanto, considerando que o processo de identificação está sujeito a erros, sejam de natureza humana ou tecnológica, surge a necessidade de aprimoramento dos sistemas automatizados baseados em algoritmos (YAGER e AMIN, 2004; CHOI, CHOI e KIM, 2011). Além disso, e considerando que o especialista desconhece o padrão datiloscópico arquivado, é possível que ele selecione regiões ótimas do datilograma questionado que podem estar ausente no padrão arquivado, devido a erros da aposição dos dedos durante o registro, ou mesmo, devido a fatores intrínsecos do indivíduo que podem ter afetado os desenhos digitais por ocasião do registro. Assim, além do erro humano e da limitação dos sistemas automatizados, possibilidades de erros como os descritos influenciam no resultado da compatibilização entre datilogramas. Isso indica a importância do aprimoramento dos métodos de obtenção dos padrões datiloscópicos, já que em locais de crime não é possível saber qual será a região obtida com cristas de fricção nítidas.

O resultado da pesquisa essencialmente automatizada que resultou em 17 indivíduos não identificados sugere a ocorrência de falhas na acurácia do sistema, uma vez que, não houve a participação do especialista; esse sistema utiliza um conjunto de etapas padrão para qualquer que seja o datilograma. Já no processo de identificação "padrão ouro" há a atuação do especialista e, mesmo assim, restou ainda a identificação de 12 indivíduos. Embora envolto do caráter subjetivo, a utilização de ferramentas de busca requer o treinamento inicial e contínuo do profissional na formação dos algoritmos de busca a serem utilizados pelo sistema e, em sendo assim, aumenta-se a possibilidade de sucesso em ampliar o percentual de autenticação. Assume-se também que a falha no processo de identificação pode 
estar relacionada ao sistema automatizado; o sistema AFIS busca impressões compatíveis com o algoritmo formado pela disposição das minúcias, mas caso a qualidade do datilograma questionado seja insatisfatória não será possível o reconhecimento, como da mesma forma, a qualidade da impressão arquivada insatisfatória prejudicará o reconhecimento.

$\mathrm{Na}$ análise qualitativa dos datilogramas, o especialista apontou possíveis causas para a indeterminação da identidade de 12 indivíduos idosos pelo padrão ouro, ou seja, o sistema não apresentou candidatos compatíveis, o que pode ser atribuído à baixa acurácia do sistema ou à baixa qualidade do banco de dados. Primeiramente, a perda da nitidez das cristas de fricção foi responsável pela impossibilidade de identificação de 5 indivíduos, o restante deles não foi identificado pelo presença de linhas albodactilares (3 indivíduos) ou por falhas na busca de padrões compatíveis com a impressão questionada (4 indivíduos).

Especificamente para os 4 indivíduos não identificados por qualquer método, não significa que as impressões de idosos sejam impróprias para a verificação e autenticação, uma vez que, outros fatores que fogem do aspecto da qualidade da pele do indivíduo podem influenciar, como a experiência do especialista, a qualidade do padrão arquivado e a qualidade da digitalização. A avaliação individual mostrou que os datilogramas dos 4 indivíduos tinham em comum a perda da nitidez das cristas de fricção e em um deles estava associado maior número de linhas albodactilares (Figuras 28 e 29).

É importante ressaltar que a identificação dos indivíduos nesse estudo se deu em apenas um quirodáctilo, o indicador direito. Sabe-se que a quantidade de quirodáctilos influencia diretamente na área disponível para análise e também na combinação dos caracteres para robustecer a convicção. Em casos de identificação de cadáveres de morte recente é comum a identificação papiloscópica a partir da ficha decadactilar, assim, aumenta a chance de em 10 dedos obter área suficiente para a identificação. A sequência de dedos ocorre inclusive no caso de fragmentos obtidos em local de crime, onde é possível estabelecer a continuidade de impressões palmares e digitais pela sua disposição (Mizokami, et al. 2015). Assim, embora neste estudo o percentual de não identificados tenha sido de $10 \%$, na rotina, esse percentual pode ser maior ou menor. Além disso, alguns datilogramas podem apresentar, conforme discutido, características consideradas raras na população, como formatos específicos para os núcleos dos datilogramas. 
Atualmente, diversas pesquisas são voltadas para avaliar a proficiência dos especialistas e a consistência de suas decisões (DROR e CHARLTON, 2006; LIU, CHAMPOD, et al., 2015). Conforme estabelecido, o protocolo da prática pericial dos exames papiloscópicos compreende as fases da análise, comparação, avaliação e verificação (ACE-V) (CHAMPOD, 2007; SWGFAST, 2013). A análise compreende uma pré-avaliação dos componentes da impressão, quanto à qualidade, quantidade, minúcias, área, fatores de degradação e viabilidade da pesquisa, em que o especialista atribui uma valoração para os caracteres examinados. A comparação corresponde à fase de exame pareado das impressões, colocando lado a lado a impressão questionada com o padrão arquivado no banco de dados, A avaliação refere-se ao julgamento, à aplicação do peso que cada detalhe avaliado possui para sua decisão final. A verificação é a fase em que outro examinador refaz o procedimento ACE, a fim de verificar concordância ou discordância com o primeiro examinador. No final dessas etapas o confronto aponta para a determinação de identidade, ou para sua exclusão ou para sua inconclusão. Nesse sentido, aponta-se o treinamento e exercício dos especialistas para aprimoramento no processo avaliativo e comparativo de impressões digitais de idosos considerando as alterações morfométricas decorrentes do envelhecimento.

Considerando que o processo de identificação tem grande dependência do perito, sugere-se a continuidade dos estudos para determinar a relação entre os tipos fundamentais e a morfometria para cristas, minúcias, linhas subsidiárias e albodactilares, ao longo do processo de envelhecimento, para esclarecer as questões relativas à determinação de identidade ainda sem respostas. 
6. CONCLUSÕES 
Os resultados obtidos nesse estudo permitem as seguintes conclusões:

- Qualitativamente, os datilogramas dos idosos apresentaram perda de nitidez e deformação das cristas de fricção, sulcos intercristas estreitados e linhas interrrompidas;

- Não houve elementos para estabelecer a correlação da determinação de identidade para o grupo com as patologias, (hipertensão arterial sistêmica e diabetes), com atividade laboral danosa ou com o uso de cosméticos;

- Foi observado o predomínio dos tipos fundamentais verticilos em homens e presilhas externas em mulheres;

- Quantitativamente, os datilogramas dos idosos $(n=40)$ apresentaram redução do total de cristas de fricção visíveis e aumento do total de linhas albodactilares;

- O tempo transcorrido entre a obtenção dos padrões datiloscópicos de adultos e idosos, somando-se homens e mulheres ( $n=40$ ), não alterou o total de minúcias visíveis.

- Quantitativamente, no grupo de homens idosos ( $n=20)$ houve redução do total de cristas de fricção, aumento das linhas albodactilares e redução do número total de minúcias no interstício temporal de 41 a 50 anos;

- Quantitativamente, no grupo de mulheres idosas $(n=20)$ houve redução do total de cristas de fricção, redução do total das linhas subsidiárias e aumento das linhas albodactilares;

- Os datilogramas dos idosos $(n=40)$ apresentaram $87 \%$ de cristas de fricção visíveis e no mínimo $60 \%$ de minúcias coincidentes e que não houve diferenças nesses parâmetros para as diferentes classes de interstício temporal;

- Em dois indivíduos as alterações no padrão idoso foram tão expressivas que inviabilizaram a classificação do tipo fundamental do datilograma;

- A busca automatizada no sistema AFIS/VRP resultou na identificação de $57,5 \%$ dos indivíduos, enquanto que pelo "padrão ouro" foi possível determinar a 
identidade de $70 \%$ deles e pelo confronto direto foram identificados $90 \%$ do total de indivíduos do grupo.

- O resultado das identificações foi otimizado pela atuação do especialista em papiloscopia, o que foi evidenciado nos métodos da análise pericial associado à busca automatizada e do confronto direto.

Em conjunto, nossos resultados mostraram de forma qualitativa e quantitativa que os datilogramas dos idosos sofreram alterações morfométricas no tempo transcorrido entre a obtenção dos padrões, adulto e idoso, de um mesmo indivíduo que inviabilizaram a identificação de $30 \%$ dos indivíduos idosos. Nossos resultados mostram a necessidade de desenvolvimento dos métodos de obtenção dos datilogramas para esclarecer os pontos obscuros relativos à determinação de identidade, visando ampliar os limites da identificação de indivíduos idosos. Em consonância, o presente estudo indica a importância da qualidade dos arquivos biométricos e sua manutenção com registros dos padrões em diversas fases da vida de um indivíduo, e ainda, reforça o papel do especialista em papiloscopia no processo de identificação. 
A dificuldade observada na prática pericial para a identificação papiloscópica de indivíduos idosos gerou o questionamento acerca das possíveis alterações sofridas na pele espessa em decorrência do envelhecimento. O presente estudo abordou uma análise longitudinal retrospectiva até então pouco explorada nas pesquisas devido à ausência de registros datiloscópicos em várias fases da vida de um mesmo individuo. No Brasil, a existência do documento de identidade civil e dos arquivos dos órgãos de segurança pública viabiliza a execução desse tipo de estudo. O objetivo principal deste trabalho foi determinar morfometricamente as alterações qualitativas e quantitativas visualizadas nos datilogramas de idosos. Com base na literatura e no presente estudo, é possível afirmar que os datilogramas dos idosos sofreram alterações morfométricas no tempo transcorrido entre a obtenção dos padrões, adulto e idoso, de um mesmo indivíduo.

Os estudos na população brasileira são ainda incipientes e podem ser valiosos na indicação do perfil étnico da população, prevalência dos tipos fundamentais por gênero, da sequência dos dedos ou da lateralidade das mãos, dos tipos de minúcias e da área de ocorrência determinando assim indicações e redução no universo de suspeitos no momento em que o perito executa sua análise e comparação. Neste trabalho, foram verificadas as frequências dos tipos fundamentais na amostra estudada, entretanto há necessidade de ampliação da população amostral e de considerações sobre características étnicas para um estudo populacional brasileiro.

Os resultados encontrados demonstraram a redução da nitidez dos datilogramas com redução na visibilidade do número de cristas de fricção e de sulcos, alteração nos contornos e formato das cristas, na conformidade das minúcias, na frequência de linhas subsidiárias e de linhas albodactilares. É importante ressaltar as variáveis não controladas que o método de registro impõe às impressões, pois a pressão exercida, o volume de tinta aplicado, a habilidade do profissional coletador e a colaboração/não intervenção com movimentos bruscos do voluntário podem interferir nos resultados, o que configura uma limitação deste estudo. Um estudo morfométrico mais detalhado dessas alterações precisa ser realizado para determinar as transformações ocorridas em função da idade, examinando detalhes como espessura das cristas, formato dos poros e a relação com a disposição espacial das minúcias a fim de subsidiar os peritos em 
papiloscopia em suas análises e comparações quanto ao conhecimento das possíveis alterações e, ainda, no aperfeiçoamento e acurácia dos sistemas automatizados de identificação de impressões digitais. Sugere-se uma abordagem para normalizar o erro próprio do método da coleta por meio de repetições do registros de cada indivíduo sendo realizado por um mesmo coletador e obtenção da média dos dados verificados. Outras análises, por exemplo, por meio de fotografia, ou varredura a laser em que excluem-se as variações impostas pela coleta e da pressão exercida podem auxiliar nos estudos morfométricos.

Embora os resultados indiquem coincidências e divergências de cristas e minúcias entre os padrões de adultos e idosos, a identificação foi alcançada para a maior parte da amostra estudada. Sendo que o processo de identificação por meio da busca automatizada teve sua eficácia melhorada quando houve associação da análise do perito o que indica a importância da experiência, do treinamento e do conhecimento do perito e a necessidade dos exames com maior detalhamento dessas impressões.

No presente estudo não foram verificadas correlações entre a identificação e hábitos manuais danosos, uso de cosméticos para pele e patologias crônicas (hipertensão arterial sistêmica e diabetes mellitus). Entretanto, é sabido que atividades manuais e uso de agentes químicos provocam impressões digitais com menor qualidade, o que indica a necessidade de estudo com uma amostra maior de indivíduos. Quanto às patologias estudadas, a revisão de literatura subsidia a hipótese de influência dessas patologias, hipertensão arterial e diabetes, nas características da pele senil, o que sugere a necessidade de empreender um estudo com um grupo controle em comparação ao grupo afetado, uma vez que a maior parte do grupo apresentou essas patologias. 
AMINI, F. Dermatoglyphics: Comparison between Negritos Orang Asli and the Malays, Chinese and Indian. Sains Malaysiana, 2009.

APC. Identificação Humana. Brasília: Academia de Polícia Civil do Distrito Federal - Divisão Técnica de Ensino, 2008a.

APC. Método Científico de Identificação Civil. Brasília: Academia de Polícia Civil do Dsitrito Federal, $2008 b$.

ARAÚJO, M. E. C.; BOSSOIS, L. M.; SANTANA, J. L. O Arquivo Datiloscópico Criminal Brasileiro: Os Tipos Fundamentais e Suas Freqüências. In: XIII Congresso Mundial de Criminologia, Sociedade Internacional de Criminologia, Criminologia Clinica. [S.I.]: [s.n.]. 2003.

ASHBAUGH, D. Ridgeology. J. Forensic Ident., 41(1), 1991. 16-64.

AVILA, M. T. et al. Neurodevelopmental interactions conferring risk for schizophrenia: a study of dermatoglyphic markers in patients and relatives. Schizophrenia bulletin, 29, n. 3, 2003. 595.

BADAWI, A. et al. Fingerprint-Based Gender Classification. In. IPCV, 2006. 41-46.

BARNES, J. G. et al. The Fingerprint Sourcebook. Washington, DC: National Institute of Justice. U.S. Department of Justice, 2011. 2-16 - 2-18 p. Acesso em: 11 agosto 2015. Disponível em: https://www.ncjrs.gov/pdffiles1/nij/225320.pdf. Acesso em 10 ago 2015.

BLOMEKE, C. R.; MODI, S. K.; ELLIOT, S. J. Investigating the relationship between fingerprint image quality and skin characteristics. Security Technology, 2008. ICCST 2008. 42nd Annual IEEE International Carnahan Conference on. [S.I.]: [s.n.]. 2008. p. 158-161.

BORTOLETTO, M. S. S. et al. Síndrome metabólica em estudos com adultos brasileiros: uma revisão sistemática. Espaço para a Saúde, 15, n. 4, 2014. 86-98.

BRASIL. Lei № 7.116, de 29 de agosto de 1983, 1983. Disponivel em: <https://www.planalto.gov.br/ccivil_03/Leis/1980-1988/L7116.htm>. Acesso em: 10 julho 2015. Acesso em: 1 jul 2015.

BRASIL. Ministério da Saúde. Conselho Nacional de Saúde. RESOLUÇÃO № 196, DE 10 DE OUTUBRO DE 1996, 1996. Disponivel em:

<http://bvsms.saude.gov.br/bvs/saudelegis/cns/1996/res0196_10_10_1996.html>. Acesso em: 16 agosto 2015.

BUCKLEY, A. F.; BOSSEN, E. H. Skeletal muscle microvasculature in the diagnosis of neuromuscular disease. Journal of Neuropathology \& Experimental Neurology, 72, n. 10, 2013. 906-918.

CHAMPOD, C. Fingerprint examination: towards more transparency. Law, Probability and Risk, 7, 2007. 111-118.

$\mathrm{CHOI}, \mathrm{H}$.; $\mathrm{CHOI}, \mathrm{K}$; $\mathrm{KIM}$, J. Fingerprint matching incorporating ridge features with minutiae.

Information Forensics and Security, IEEE Transactions on, 6, n. 2, 2011. 338-345. 
DANIEL, S.; RETO, M.; FRED, Z. Collagen glycation and skin aging. Cosmetics and Toiletries Manufacture Worldwide, 2002.

DE BRUIN, E. I. et al. The association between formal thought disorder and finger print asymmetry in children with a psychiatric disorder: an exploratory study. European child \& adolescent psychiatry, 21, n. 12, 2012. 691-698.

DRAHANSKY, M. et al. Influence of skin diseases on fingerprint recognition. BioMed Research International, 2012, 2012.

DROR, I. E.; CHARLTON, D. Why experts make errors. Journal of Forensic Identification, 56, n. 4, 2006. 600 .

FARAGE, M. A. et al. Characteristics of the aging skin. Advances in wound care, 2, n. 1, 2013. 5-10.

FARIAS, D. R. E.; PEREIRA, A. F.; ROSA, G. Síndrome metabólica na doença arterial coronariana e vascular oclusiva: uma revisão sistemática. Arq Bras Cardiol, 94, n. 6, 2010. 150-78.

FOURNIER, N. A. Minutiae Variation Between Sexes, Ancestries, and Pattern Types: A Study to Strengthen and Validate the Science of Fingerprints. Tese (Tese de Mestrado). North Carolina State University, 2013. Disponivel em:

<http://repository.lib.ncsu.edu/ir/bitstream/1840.16/8655/1/etd.pdf>. Acesso em: 10 agosto 2015.

FRANCA, G. V. Medicina Legal. 9ạ. ed. Rio de Janeiro: Guanabara Koogan, 2011.

FREITAS, L. M. A. Estudo cefalométrico das estruturas esqueléticas, dentárias e tegumentares, em jovens brasileiros, leucodermas, feodermas e melanodermas.. Tese (Tese de doutorado).

Universidade de São Paulo, 2008.

GALTON, F. Fingerprint directories. [S.I.]: [s.n.], 1895.

GODFREY, K. M. et al. Relation of fingerprints and shape of the palm to fetal growth and adult blood pressure. BMJ, 307, n. 6901, 1993. 405-409.

GUTIÉRREZ, E. et al. Biological variability of the minutiae in the fingerprints of a sample of the Spanish population. Forensic Science International, 172, n. 2, 2007. 98-105.

GUTIÉRREZ-REDOMERO, E. et al. Variability of fingerprint ridge density in a sample of Spanish Caucasians. Forensic Science International, 2008. 17-22.

GUTIERREZ-REDOMERO, E. et al. Distribution of the minutiae in the fingerprints of a sample of the Spanish population. Forensic science international, 208, n. 1, 2011. 79-90.

GUTIÉRREZ-REDOMERO, E. et al. A comparative study of topological and sex differences in fingerprint ridge density in Argentinian and Spanish population samples. Journal of forensic and legal medicine, 20, n. 5, 2013. 419-429.

HERNÁNDEZ, N. et al. Capillary changes in skeletal muscle of patients with essential hypertension. The anatomical record, 256, n. 4, 1999. 425-432. 
KAHANA, T. et al. Fingerprinting the deceased: tradicional and new techniques. Journal of Forensic Identification, 46, n.4, 2001. 908-912.

KAHN, H. S. et al. A fingerprint marker from early gestation associated with diabetes in middle age: the Dutch Hunger Winter Families Study. International journal of epidemiology, 38, n. 1, 2009. 101109.

KÜCKEN, M. Models for fingerprint pattern formation. Forensic science international, 171, n. 2, 2007. 85-96.

LAHIRI, A. et al. A Study on Relationship between Dermatoglyphics and Hypertension. Journal of Dental and Medical Sciences, 7, n. 6, 2013.

LIU, S. et al. Study on Accuracy of Judgments by Chinese Fingerprint Examiners. Journal of Forensic Science and Medicine, 1, n. 1, 2015. 33.

MAKRANTONAKI, E.; ZOUBOULIS, C. C. The skin as a mirror of the aging process in the human organism-state of the art and results of the aging research in the German National Genome Research Network 2 (NGFN-2). Experimental gerontology, 42, n. 9, 2007. 879-886.

MARANHÃO, O. R. Curso básico de medicina legal. 8a. ed. São Paulo: Malheiros Editores, 2002.

MEHTA, A. A.; MEHTA, A. A. Study of fingerprint patterns among medical students in Vidarbha Region, India. Int J Anat Res, 3, n. 2, 2015. 1043-45.

MINISTÉRIO DA SAÚDE. Portal da saúde. DATASUS, 2012. Disponivel em:

<http://tabnet.datasus.gov.br>. Acesso em: 6 agosto 2015.

MISUMI, Y.; AKIYOSHI, T. Scanning electron microscopic structure of the finger print as related to the dermal surface. The Anatomical Record, 208, n. 1, 1984. 49-55.

MIZOKAMI, L. L. Estudo morfológico comparativo das superfícies epidérmica e dérmica: perspectivas na identificação necropapiloscópica. Dissertação (Dissertação de mestrado). Universidade de Brasília, 2014.

MIZOKAMI, L. L.; SILVA, L. R. V.; KÜCKELHAUS, S. A. S. Comparison between fingerprints of the epidermis and dermis: Perspectives in the identifying of corpses. Forensic science international, 252, 2015. 77-81.

MODI, H. H.; PRAJAPATI, H. K. Sexual Dimorphism in Dermatoglyphic Pattern Study. Medical Science, 1, n. 1, 2013. 24-26.

MODI, S. K. et al. Impact of age groups on fingerprint recognition performance. Automatic Identification Advanced Technologies, 2007 IEEE Workshop on., 2007. 19-23.

NITHIN, M. D. et al. Gender differentiation by finger ridge count among South Indian population. Journal of forensic and legal medicine, 18, n. 2, 2011. 79-81.

OKAJIMA, M. Frequency of forks in epidermal-ridge minutiae in the finger print. American journal of physical anthropology, 32, n. 1, 1970. 41-48. 
OKAJIMA, M. Dermal and epidermal structures of the volar skin. Birth defects original article series, 15, n. $6,1979.179-198$.

ORIÁ, R. B. et al. Estudo das alterações relacionadas com a idade na pele humana, utilizando métodos de histo-morfometria e autofluorescência Study of age-related changes in human skin using histomorphometric and autofluorescence approaches. An Bras Dermatol, 78, n. 4, 2003. 425-434.

PAGE, M.; TAYLOR, J.; BLENKIN, M. Uniqueness in the forensic identification sciences-Fact or fiction? Forensic Science International, 206, n. 1, 2011. 12-18.

PEREIRA, I. et al. Associação entre índice glicêmico e carga glicêmica dietéticos e síndrome metabólica em idosos. Rev Bras Geriatr Gerontol, 15, n. 3, 2012. 567-76.

PLOTNICK, H.; PINKUS, H. The epidermal vs. the dermal fingerprint: an experimental and anatomical study. AMA archives of dermatology, 77, n. 1, 1958. 12-17.

RAVINDRANATH, R.; THOMAS, I. M. Finger ridge count and finger print pattern in maturity onset diabetes mellitus. Indian journal of medical Sciences, 49, n. 7, 1995. 153.

RODRIGUEZ, J. South Atlantic crossings: fingerprints, science, and the State in turn-of-the-century Argentina. The American historical review, 109, n. 2, 2004. 387-416.

STÜCKER, M. et al. Interpapillary lines-the variable part of the human fingerprint. Journal of forensic sciences, 46, n. 4, 2001. 857-861.

SWGFAST. Scientific Working Group on Friction Ridge Analysis Study and Technology. Standards for Examining Friction Ridge, 2013. Disponivel em: <http://www.swgfast.org/documents/examinationsconclusions/130427_Examinations-Conclusions_2.0.pdf>. Acesso em: 12 agosto 2015.

VANRELL, J. P. Odontologia Legal e antropologia forense. 2ª. ed. Rio de Janeiro: Guanaba koogan, 2012.

WAAIJER, M. E. et al. Morphometric skin characteristics dependent on chronological and biological age: the Leiden Longevity Study. Age, 34, n. 6, 2012. 1543-1552.

WIJERATHNE, B. T. et al. Dermatoglyphics in hypertension: a review. Journal of Physiological Anthropology, 34, n. 1, 2015. 29.

WMA. Declaration of Helsinki, amended by 59th World Medical Association General Assembly. 2013, 2013. Disponivel em: <http://www.wma.net/en/30publications/10policies/b3/17c.pdf>. Acesso em: 16 agosto 2015.

$\mathrm{XIE}$, S. J. et al. Intelligent fingerprint quality analysis using online sequential extreme learning machine. Soft Computing, 16 n. 9, 2012. 1555-1568.

YAGER, N.; AMIN, A. Fingerprint verification based on minutiae features: a review. Pattern Analysis and Applications, 7, n. 1, 2004. 94-113.

ZUGIBE, F. T.; COSTELLO, J. T. A new method for softening mummified fingers. Journal of Forensic Identification, 31, n.2, 1986. 726-731. 
APÊNDICES 
Apêndice A - Termo de Consentimento Livre e Esclarecido

\section{TERMO DE CONSENTIMENTO LIVRE E ESCLARECIDO}

Eu, Lara Rosana Vieira Silva, estou desenvolvendo a pesquisa com título "DETERMINAÇÃO DE VARIAÇÕES MORFOMÉTRICAS EM IMPRESSÕES DIGITAIS OBTIDAS DE INDIVÍDUOS IDOSOS". Essa pesquisa tem por objetivo analisar impressões digitais de indivíduos idosos e compará-las com impressões obtidas em idade jovem. Com essa pesquisa busca-se melhorar os métodos de pesquisa e autenticação de impressões digitais de indivíduos idosos. Essa pesquisa será de grande importância para a identificação humana e para a Segurança Pública.

Sua participação nessa pesquisa é voluntária, não será remunerada e serão mantidos em sigilo os dados do doador. Não haverá benefício direto e imediato. É garantida a liberdade da retirada do consentimento a qualquer momento sem qualquer prejuízo. Informo ainda que estarei à disposição para esclarecer qualquer dúvida pelos telefones (61) 33072273, (61)99623034 e e-mail lararosana@gmail.com . Também é possível entrar em contato com o Comitê de Ética em Pesquisa da Faculdade de Medicina - UnB por meio do telefone (61) 31071918.

Eu me comprometo a:

- Garantir o sigilo e a privacidade de cada indivíduo;

- Utilizar as informações somente para a execução deste projeto;

- Não divulgar informações que possam identificar o sujeito da pesquisa.

\section{PARTICIPANTE}

Acredito ter sido suficientemente informado a respeito das informações que li sobre o estudo "DETERMINAÇÃO DE VARIAÇÕES MORFOMÉTRICAS EM IMPRESSÕES DIGITAIS OBTIDAS DE INDIVÍDUOS IDOSOS”. Ficaram claros para mim quais os objetivos do estudo, método a ser realizado e a garantia de esclarecimentos em qualquer etapa da pesquisa. Ficou claro também que minha 
participação é isenta de despesas e que tenho garantia de esclarecimentos das minhas dúvidas a qualquer tempo.

Concordo voluntariamente em participar deste estudo e poderei retirar o meu consentimento a qualquer momento, antes ou durante o mesmo, sem qualquer tipo de penalidade ou prejuízo.

Brasília,

Assinatura e RG do participante

Lara Rosana Vieira Silva

Pesquisadora 


\section{Apêndice B - Questionário}

FORMULÁRIO DE PESQUISA

Nome:

Data de nascimento:

Endereço:

Telefone:

RG:

1. O Sr(a) possui alguma doença?

2. O Sr (a) faz uso de algum medicamento regularmente? Se sim, cite os nomes.

3. Qual a sua atividade laboral principal ao longo de sua vida e qual sua principal atividade atual?

4. Normalmente, o Sr(a) faz uso de cremes, pomadas ou cosméticos para pele?

5. O Sr(a) faz trabalhos manuais com frequência e/ou manuseia substâncias químicas? Se sim, liste-os. 


\section{Apêndice C - Perfil dos indivíduos}

\begin{tabular}{|c|c|c|c|c|c|c|c|c|}
\hline \multirow{2}{*}{ № } & \multirow{2}{*}{ Gênero } & \multicolumn{2}{|c|}{ Idade } & \multirow{2}{*}{$\begin{array}{c}\text { Interstício } \\
\text { temporal } \\
\text { (anos) }\end{array}$} & \multirow{2}{*}{$\begin{array}{l}\text { Atividade } \\
\text { laboral }\end{array}$} & \multirow{2}{*}{ Atividades manuais } & \multirow{2}{*}{ Patologias } & \multirow{2}{*}{$\begin{array}{c}\text { Cosméticos } \\
\text { para pele }\end{array}$} \\
\hline & & Adulto & Idoso & & & & & \\
\hline 1 & M & 29 & 70 & 42 & Professor & Não & HAS, Neoplasia & Não \\
\hline 2 & $M$ & 43 & 67 & 24 & Motorista & Não & DM & Não \\
\hline 3 & M & 26 & 66 & 40 & Servidor público & Não & $\begin{array}{c}\text { Neoplasia (próstata), } \\
\text { Hepatite B }\end{array}$ & Não \\
\hline 4 & M & 38 & 78 & 40 & $\begin{array}{l}\text { Mecânico, } \\
\text { Agricultor }\end{array}$ & Plantação (adubação) & HAS, catarata & Não \\
\hline 5 & $M$ & 29 & 70 & 41 & Comerciante & Não & Não & Não \\
\hline 6 & $M$ & 50 & 78 & 28 & Servidor público & Não & DM & Não \\
\hline 7 & M & 23 & 66 & 43 & Serralheiro & $\begin{array}{l}\text { Serralheria, } \\
\text { Horticultura } \\
\end{array}$ & HAS & Sim \\
\hline 8 & M & 38 & 60 & 22 & Bancário & Não & HAS & Sim \\
\hline 9 & M & 26 & 66 & 40 & Eletrotécnico & Limpeza doméstica & $\begin{array}{c}\text { Artrose, } \\
\text { Hiperplasia (próstata) } \\
\end{array}$ & Não \\
\hline 10 & $\mathrm{M}$ & 47 & 65 & 18 & Pedreiro & Cimentação & Hérnia de disco & Não \\
\hline 11 & M & 36 & 65 & 29 & Motorista & Não & Não & Sim \\
\hline 12 & M & 44 & 88 & 44 & Servidor público & Não & Cardiopatia & Não \\
\hline 13 & M & 44 & 65 & 21 & Jardineiro & Jardinagem & $\begin{array}{l}\text { Surdez, Oftalmológica, } \\
\text { Ortopédica (coluna) }\end{array}$ & Não \\
\hline 14 & $M$ & 26 & 62 & 35 & Servidor público & Não & Não & Não \\
\hline 15 & $M$ & 36 & 68 & 31 & Servidor público & Limpeza doméstica & Degeneração macular & Não \\
\hline 16 & M & 40 & 67 & 28 & Servidor público & Não & HAS & Não \\
\hline 17 & $M$ & 35 & 79 & 43 & Agricultor & Agricultura & HAS & Não \\
\hline 18 & $M$ & 28 & 69 & 41 & Servidor público & Não & HA, Refluxo & Não \\
\hline 19 & $M$ & 46 & 63 & 17 & Secretário & Limpeza doméstica & Neoplasia (rim) & Não \\
\hline 20 & M & 29 & 72 & 43 & Servidor público & Não & $\begin{array}{c}\text { HAS, neoplasia } \\
\text { (próstata) }\end{array}$ & Não \\
\hline 1 & $\mathrm{~F}$ & 25 & 66 & 41 & Professora & Limpeza doméstica & HAS, DM & Sim \\
\hline 2 & $\mathrm{~F}$ & 32 & 61 & 29 & Professora & $\begin{array}{c}\text { Crochetagem, } \\
\text { Limpeza doméstica }\end{array}$ & $\begin{array}{c}\text { DM, Asma, } \\
\text { Hipertireoidismo }\end{array}$ & Sim \\
\hline 3 & $\mathrm{~F}$ & 23 & 64 & 41 & $\begin{array}{l}\text { Doméstica, } \\
\text { agricultura }\end{array}$ & Limpeza doméstica & Síndrome do pânico & Sim \\
\hline 4 & $\mathrm{~F}$ & 29 & 71 & 42 & Professora & Limpeza doméstica & Não & Sim \\
\hline 5 & $\mathrm{~F}$ & 24 & 61 & 37 & Secretária & $\begin{array}{c}\text { Costura, } \\
\text { Limpeza doméstica }\end{array}$ & DM & Sim \\
\hline 6 & $\mathrm{~F}$ & 27 & 63 & 36 & Comerciária & Limpeza doméstica & $\begin{array}{c}\text { Epilepsia, Gastrite, } \\
\text { Catarata }\end{array}$ & Sim \\
\hline 7 & $\mathrm{~F}$ & 57 & 71 & 14 & Serviços gerais & Limpeza doméstica & Insônia, Amnésia & Sim \\
\hline 8 & $\mathrm{~F}$ & 21 & 64 & 43 & Administrativo & Não & HAS, Hipotireoidismo & Sim \\
\hline 9 & $\mathrm{~F}$ & 26 & 67 & 41 & Enfermeira & Limpeza doméstica & HAS, Hipotireoidismo & Sim \\
\hline 10 & $\mathrm{~F}$ & 50 & 66 & 16 & Servidor público & Artesanato & DM, Arritmia cardíaca & Não \\
\hline 11 & $\mathrm{~F}$ & 26 & 67 & 41 & Servidor público & $\begin{array}{c}\text { Bordado, } \\
\text { Limpeza doméstica }\end{array}$ & $\begin{array}{c}\text { Labirintite, Disfunção } \\
\text { temporomandibular }\end{array}$ & Sim \\
\hline 12 & $\mathrm{~F}$ & 25 & 67 & 42 & Servidor público & Limpeza doméstica & DM & Sim \\
\hline 13 & $\mathrm{~F}$ & 22 & 60 & 39 & Servidor público & Costura & Neoplasia (tireoide) & $\operatorname{Sim}$ \\
\hline 14 & $\mathrm{~F}$ & 48 & 72 & 23 & Almoxarifado & Limpeza doméstica & HAS, DM & Sim \\
\hline 15 & $\mathrm{~F}$ & 35 & 65 & 30 & Doméstica & Limpeza doméstica & HAS, neoplasia (mama) & Sim \\
\hline 16 & $\mathrm{~F}$ & 38 & 65 & 27 & Serviços gerais & Limpeza doméstica & $\begin{array}{c}\text { HAS, DM, Artrose, } \\
\text { Arritmia cardíaca }\end{array}$ & Sim \\
\hline 17 & $\mathrm{~F}$ & 49 & 65 & 16 & Servidor público & $\begin{array}{c}\text { Crochetagem, } \\
\text { Tricotagem, Costura }\end{array}$ & Fibromialgia & Sim \\
\hline 18 & $\mathrm{~F}$ & 24 & 62 & 37 & Servidor público & $\begin{array}{c}\text { Crochetagem, } \\
\text { Tricotagem }\end{array}$ & Hipercolesterolemia & Sim \\
\hline 19 & $\mathrm{~F}$ & 31 & 64 & 33 & Servidor público & Não & $\begin{array}{c}\text { DM, Tendinite - LER, } \\
\text { Esteatose hepática, } \\
\text { Hipercolesterolemia }\end{array}$ & Sim \\
\hline 20 & $\mathrm{~F}$ & 29 & 69 & 40 & Professora & Artesanato & HAS, Alergia, Depressão & Sim \\
\hline$\mu \pm D P$ & - & $33,9 \pm 9,6$ & $67,4 \pm 5,6$ & $33,5 \pm 9,4$ & - & - & - & - \\
\hline
\end{tabular}


Apêndice D - Quantidade de cristas, minúcias, linhas subsidiárias e linhas albodactilares observadas nos indivíduos em idade adulta e idosa

\begin{tabular}{|c|c|c|c|c|c|c|c|c|c|c|}
\hline \multirow{2}{*}{$\mathbf{N}$} & \multirow{2}{*}{ Gênero } & \multirow{2}{*}{$\begin{array}{l}\text { Tipo fundamental } \\
\left(2^{\circ} \mathrm{D}\right)\end{array}$} & \multicolumn{2}{|c|}{ № de cristas de fricção } & \multicolumn{2}{|c|}{ Minúcias } & \multicolumn{2}{|c|}{$\begin{array}{c}\text { Linhas } \\
\text { subsidiárias }\end{array}$} & \multicolumn{2}{|c|}{$\begin{array}{c}\text { Linhas } \\
\text { albodactilares }\end{array}$} \\
\hline & & & Adulto & Idoso & Adulto & Idoso & Adulto & Idoso & Adulto & Idoso \\
\hline 1 & $M$ & Presilha externa & 19 & 14 & 25 & 34 & 2 & 4 & 0 & 1 \\
\hline 2 & M & Presilha externa & 16 & 14 & 24 & 34 & 0 & 0 & 1 & 3 \\
\hline 3 & M & Verticilo & 23 & 20 & 25 & 31 & 0 & 5 & 0 & 0 \\
\hline 4 & M & Verticilo & 17 & 14 & 24 & 22 & 0 & 0 & 0 & 3 \\
\hline 5 & M & Verticilo & 18 & 15 & 37 & 38 & 0 & 3 & 0 & 2 \\
\hline 6 & M & Verticilo & 16 & 17 & 45 & 21 & 10 & 10 & 0 & 0 \\
\hline 7 & $M$ & Verticilo & 23 & 21 & 40 & 23 & 6 & 0 & 1 & 2 \\
\hline 8 & M & Verticilo & 25 & 26 & 29 & 33 & 0 & 0 & 0 & 1 \\
\hline 9 & M & Presilha interna & 18 & 19 & 37 & 38 & 5 & 0 & 1 & 2 \\
\hline 10 & $M$ & Presilha externa & 18 & 12 & 27 & 37 & 0 & 7 & 2 & 2 \\
\hline 11 & M & Verticilo & 21 & 21 & 22 & 15 & 0 & 0 & 0 & 2 \\
\hline 12 & M & Arco & 11 & 3 & 22 & 27 & 0 & 0 & 3 & 6 \\
\hline 13 & M & Verticilo & 17 & 14 & 12 & 21 & 4 & 5 & 0 & 0 \\
\hline 14 & M & Presilha interna & 22 & 20 & 34 & 36 & 0 & 0 & 1 & 2 \\
\hline 15 & M & Verticilo & 17 & 8 & 19 & 18 & 0 & 0 & 1 & 4 \\
\hline 16 & M & Presilha externa & 13 & 11 & 35 & 28 & 0 & 0 & 0 & 2 \\
\hline 17 & M & Arco & 18 & 15 & 27 & 34 & 0 & 0 & 0 & 2 \\
\hline 18 & M & Verticilo & 26 & 23 & 14 & 14 & 0 & 8 & 1 & 0 \\
\hline 19 & M & Presilha externa & 18 & 18 & 18 & 14 & 8 & 10 & 0 & 1 \\
\hline 20 & M & Verticilo & 14 & 13 & 24 & 28 & 0 & 7 & 0 & 2 \\
\hline 1 & $\mathrm{~F}$ & Presilha externa & 15 & 9 & 25 & 34 & 3 & 0 & 5 & 12 \\
\hline 2 & $\mathrm{~F}$ & Presilha externa & 16 & 12 & 24 & 34 & 0 & 0 & 4 & 11 \\
\hline 3 & $F$ & Verticilo & 17 & 15 & 25 & 31 & 0 & 0 & 0 & 2 \\
\hline 4 & $\mathrm{~F}$ & Verticilo & 21 & 15 & 24 & 22 & 0 & 0 & 0 & 4 \\
\hline 5 & $\mathrm{~F}$ & Verticilo & 29 & 28 & 37 & 38 & 0 & 0 & 0 & 2 \\
\hline 6 & $\mathrm{~F}$ & Verticilo & 15 & 14 & 24 & 28 & 8 & 2 & 2 & 1 \\
\hline 7 & $\mathrm{~F}$ & Verticilo & 28 & 15 & 45 & 21 & 3 & 0 & 0 & 2 \\
\hline 8 & $\mathrm{~F}$ & Verticilo & 17 & 17 & 40 & 23 & 0 & 0 & 1 & 4 \\
\hline 9 & $F$ & Presilha interna & 19 & 17 & 29 & 33 & 0 & 0 & 3 & 5 \\
\hline 10 & $\mathrm{~F}$ & Presilha externa & 20 & 16 & 37 & 38 & 15 & 0 & 2 & 3 \\
\hline 11 & $F$ & Verticilo & 17 & 17 & 27 & 37 & 3 & 3 & 0 & 0 \\
\hline 12 & $\mathrm{~F}$ & Arco & 18 & 16 & 22 & 15 & 0 & 0 & 0 & 5 \\
\hline 13 & $\mathrm{~F}$ & Verticilo & 23 & 24 & 22 & 27 & 0 & 0 & 0 & 3 \\
\hline 14 & $F$ & Presilha interna & 12 & 7 & 12 & 21 & 0 & 0 & 4 & 6 \\
\hline 15 & $\mathrm{~F}$ & Verticilo & 15 & 13 & 34 & 36 & 17 & 5 & 0 & 0 \\
\hline 16 & $\mathrm{~F}$ & Presilha externa & 18 & 15 & 19 & 18 & 2 & 0 & 0 & 1 \\
\hline 17 & $F$ & Arco & 21 & 19 & 35 & 28 & 3 & 0 & 1 & 4 \\
\hline 18 & $\mathrm{~F}$ & Verticilo & 11 & 21 & 27 & 34 & 0 & 0 & 4 & 10 \\
\hline 19 & $\mathrm{~F}$ & Presilha externa & 18 & 8 & 14 & 14 & 4 & 3 & 1 & 4 \\
\hline 20 & $\mathrm{~F}$ & Verticilo & 12 & 10 & 18 & 14 & 0 & 0 & 0 & 0 \\
\hline$\mu \pm D P$ & - & - & - & $15,6 \pm 5,2$ & - & - & - & - & - & - \\
\hline Mediana & - & - & 18,0 & - & 25,0 & 28,0 & 0 & 0 & 0 & 2,0 \\
\hline
\end{tabular}


Apêndice $E$ - Frequência dos tipos fundamentais por quirodáctilo observada na individual decadactilar dos indivíduos idosos

Grupo Masculino

\begin{tabular}{|c|c|c|c|c|c|c|}
\hline Quirodáctilo & Verticilo & Presilha externa & Presilha interna & Arco & Anomalia/Cicatriz & Amputação \\
\hline $1 \stackrel{0}{1} \mathrm{D}$ & 14 & 6 & - & - & - & - \\
\hline $2^{\circ} \mathrm{D}$ & 11 & 5 & 2 & 2 & - & - \\
\hline $3 \div D$ & 6 & 14 & - & - & - & - \\
\hline $4^{\circ} \mathrm{D}$ & 10 & 10 & - & - & - & - \\
\hline 5D & 4 & 16 & - & - & - & - \\
\hline $1^{\circ} \mathrm{E}$ & 13 & - & 5 & 1 & - & 1 \\
\hline $2^{\circ} \mathrm{E}$ & 9 & 3 & 5 & 1 & 2 & - \\
\hline $3^{\circ} \mathrm{E}$ & 6 & 0 & 12 & 2 & - & - \\
\hline $4^{\circ} \mathrm{E}$ & 9 & 0 & 11 & 0 & - & - \\
\hline 5으 & 5 & 1 & 14 & 0 & - & - \\
\hline Total & 87 & 55 & 49 & 6 & 2 & 1 \\
\hline$\%$ & 43,5 & 27,5 & 24,5 & 3 & 1 & 0,5 \\
\hline
\end{tabular}

Grupo Feminino

\begin{tabular}{|c|c|c|c|c|c|c|}
\hline Quirodáctilo & Verticilo & Presilha externa & Presilha interna & Arco & Anomalia/Cicatriz & Amputação \\
\hline $1 \stackrel{\circ D}{ }$ & 8 & 9 & 1 & 2 & - & - \\
\hline $2 \stackrel{\circ}{D}$ & 4 & 9 & 3 & 4 & - & - \\
\hline $3 \stackrel{D}{D}$ & 2 & 16 & 0 & 2 & - & - \\
\hline $4 \stackrel{D}{-D}$ & 7 & 12 & 0 & 1 & - & - \\
\hline 5D & 1 & 16 & 1 & 2 & - & - \\
\hline $1 \stackrel{\circ}{E}$ & 10 & 0 & 8 & 2 & - & - \\
\hline $2^{\circ} \mathrm{E}$ & 5 & 4 & 3 & 7 & 1 & - \\
\hline $3^{\circ} \mathrm{E}$ & 2 & 0 & 13 & 5 & - & - \\
\hline $4^{\circ} \mathrm{E}$ & 5 & 0 & 14 & 1 & - & - \\
\hline $5^{\circ} \mathrm{E}$ & 3 & 0 & 16 & 1 & - & - \\
\hline Total & 47 & 66 & 59 & 27 & 1 & - \\
\hline$\%$ & 23,5 & 33 & 29,5 & 13,5 & 0,5 & - \\
\hline
\end{tabular}


Apêndice $F$ - Número de cristas de friç̧ão na área de $1 \mathrm{~cm}^{2}$ do dedo indicador direito distribuído por tipo fundamental

Grupo Masculino

\begin{tabular}{ccccccccc}
\hline & \multicolumn{2}{c}{ Presilha Externa } & \multicolumn{2}{c}{ Verticilo } & \multicolumn{2}{c}{ Arco } & \multicolumn{2}{c}{ Presilha Interna } \\
& Adulto & Idoso & Adulto & Idoso & Adulto & Idoso & Adulto & Idoso \\
\hline 19 & 14 & 23 & 20 & 11 & 3 & 18 & 19 \\
& 16 & 14 & 17 & 14 & 18 & 15 & 22 & 20 \\
18 & 12 & 18 & 15 & - & - & - & - \\
13 & 11 & 16 & 17 & - & - & - & - \\
& 18 & 18 & 23 & 21 & - & - & - & - \\
& - & - & 25 & 26 & - & - & - & - \\
& - & - & 21 & 21 & - & - & - & - \\
& - & - & 17 & 14 & - & - & - & - \\
& - & - & 17 & 8 & - & - & - & - \\
& - & - & 26 & 23 & - & - & - & - \\
\hline $\boldsymbol{\mu} \pm \mathbf{D P}$ & $\mathbf{1 6 , 8 \pm 2 , 4}$ & $\mathbf{1 3 , 8 \pm \mathbf { 2 , 7 }}$ & $\mathbf{1 9 , 7 \pm 4 , 0}$ & $\mathbf{1 7 , 4 \pm 5 , 2}$ & - & - & - & - \\
\hline Mediana & - & - & - & - & $\mathbf{1 4 , 5}$ & $\mathbf{9 , 0}$ & $\mathbf{2 0 , 0}$ & $\mathbf{1 9 , 5}$ \\
\hline
\end{tabular}

Grupo Feminino

\begin{tabular}{|c|c|c|c|c|c|c|c|c|}
\hline & \multicolumn{2}{|c|}{ Presilha Externa } & \multicolumn{2}{|c|}{ Verticilo } & \multicolumn{2}{|c|}{ Arco } & \multicolumn{2}{|c|}{ Presilha Interna } \\
\hline & Adulto & Idoso & Adulto & Idoso & Adulto & Idoso & Adulto & Idoso \\
\hline & 15 & 9 & 16 & 12 & 17 & 15 & 21 & 15 \\
\hline & 15 & 14 & 28 & 15 & 19 & 17 & 29 & 28 \\
\hline & 17 & 17 & 18 & 16 & 12 & 7 & 21 & 19 \\
\hline & 20 & 16 & 23 & 24 & 12 & 10 & - & - \\
\hline & 17 & 17 & - & - & - & - & - & - \\
\hline & 15 & 13 & - & - & - & - & - & - \\
\hline & 18 & 15 & - & - & - & - & - & - \\
\hline & 11 & 21 & - & - & - & - & - & - \\
\hline & 18 & 8 & - & - & - & - & - & - \\
\hline$\mu \pm D P$ & $16,22 \pm 2,5$ & $14,4 \pm 4,1$ & - & - & - & - & - & - \\
\hline Mediana & - & - & 20,5 & 15,5 & 14,5 & 12,5 & 21,0 & 19,0 \\
\hline
\end{tabular}


Apêndice G - Quantificação das minúcias e linhas subsidiárias marcadas e coincidentes

Grupo Masculino

\begin{tabular}{|c|c|c|c|c|c|}
\hline \multirow[b]{2}{*}{$\mathbf{N}$} & \multicolumn{3}{|c|}{ Minúcias } & \multicolumn{2}{|c|}{ Linhas subsidiárias } \\
\hline & Total & Coincidentes & Discrepantes & Total & Coincidentes \\
\hline 1 & 30 & 21 & 9 & 5 & 1 \\
\hline 2 & 27 & 12 & 15 & 0 & 0 \\
\hline 3 & 29 & 20 & 9 & 5 & 0 \\
\hline 4 & 28 & 22 & 6 & 0 & 0 \\
\hline 5 & 18 & 17 & 1 & 3 & 0 \\
\hline 6 & 42 & 21 & 21 & 12 & 8 \\
\hline 7 & 38 & 19 & 19 & 6 & 0 \\
\hline 8 & 28 & 22 & 6 & 0 & 0 \\
\hline 9 & 31 & 24 & 7 & 5 & 0 \\
\hline 10 & 35 & 16 & 19 & 7 & 0 \\
\hline 11 & 39 & 28 & 11 & 0 & 0 \\
\hline 12 & 16 & 7 & 9 & 0 & 0 \\
\hline 13 & 36 & 22 & 14 & 6 & 3 \\
\hline 14 & 19 & 13 & 6 & 0 & 0 \\
\hline 15 & 32 & 15 & 17 & 0 & 0 \\
\hline 16 & 19 & 12 & 7 & 0 & 0 \\
\hline 17 & 29 & 12 & 17 & 0 & 0 \\
\hline 18 & 33 & 16 & 17 & 8 & 0 \\
\hline 19 & 22 & 16 & 6 & 14 & 4 \\
\hline 20 & 25 & 13 & 12 & 7 & 0 \\
\hline$\mu \pm D P$ & $28,8 \pm 7,3$ & $17,4 \pm 5,1$ & $11,4 \pm 5,6$ & - & - \\
\hline Mediana & - & - & - & 4,0 & 0 \\
\hline
\end{tabular}

Grupo Feminino

\begin{tabular}{|c|c|c|c|c|c|}
\hline \multirow[b]{2}{*}{$\mathbf{N}$} & \multicolumn{3}{|c|}{ Minúcias } & \multicolumn{2}{|c|}{ Linhas subsidiárias } \\
\hline & Total & Coincidentes & Discrepantes & Total & Coincidentes \\
\hline 1 & 39 & 20 & 19 & 3 & 0 \\
\hline 2 & 39 & 19 & 20 & 4 & 0 \\
\hline 3 & 35 & 21 & 14 & 4 & 0 \\
\hline 4 & 25 & 21 & 4 & 0 & 0 \\
\hline 5 & 48 & 30 & 18 & 2 & 0 \\
\hline 6 & 39 & 15 & 24 & 18 & 2 \\
\hline 7 & 50 & 16 & 34 & 3 & 0 \\
\hline 8 & 45 & 23 & 22 & 0 & 0 \\
\hline 9 & 39 & 23 & 16 & 2 & 0 \\
\hline 10 & 43 & 32 & 11 & 19 & 0 \\
\hline 11 & 38 & 26 & 12 & 7 & 3 \\
\hline 12 & 23 & 14 & 9 & 0 & 0 \\
\hline 13 & 28 & 21 & 7 & 0 & 0 \\
\hline 14 & 24 & 9 & 15 & 0 & 0 \\
\hline 15 & 42 & 28 & 14 & 18 & 5 \\
\hline 16 & 22 & 15 & 7 & 5 & 0 \\
\hline 17 & 39 & 24 & 15 & 3 & 0 \\
\hline 18 & 43 & 21 & 22 & 0 & 0 \\
\hline 19 & 17 & 11 & 6 & 8 & 3 \\
\hline 20 & 21 & 11 & 10 & 0 & 0 \\
\hline$\mu \pm D P$ & - & $20,0 \pm 6,35$ & $14,9 \pm 7,3$ & - & - \\
\hline Mediana & 39,0 & - & - & 3,0 & 0 \\
\hline
\end{tabular}


ANEXOS 


\title{
Anexo 1 - Autorização do Comitê de Ética FM/UnB
}

\author{
Universidade de Brasília \\ Faculdade de Medicina \\ Comitê de Ética em Pesquisa em Seres Humanos $\square$ CEP-FM
}

\section{ANÁLISE DE PROJETO DE PESQUISA}

Registro do projeto: CEP/FM 065/2011.

Título: "Morfometria comparativa de pele humana normal e submetida a fenômenos transformativos: perspectivas na Papiloscopia Forense".

Pesquisador responsável: Selma Aparecida de Souza Kuchelhaus.

Documentos analisados: Folha de rosto, carta de encaminhamento assinada por todos os pesquisadores, projeto de pesquisa em português, Termo de Consentimento Livre e Esclarecido, curriculum vitae do pesquisador principal e dos demais pesquisadores participantes, orçamento do projeto de pesquisa, cronograma, bibliografia pertinente.

Data de entrada: 15/09/2011.

Data da primeira avaliação: 26/10/2011.

Proposição do(a) Relator(a):

[ ] Aprovação

[X] Reencaminhar ao pesquisador responsável para atendimento de pendências

[ ] Não aprovação

Data do parecer final do(a) Relator(a): 26/11/2012.

[X] Aprovação

[ ] Não aprovação

Data da análise pelo CEP-FM/UnB: 28/11/2012.

\section{PARECER}

Com base na Resolução CNS/MS n.0 196/96 e resoluções posteriores que regulamentam a matéria, o Comitê de Ética em Pesquisa da Faculdade de Medicina da Universidade de Brasília, em sua Reunião Ordinária, realizada em 28/11/2012, decidiu aprovar, de acordo com o parecer do(a) Relator(a), o projeto de pesquisa acima especificado quanto aos seus aspectos éticos.

\section{Observações:}

1. Modificações no protocolo devem ser submetidas ao CEP/FM/UnB antes de serem implementadas.

2. Os pesquisadores devem apresentar relatórios periódicos do andamento da pesquisa ao CEP-FM, estando o primeiro previsto para 30/05/2013.

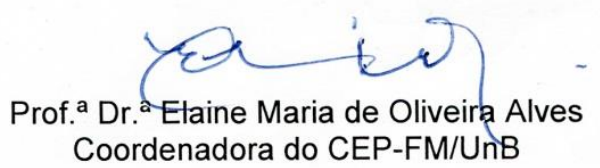

Faculdade de Medicina, Campus Universitário Darcy Ribeiro, Asa Norte, Brasilia-DF. CEP 70910-900. Telefone: (61) 3107-1918. Endereço eletrônico: cepfm@unb.br 
Anexo 2 - Termo de concordância da Polícia Civil do Distrito Federal

GOVERNO DO DISTRITO FEDERAL

POLÍCIA CIVIL DO DISTRITO FEDERAL

DEPARTAMENTO DE POLÍCIA TÉCNICA

OFíCIO

N. ${ }^{\circ} 112 / 2012-\mathrm{DPT}$

Brasilia, 18 de maio de 2012

Protocolo n. ${ }^{\circ} 248975 / 2012-$ II

Senhora Coordenadora,

TERMO DECONCORDÂNCIA

CONSIDERANDO que o projeto de pesquisa na área de necropapiloscopia, em conjunto com a Universidade de Brasília, intitulado "MORFOMEIRIA COMPARATIVA DE PEE HUMANA NORMALE SUBMETIDA A FENÔMENOS TRANSFORMATIVOS: PERSPECTIVAS NA PAPILOSCOPIA FORENSE" que está sendo realizado pelas servidoras, Papiloscopistas Policiais, Leila Lopes Mizokami, matrícula n. ${ }^{\circ}$ 180.066-3, e Lara Rosana Vieira Silva, matrícula n. ${ }^{\circ} 180.058-2$, pretende trazer conhecimentos e avanços na área de identificação humana conforme atribuição do Instituto de Identificação.

CONSIDERANDO que o referido estudo será realizado a partir da análise de polpas digitais provenientes de cadáveres mediante termo de consentimento livre e esclarecido por meio dos familiares ou com a aplicação do protocolo para destinação $\mathrm{e}$ utilização de cadáveres para o ensino e a pesquisa científica quando tratar-se de vítimas com identificação ignorada.

CONSIDERANDO que os Institutos de Identificação e de Medicina Legal concordam com o desenvolvimento do projeto de pesquisa.

CONSIDERANDO que os frutos desse projeto de pesquisa serão os avanços técnicocientíficos na área de necropapiloscopia. 
GOVERNO DO DISTRITO FEDERAL

POLÍCIA CIVIL DO DISTRITO FEDERAL

DEPARTAMENTO DE POLÍCIA TÉCNICA

CONSIDERANDO que a Instituição Polícia Civil do Distrito Federal, a comunidade científica e a sociedade serão beneficiadas com esse estudo.

A direção do Departamento de Polícia Técnica resolve concordar com os termos do projeto de pesquisa apresentados autorizando a sua execução nas dependências deste Complexo de Polícia Civil do DF.

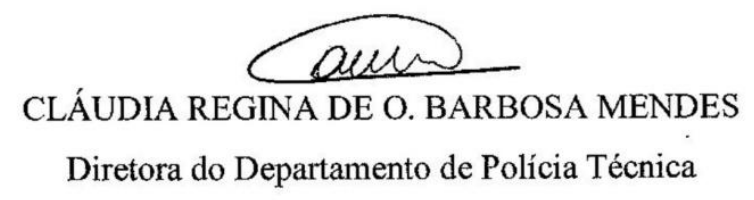

Doutora

\section{ELAINE MARIA DE OLIVEIRA ALVES}

Coordenadora do Comitê de Ética em Pesquisa da Faculdade de Medicina

Comitê de Ética em Pesquisa da Faculdade de Medicina-UNB

Universidade de Brasilia - UNB 